NBER WORKING PAPER SERIES

\title{
BANKING SYSTEM STABILITY: A CROSS-ATLANTIC PERSPECTIVE
}

\author{
Philipp Hartmann \\ Stefan Straetmans \\ Casper de Vries \\ Working Paper 11698 \\ http://www.nber.org/papers/w11698 \\ NATIONAL BUREAU OF ECONOMIC RESEARCH \\ 1050 Massachusetts Avenue \\ Cambridge, MA 02138 \\ October 2005
}

Paper prepared for the NBER project on "Risks of Financial Institutions". We benefited from suggestions and criticism by many participants in the NBER project on "Risks of financial institutions", in particular by the organizers Mark Carey (also involving Dean Amel and Allen Berger) and Rene Stulz, by our discussant Tony Saunders and by Patrick de Fontnouvelle, Gary Gorton, Andy Lo, Jim O'Brien and Eric Rosengren. Furthermore, we are grateful for comments we received at the 2004 European Finance Association Meetings in Maastricht, in particular by our discussant Marco da Rin and by Christian Upper, at the 2004 Ottobeuren seminar in economics, notably the thoughts of our discussant Ernst Baltensberger, of Friedrich Heinemann and of Gerhard Illing, as well as at seminars of the Max Planck Institute for Research on Collective Goods, the Federal Reserve Bank of St. Louis, the ECB and the University of Frankfurt. Gabe de Bondt and David Marques Ibanez supported us enormously in finding yield spread data, Lieven Baele and Richard Stehle kindly made us aware of pitfalls in Datastream equity data. Very helpful research assistance by Sandrine Corvoisier, Peter Galos and Marco Lo Duca as well as editorial support by Sabine Wiedemann are gratefully acknowledged. Any views expressed only reflect those of the authors and should not be interpreted as the ones of the ECB or the Eurosystem. The views expressed herein are those of the author(s) and do not necessarily reflect the views of the National Bureau of Economic Research.

(C2005 by Philipp Hartmann, Stefan Straetmans, and Casper de Vries. All rights reserved. Short sections of text, not to exceed two paragraphs, may be quoted without explicit permission provided that full credit, including $($ ) notice, is given to the source. 
Banking System Stability: A Cross-Atlantic Perspective

Philipp Hartmann, Stefan Straetmans, and Casper de Vries

NBER Working Paper No. 11698

October 2005

JEL No. G21, G28, G29, G12, C49

\begin{abstract}
This paper derives indicators of the severity and structure of banking system risk from asymptotic interdependencies between banks' equity prices. We use new tools available from multivariate extreme value theory to estimate individual banks' exposure to each other ("contagion risk") and to systematic risk. Moreover, by applying structural break tests to those measures we study whether capital markets indicate changes in the importance of systemic risk over time. Using data for the United States and the euro area, we can also compare banking system stability between the two largest economies in the world. Finally, for Europe we assess the relative importance of cross-border bank spillovers as compared to domestic bank spillovers. The results suggest, inter alia, that systemic risk in the US is higher than in the euro area, mainly as cross-border risks are still relatively mild in Europe. On both sides of the Atlantic systemic risk has increased during the 1990s.
\end{abstract}

\author{
Philipp Hartmann \\ European Central Bank and CEPR \\ DG Research \\ Kaiserstrabe 29, 60311 \\ Frankfurt, Germany \\ Stefan Straetmans \\ Limburg Institute of Financial Economics \\ Economics Faculty \\ Maastricht University \\ PO Box 616 \\ 6200 MD Maastricht \\ The Netherlands \\ Casper G. De Vries \\ Erasmus Universiteit Rotterdam, Economics \\ PO Box 1738 \\ 3000 DR Rotterdam \\ The Netherlands
}




\section{INTRODUCTION}

A particularly important sector for the stability of financial systems is the banking sector. Banks play a central role in the money creation process and in the payment system. Moreover, bank credit is an important factor in the financing of investment and growth. Faltering banking systems have been associated with hyperinflations and depressions in economic history. Hence, to preserve monetary and financial stability central banks and supervisory authorities have a special interest in assessing banking system stability.

This is a particularly complex task in very large economies with highly developed financial systems, such as the United States and the euro area. Moreover, structural changes in the financial systems of both these economies make it particularly important to track risks over time. In Europe, gradually integrating financial systems under a common currency increase the relationships between banks across borders. This development raises the question how banking systems should be monitored in a context where banking supervision - in contrast to monetary policy - remains a national responsibility. In the US, tremendous consolidation as well as the removal of regulatory barriers to universal and cross-state banking has led to the emergence of large and complex banking organizations (LCBOs), whose activities and interconnections are particularly difficult to follow. For all these reasons we present a new approach how to assess banking system risk in this paper and apply it to the euro area and the US.

A complication in assessing banking system stability is that, in contrast to other elements of the financial system, such as securities values, interbank relationships that can be at the origin of bank contagion phenomena or the values of and correlations between loan portfolios are particularly hard to measure and monitor. ${ }^{1}$ Hence, a large part of the published banking stability literature has resorted to more indirect market indicators. In particular, spillovers in bank equity prices have been used for this purpose. ${ }^{2}$ Pioneered by Aharony and Swary (1983) and Swary (1986) a series of papers have applied the event

\footnotetext{
${ }^{1}$ Even central banks and supervisory authorities usually do not have continuous information about interbank exposures. For the Swedish example of a central bank monitoring interbank exposures at a quarterly frequency, see Blavarg and Nimander (2002).

${ }^{2}$ The choice of bank equity prices for measuring banking system risk may be motivated by Merton's (1974) option-theoretic framework toward default. The latter approach has become the cornerstone of a large body of approaches for quantifying credit risk and modeling credit rating migrations, including J.P. Morgan's CreditMetrics (1999).
} 
study methodology to the effects of specific bank failures or bad news for certain banks on other banks' stock prices (see, e.g., also Wall and Petersen, 1990; Docking, Hirschey and Jones, 1997; Slovin, Sushka and Polonchek, 1999). In another series of papers various regression approaches are used in order to link abnormal bank stock returns to asset-side risks, including those related to aggregate shocks (see, e.g., Cornell and Shaphiro, 1986; Smirlock and Kaufold, 1987; Musumeci and Sinkey, 1990; or Kho, Lee and Stulz, 2000). De Nicolo and Kwast (2002) relate changes in correlations between bank stock prices over time to banking consolidation. Gropp and Moerman (2004) measure conditional co-movements of large abnormal bank stock returns and of equity-derived distances to default. Gropp and Vesala (2004) apply an ordered logit approach to estimate the effect of shocks in distances to default for some banks on other banks' distances to default. ${ }^{3}$

Some authors point out that most banking crises have been related to macroeconomic fluctuations rather than to prevalent contagion. Gorton (1988) provides ample historical evidence for the US, GonzalezHermosillo, Pazarbasioglu and Billings (1997) also find related evidence

\footnotetext{
${ }^{3}$ Other market indicators used in the literature to assess bank contagion include bank debt risk premia (see, in particular, Saunders (1986) and Cooperman, Lee and Wolfe (1992)).

A number of approaches that do not rely on market indicators have also been developed in the literature. Grossman (1993) and Hasan and Dwyer (1994) measure autocorrelation of bank failures after controlling for macroeconomic fundamentals during various episodes of US banking history. Saunders and Wilson (1996) study deposit withdrawals of failing and non-failing banks during the Great Depression. Calomiris and Mason (1997) look at deposit withdrawals during the 1932 banking panic and ask whether also ex ante healthy banks failed as a consequence of them. Calomiris and Mason (2000) estimate the survival time of banks during the Great Depression, with explanatory variables including national and regional macro fundamentals, dummies for well known panics and the level of deposits in the same county (contagion effect).

A recent central banking literature attempts to assess the importance of contagion risk by simulating chains of failures from (incomplete and mostly confidential) national information about interbank exposures. See, e.g., Furfine (2003), Elsinger, Lehar and Summer (2002), Upper and Worms (2004), Degryse and Nguyen (2004), Lelyveld and Liedorp (2004) or Mistrulli (2005).

Chen (1999), Allen and Gale (2000) and Freixas, Parigi and Rochet (2002) develop the theoretical foundations of bank contagion.
} 
for the Mexican crisis of 1994-1995 and Demirgüc-Kunt and Detragiache (1998) add substantial further support for this hypothesis using a large multi-country panel dataset. ${ }^{4}$

The new approach for assessing banking system risk presented in this paper also employs equity prices. It is based on extreme value theory (EVT) and allows us to estimate the probabilities of spillovers between banks, their vulnerability to aggregate shocks and changes in those risks over time. More precisely, we want to make three main contributions compared to the previous literature. First, we use the novel multivariate extreme value techniques applied by Hartmann, Straetmans and de Vries (2003a/b and 2004) and Poon, Rockinger and Tawn (2004) to estimate the strength of banking system risks. In particular, we distinguish conditional "co-crash" probabilities between banks from crash probabilities conditional on aggregate shocks. While EVT - both univariate and multivariate - has been applied to general stock indices before, it has not yet been used to assess the extreme dependence between bank stock returns with the aim to measure banking system risk. Second, we cover both euro area countries and the United States to compare banking system stability internationally. We are not aware of any other study that tries to compare systemic risk between these major economies. Third, we apply the test of structural stability for tail indexes by Quintos, Fan and Phillips (2001) to the multivariate case of extreme linkages and assess changes in banking system stability over time with it. Again, whereas a few earlier papers addressed the changing correlations between bank stock returns, none focused on the extreme interdependence we are interested in in the present paper.

The idea behind our approach is as follows. We assume that bank stocks are efficiently priced, in that they reflect all publicly available information about (i) individual banks' asset and liability side risks and (ii) relationships between different banks' risks (be it through correlations of their loan portfolios, interbank lending or other channels). We identify a critical situation of a bank with a dramatic slump of its stock price. We identify the risk of a problem in one or several banks spilling over to other banks ("contagion risk") with extreme negative co-movements between individual bank stocks (similar to the conditional co-crash probability in our earlier stock, bond and currency papers). In addition, we identify the risk of banking system destabilization through aggregate shocks with the help of the "tail- $\beta$ " proposed

\footnotetext{
${ }^{4}$ Hellwig (1994) argues that the observed vulnerability of banks to macroeconomic shocks may be explained by the fact that deposit contracts are not conditional on aggregate risk. Chen (1999) models, inter alia, how macro shocks and contagion can reinforce each other in the banking system.
} 
by Straetmans, Verschoor and Wolf (2003). The tail- $\beta$ is measured by conditioning our co-crash probability on a general stock index (or another measure of systematic risk) rather than on individual banks' stock prices. Therefore, in some respects it reflects the tail equivalent to standard asset pricing models. In this paper we further extend the analysis of tail- $\beta$ by also using high-yield bond spreads as measures of aggregate risk. Based on the estimated individual co-crash probabilities and tail- $\beta \mathrm{s}$, we can then test for the equality of banking system risk between the US and the euro area and for changes in systemic risk over time.

Our work is also related to an active literature examining which phenomena constitute financial contagion and how they can be identified empirically. In our reading, the main criteria proposed so far to identify contagion are that (i) a problem at a financial institution adversely affects other financial institutions or that a decline in an asset price leads to declines in other asset prices; (ii) the relationships between failures or asset price declines must be different from those observed in normal times (regular "interdependence"); (iii) the relationships are in excess of what can be explained by economic fundamentals; (iv) the events constituting contagion are negative "extremes", such as full-blown institution failures or market crashes, so that they correspond to crisis situations; (v) the relationships are the result of propagations over time rather than being caused by the simultaneous effects of common shocks.

Most empirical approaches proposed in the recent literature how to measure contagion capture the first criterion (i), but this is where the agreement usually ends. Authors differ in their view which of the other criteria (ii) through (v) are essential for contagion. Forbes and Rigobon (2002) stress statistically significant changes in correlations over time as a contagion indicator and illustrate how they emerge among emerging country equity markets. Shiller (1989), Pindyck and Rotemberg (1993) and Bekaert, Harvey and Ng (forthcoming) emphasize "excess co-movements" between stock markets and stock prices, beyond what is explained in various forms of regressions by dividends, macroeconomic fundamentals or asset pricing "factors". Eichengreen, Rose and Wyplosz (1996) estimate probit models to examine whether the occurrence of a balance-of-payments crisis in one country increases the probability of a balance-of-payments crisis in other countries, conditional on macroeconomic country fundamentals. Bae, Karolyi and Stulz (2003) propose the logit regression model to estimate probabilities that several stock markets experience large negative returns, given that a smaller number of stock markets experience large negative returns, conditional on interest and exchange rates. Longin and Solnik (2001) are among 
the first to apply bivariate EVT to estimate extreme equity market correlations, also assuming the logistic distribution. Hartmann et al. $(2003 \mathrm{a} / \mathrm{b}, 2004)$ stress that market co-movements far out in the tails ("asymptotic dependence") may be very different from regular dependence in multivariate distributions and that such crisis behavior may not have the same parametric form in different markets. Based on a different branch of EVT, they estimate semi-parametrically for stocks, bonds and currencies the likelihood of widespread market crashes conditional on contemporaneous and lagged other market crashes. The reason why we particularly focus on criterion (iv) is that it allows us to concentrate on events that are severe enough to be basically always of a concern for policy. Other criteria are also interesting and have their own justifications, but more regular propagations or changes in them are not necessarily a concern for policies that aim at the stability of financial systems. ${ }^{5}$

The data we use in this work are daily bank stock excess returns in euro area countries and the United States between April 1992 and February 2004. For each area or country we choose 25 banks based on the criteria of balance-sheet size and involvement in interbank lending. So, our sample represents the systemically most relevant financial institutions, but neglects a large number of smaller banks. During our sample period several of the banks selected faced failure-like situations and also global markets passed several episodes of stress. All in all, we have about 3,100 observations per bank.

Our results suggest that the risk of multivariate extreme spillovers between US banks is higher than between European banks. Hence, despite the fact that available balance-sheet data show higher interbank exposures in the euro area, the US banking system seems to be more prone to contagion risk. Second, the lower spillover risk among European banks is mainly related to relatively weak cross-border linkages. Domestic linkages in France, Germany and Italy, for example, are of the same order as domestic US linkages. One interpretation of this result is that further banking integration in Europe could lead to higher cross-border contagion risk in the future, with the more integrated US banking system providing a benchmark. Third, cross-border spillover probabilities tend to be smaller than domestic spillover probabilities, but only for a few countries this difference is statistically significant.

\footnotetext{
${ }^{5}$ Less extreme spillovers might still indicate some form of microeconomic inefficiencies but not necessarily widespread destabilization.

De Bandt and Hartmann (2000) provide a more complete survey of the market and banking contagion literature. Pritsker (2001) discusses different channels of contagion.
} 
For example, among the banks from a number of larger countries such as France, Germany, the Netherlands and Spain - extreme crossborder linkages are statistically indistinguishable from domestic linkages. In contrast, the effects of banks from these larger countries on the main banks from some smaller countries - including particularly Finland and Greece, and sometimes also Ireland or Portugal - tend to be significantly weaker than the effects on their domestic banks. Hence, those smaller countries located further away from the center of Europe seem to be more insulated from European cross-border contagion.

Fourth, the effects of macro shocks emphasized by the estimated tail- $\beta$ s are similar for the euro area and the US, and they illustrate the relevance of aggregate risks for banking system stability. While stock market indices perform well as indicators of aggregate risk, we find that high-yield bond spreads capture extreme systematic risk for banks relatively poorly, both in Europe and the US. Fifth, structural stability tests for our indicators suggest that systemic risk, both in the form of interbank spillovers and in the form of aggregate risk, has increased in Europe and in the US. Our tests detect the break points during the second half of the 1990s, but graphical illustrations of our extreme dependence measures show that this was the result of developments spread out over time. In particular in Europe the process was very gradual, in line with what one would expect during a slowly advancing financial integration process. Interestingly, the introduction of the euro in January 1999 seems to have had a reductionary or no effect on banking system risk in the euro area. This may be explained by the possibility that stronger cross-border crisis transmission channels through a common money market could be offset by better risk sharing and the better ability of a deeper market to absorb shocks.

The paper is structured as follows. The next section describes our theoretical indicators of banking system stability, distinguishing the multivariate spillover or contagion measure from the aggregate tail- $\beta$ measure for stock returns. Section 3 outlines the estimation procedures for both measures; and section 4 presents two tests, one looking at the stability of spillover and systematic risk over time and the other looking at the stability of both measures across countries and continents (crosssectional stability). Section 5 summarizes the data set we employ, in particular how we selected the banks covered, provides some standard statistics for the individual bank and index returns, and gives some information about the occurrence of negative extremes for individual banks and the related events. 
Section 6 then presents the empirical results on extreme bank spillover risks. For both the euro area and the US we estimate the overall multivariate extreme dependence in the banking sector and we test whether one is larger than the other. Moreover, for Europe we assess whether domestic spillover risk is stronger or weaker than cross-border risk. Section 7 turns to the empirical results for aggregate banking system risk on both continents. We estimate individual tail- $\beta$ s for European banks and for US banks. We also aggregate those $\beta$ s and test for the equality of them in the euro area and the US. Section 8 then asks the question whether on any of the two continents the risk of interbank spillovers or the vulnerability of the banking system to aggregate shocks has changed over time. The final section concludes. We have five appendices. The first one (appendix A) discusses small sample properties of estimators and tests. Appendix B lists the banks in our sample and the abbreviations used for them across the paper. Appendix $\mathrm{C}$ presents some balance-sheet information characterizing the systemic relevance of banks. Appendix D contains the standard statistics for our return data and for yield spreads. Finally, appendix E discusses the role of volatility clustering for extreme dependence in bank stock returns.

\section{INDICATORS OF BANKING SYSTEM STABILITY}

Our indicators of banking system stability are based on extreme stock price movements. They are constructed as conditional probabilities, conditioning single or multiple bank stock price "crashes" on other banks' stock price crashes or on crashes of the market portfolio. Extreme co-movements, as measured by multivariate conditional probabilities between individual banks' stock returns, are meant to capture the risk of contagion from one bank to another. Extreme co-movements between individual banks' stock returns and the returns of a general stock market index or another measure of non-diversifiable risk (the socalled "tail- $\beta$ ") are used to assess the risk of banking system instability through aggregate shocks. The two forms of banking system instability are theoretically distinct, but in practice they may sometimes interact. Both have been extensively referred to in the theoretical and empirical banking literature. In what follows we describe them in more precise terms.

2.1. Multivariate extreme spillovers: A measure of bank contagion risk. Let us start with the measure of multivariate extreme bank spillovers. The measure can be expressed in terms of marginal (univariate) and joint (multivariate) exceedance probabilities. Consider an $N$-dimensional banking system, i.e., a set of $N$ banks from, 
e.g., the same country or continent. Denote the log first differences of the price changes in bank stocks minus the risk-free interest rate by the random variables $X_{i}(i=1, \cdots, N)$. Thus, $X_{i}$ describes a bank $i$ 's excess return. We adopt the convention to take the negative of stock returns, so that we can define all used formulae in terms of upper tail returns. The crisis levels or extreme quantiles $Q_{i}(i=1, \cdots, N)$ are chosen such that the tail probabilities are equalized across banks, i.e.,

$$
P\left\{X_{1}>Q_{1}\right\}=\cdots=P\left\{X_{i}>Q_{i}\right\}=\cdots=P\left\{X_{N}>Q_{N}\right\}=p .
$$

With the significance level in common, crisis levels $Q_{i}$ will generally not be equal across banks, because the marginal distribution functions $P\left\{X_{i}>Q_{i}\right\}=1-F_{i}\left(Q_{i}\right)$ are bank specific. The crisis levels can be interpreted as "barriers" that will on average only be broken once in $1 / p$ time periods, i.e., $p^{-1}$ days if the data frequency is daily. ${ }^{6}$ Suppose now that we want to measure the propagation of severe problems through the European and US banking sectors by calculating the probability of joint collapse in an arbitrarily large set of $N$ bank stocks, conditional on the collapse of a subset $L<N$ banks:

$$
\begin{aligned}
P_{N \mid L} & =P\left\{\bigcap_{i=1}^{N} X_{i}>Q_{i}(p) \mid \bigcap_{j=1}^{L} X_{j}>Q_{j}(p)\right\} \\
& =\frac{P\left\{\bigcap_{i=1}^{N} X_{i}>Q_{i}(p)\right\}}{P\left\{\bigcap_{j=1}^{L} X_{j}>Q_{j}(p)\right\}} .
\end{aligned}
$$

Clearly, the right-hand side immediately follows from the definition of conditional probability. With independence the measure reduces to $p^{N-L}$. This provides a benchmark against which the dependent cases are to be judged.

Equation (2.1) is very flexible in terms of the conditioning set on the right-hand side. For example, the conditioning banks do not necessarily have to be a subset of the bank set on the left-hand side. Moreover, the conditioning random variables could also be others than just bank stock prices. ${ }^{7}$

\footnotetext{
${ }^{6}$ Notice that the set of banks in a given country can be thought of as a "portfolio" for which the supervisory authority is responsible. From a risk management point of view a common significance level makes the different portfolio positions comparable in terms of their downside risk. Moreover, we argue later on that our bivariate and multivariate probability measures that use the common tail probability as an input will solely reflect dependence information.

${ }^{7}$ In Hartmann, Straetmans and de Vries (2003b) we applied an analogous measure to assess the systemic breadth of currency crises.
} 
2.2. Tail- $\beta$ s: A measure of aggregate banking system risk. Our second measure of banking system risk is from a methodological point of view a bivariate "variant" of (2.1), in which $N=1$ and the conditioning set is limited to extreme downturns of the market portfolio or another indicator of aggregate risk $(L=1){ }^{8}$ This tail- $\beta$ measure is inspired by portfolio theory and has been used before by Straetmans et al. (2003) to examine the intraday effects of the September 11 catastrophe on US stocks. Let $M$ be the excess return on the market portfolio (e.g. using a stock market index) and let $p$ be the common tail probability, then this measure can be written as:

$$
\begin{aligned}
P\left\{X_{k}>Q_{k}(p) \mid X_{M}>Q_{M}(p)\right\} & =\frac{P\left\{X_{k}>Q_{k}(p), X_{M}>Q_{M}(p)\right\}}{P\left\{X_{M}>Q_{M}(p)\right\}} \\
(2.2) & =\frac{P\left\{X_{k}>Q_{k}(p), X_{M}>Q_{M}(p)\right\}}{p} .
\end{aligned}
$$

The measure captures how likely it is that an individual bank's value declines dramatically, if there is an extreme negative systematic shock. Analogous to the multivariate spillover probability (2.1), the tail- $\beta$ (2.2) reduces to $p^{2} / p=p$ under the benchmark of independence. We extend the analysis of extreme aggregate risk in this paper by also experimenting with high-yield bond spreads as a measure $X_{M}$ of systematic shocks. ${ }^{9}$

\section{Estimation of the indicators}

The joint probabilities in (2.1) and (2.2) have to be estimated. Within the framework of a parametric probability law, the calculation of the proposed multivariate probability measures is straightforward, because one can estimate the distributional parameters by, e.g., maximum likelihood techniques. However, if one makes the wrong distributional assumptions, the linkage estimates may be severely biased due to misspecification. As there is no clear evidence that all stock returns follow the same distribution - even less so for the crisis situations we are interested in here -, we want to avoid very specific assumptions for bank stock returns. Therefore, we implement the semi-parametric EVT approach proposed by Ledford and Tawn (1996; see also Draisma et al., 2001, and Poon et al., 2004, for recent applications). Loosely

\footnotetext{
${ }^{8}$ Technically, it is also possible to derive and estimate this measure for $N>1$, but we do not do this in the present paper.

${ }^{9}$ In the present paper we limit ourselves to these two measures of banking system risk. In future research, the approach could be extended by also including further economic variables in the conditioning set, such as interest rates or exchange rates.
} 
speaking, their approach consists of generalizing some "best practice" in univariate extreme value analysis - based on the generalized Pareto law behavior of the minima and maxima of the relevant distributions for financial market returns - to the bivariate case. So, they derive the tail probabilities that occur in measures (2.1) and (2.2) for the bivariate case. We go a step further by applying their approach to the multivariate case.

Before going ahead with applying the Ledford-Tawn approach to our two measures of banking system stability, it is important to stress that the dependence between two random variables and the shape of the marginal distributions are unrelated concepts. To extract the dependence, given by the copula function, it is convenient to transform the data and remove any possible influences of marginal aspects on the joint tail probabilities. One can transform the different original excess returns to ones with a common marginal distribution (see, e.g., Ledford and Tawn, 1996, and Draisma et al., 2001). After such a transformation, differences in joint tail probabilities across banking systems (e.g., Europe versus the US) can be solely attributed to differences in the tail dependence structure of the extremes. This is different, e.g., from correlation-based measures that are still influenced by the differences in marginal distribution shapes.

In this spirit we transform the bank stock excess returns $\left(X_{1}, \cdots, X_{i}\right.$, $\left.\cdots, X_{N}\right)$ to unit Pareto marginals:

$$
\widetilde{X}_{i}=\frac{1}{1-F_{i}\left(X_{i}\right)}, i=1, \cdots, N
$$

with $F_{i}(\cdot)$ representing the marginal cumulative distribution function (cdf) for $X_{i}$. However, since the marginal cdfs are unknown, we have to replace them with their empirical counterparts. For each $X_{i}$ this leads (with a small modification to prevent division by 0 ) to:

$$
\widetilde{X}_{i}=\frac{n+1}{n+1-R_{X_{i}}}, i=1, \cdots, N
$$

where $R_{X_{i}}=\operatorname{rank}\left(X_{i l}, l=1, \cdots, n\right)$. Using this variable transform, we can rewrite the joint tail probability that occurs in (2.1) and (2.2):

$$
P\left\{\bigcap_{i=1}^{N} X_{i}>Q_{i}(p)\right\}=P\left\{\bigcap_{i=1}^{N} \tilde{X}_{i}>q\right\},
$$


where $q=1 / p \cdot{ }^{10}$ The multivariate estimation problem can now be reduced to estimating a univariate exceedance probability for the crosssectional minimum of the $N$ bank excess return series, i.e., it is always true that:

$$
P\left\{\bigcap_{i=1}^{N} \tilde{X}_{i}>q\right\}=P\left\{\min _{i=1}^{N}\left(\tilde{X}_{i}\right)>q\right\}=P\left\{\tilde{X}_{\min }>q\right\} .
$$

The marginal tail probability at the right-hand side can now be calculated, provided the following additional assumption on the univariate tail behavior of $\widetilde{X}_{\text {min }}$ is made. Ledford and Tawn (1996) argue that the bivariate dependence structure is a regular varying function under fairly general conditions. ${ }^{11}$ Peng (1999) and Draisma et al. (2001) give sufficient conditions and further motivation. Therefore, we assume that the auxiliary variable $\widetilde{X}_{\min }$ has a regularly varying tail. Notice, however, that in contrast to Ledford and Tawn (1996) we often consider more than two dimensions. ${ }^{12}$

Assuming that $\widetilde{X}_{\min }$ exhibits heavy tails with tail index $\alpha$, then the regular variation assumption for the auxiliary variables implies that the univariate probability in (3.2) exhibits a tail descent of the Pareto type:

$$
P\left\{\tilde{X}_{\min }>q\right\} \approx \ell(q) q^{-\alpha}, \alpha \geq 1,
$$

with $q$ large ( $p$ small) and where $\ell(q)$ is a slowly varying function (i.e., $\lim _{q \rightarrow \infty} \ell(x q) / \ell(q)=1$ for all fixed $\left.x>0\right)$. We can now distinguish the

\footnotetext{
${ }^{10}$ The multivariate probability stays invariant under the variable transformation $\left(X_{1}, \cdots, X_{i}, \cdots, X_{N}\right) \rightarrow\left(\widetilde{X}_{1}, \cdots, \widetilde{X}_{i}, \cdots, \widetilde{X}_{N}\right)$, because the determinant of the Jacobian matrix can be shown to be equal to 1 .

${ }^{11} \mathrm{~A}$ function $F(x)$ is said to have a regularly varying left tail if

$$
\lim _{u \rightarrow \infty} F(-u x) / F(-u)=x^{-\alpha}
$$

for any $x>0$ and tail index $\alpha>0$.

${ }^{12}$ Equation (3.2) requires a common quantile $q$. This can, however, be easily generalized to the case where $q$ differs across the marginals. Assume that we both allow the quantiles of the original distribution function $Q_{1}$ and $Q_{2}$ and the corresponding marginal probabilities $p_{1}$ and $p_{2}$ to be different from each other. For the bivariate case this would imply, for example, that

$$
P\left\{X_{1}>Q_{1}\left(p_{1}\right), X_{2}>Q_{2}\left(p_{2}\right)\right\}=P\left\{\tilde{X}_{1}>q_{1}, \tilde{X}_{2}>q_{2}\right\},
$$

with $q_{i}=1 / p_{i}(i=1,2)$. By multiplying $\widetilde{X}_{2}$ with $q_{1} / q_{2}$ the above joint probability again reduces to a probability with a common quantile $q_{1}$ and we are back to the framework described above, where the loading variable $\widetilde{X}_{\text {min }}$ can be calculated.
} 
two cases in which the $\widetilde{X}_{i}$ are asymptotically dependent and asymptotically independent. In the former case $\alpha=1$ and

$$
\lim _{q \rightarrow \infty} \frac{P\left\{\widetilde{X}_{\min }>q\right\}}{P\left\{\widetilde{X}_{\max }>q\right\}}>0,
$$

with $P\left\{\widetilde{X}_{\max }>q\right\}=P\left\{\max _{i=1}^{N}\left(\tilde{X}_{i}\right)>q\right\}$. Examples of asymptotically dependent random variables include, e.g., the multivariate Student-T distribution. For asymptotic independence of the random variables $\alpha>1$, and we have that

$$
\lim _{q \rightarrow \infty} \frac{P\left\{\widetilde{X}_{\min }>q\right\}}{P\left\{\widetilde{X}_{\max }>q\right\}}=0 .
$$

An example of this case is the bivariate standard normal distribution with correlation coefficient $\rho$. For this distribution $\alpha=2 /(1+\rho)$ and the limit (3.4) applies. When the normal random variables are independent $(\rho=0)$, one immediately obtains that $\alpha=2$. In general, whenever the $\tilde{X}_{i}$ are fully independent in the $N$-dimensional space, $\alpha=N$ and $P\left\{\widetilde{X}_{\min }>q\right\}=p^{N}$. But the reverse is not true, i.e., there are joint $N$-dimensional distributions with non-zero pairwise correlation that nevertheless have $\alpha=N$. The Morgenstern distribution constitutes an example of this tail behavior. (A bivariate version is employed in a Monte Carlo exercise in appendix A.1.)

The steps (3.1), (3.2) and (3.3) show that the estimation of multivariate probabilities can be reduced to a univariate estimation problem that is well known. Univariate tail probabilities for fat-tailed random variables - like the one in (3.2) - can be estimated by using the semiparametric probability estimator from De Haan et al. (1994):

$$
\widehat{P}\left\{\widetilde{X}_{\min }>q\right\}=\frac{m}{n}\left(\frac{C_{n-m, n}}{q}\right)^{\alpha},
$$

where the "tail cut-off point" $C_{n-m, n}$ is the $(n-m)$-th ascending order statistic from the cross-sectional minimum series $\widetilde{X}_{\min }$. The estimator (3.5) basically extends the empirical distribution function of $\widetilde{X}_{\min }$ outside the domain of the sample by means of its asymptotic Pareto tail from (3.3). An intuitive derivation of the estimator is provided in Danielsson and de Vries (1997). The tail probability estimator is conditional upon the tail index $\alpha$ and a choice of the threshold parameter $m$. 
To estimate $\alpha$ we use the popular Hill (1975) estimator for the index of regular variation:

$$
\widehat{\eta}=\frac{1}{m} \sum_{j=0}^{m-1} \ln \left(\frac{C_{n-j, n}}{C_{n-m, n}}\right)=\frac{1}{\widehat{\alpha}},
$$

where $\widehat{\eta}$ is the estimate of our parameter of tail dependence and $m$ is the number of higher order extremes that enter the estimation. The higher $\hat{\eta}$, and given the slowly varying function $\ell(s)$, the more dependent are the components $\left(\widetilde{X}_{1}, \cdots, \widetilde{X}_{i}, \cdots, \widetilde{X}_{N}\right)$ from $(3.2)$ far out in their joint tail. Following from the discussion above, for asymptotic dependence our tail dependence parameter $\eta=1$ and for asymptotic independence $\eta=1 / N$. Draisma et al. (2001) derive asymptotic normality of $\sqrt{m}\left(\frac{\widehat{\eta}}{\eta}-1\right)$ under fairly general conditions. ${ }^{13}$ The asymptotic normality will prove convenient for the tests implemented later on. Further details on the Hill estimator can be found in Jansen and De Vries (1991), for example, and in the monograph by Embrechts, Klüppelberg and Mikosch (1997).

The optimal choice of the threshold parameter $m$ is a point of concern in the extreme value theory literature. Goldie and Smith (1987) suggest to select the nuisance parameter $m$ so as to minimize the asymptotic mean-squared error. A widely used heuristic procedure plots the tail estimator as a function of $m$ and selects $m$ in a region where $\widehat{\eta}$ is stable. Double bootstrap techniques based upon this idea have been developed recently (see, e.g., Danielsson et al., 2001), but these are only advisable for sample sizes that are larger than the ones we have available for this paper. For simplicity and in accordance with the minimization criterion of Goldie and Smith (1987), we select $m=\kappa n^{\gamma}$ with $\gamma=2 / 3$, sample size $n$ and where $\kappa$ is derived from the widely used Hill plot method. ${ }^{14}$ We provide in appendix A.1 a discussion of the properties of our tail dependence parameter $\eta$ in small samples.

\footnotetext{
${ }^{13}$ For discussions of alternative estimators and proper convergence behavior, see e.g. Draisma et al. (2001), Peng (1999), and Beirlandt and Vandewalle (2002).

${ }^{14}$ Minimizing the asymptotic mean-squared error for the Hill estimator by balancing bias and variance renders a nonlinear selection rule like the one above. For convenience, we impose the parameter restriction $\gamma=2 / 3$. While simplifying, it can be shown to hold for a wide variety of distribution functions (see Hall, 1990). Moreover, establishing stable and accurate estimates of $\gamma$ is notoriously difficult (see, e.g., Gomes et al., 2002, for a recent example). $\kappa$ is calibrated by means of the heuristic Hill plot method. Once a value of $m^{*}$ is selected in a horizontal range of $\widehat{\eta}=\widehat{\eta}(m)$, the scale factor immediately follows from $\kappa=m^{*} / n^{2 / 3}$.
} 


\section{Hypothesis testing}

In this section we introduce some tests that can be used to assess various hypotheses regarding the evolution and structure of systemic risk in the banking system. The first one allows to test for the structural stability of the amount of risk found with our two indicators. The second test allows us to compare the systemic risk across countries and continents.

4.1. Time variation. The multivariate linkage estimator (2.1) and its bivariate counterpart in (2.2) were presented so far assuming stationarity of tail behavior over time. From a policy perspective, however, it is important to know whether systemic risk in the banking system - either in terms of contagion risk (2.1) or in terms of extreme systematic risk (2.2) - has changed over time. As the discussion of the Ledford and Tawn approach toward estimating (2.1) or (2.2) has shown, the structural (in)stability of systemic risk will critically depend on whether the tail dependence parameter $\eta$ is constant or not. We study the occurrence of upward and downward swings in $\eta$ with a recently developed structural stability test for the Hill statistic (3.6).

Quintos, Fan and Phillips (2001) present a number of tests for identifying single unknown breaks in the estimated tail index $\widehat{\alpha}$. As our estimation approach allows to map the multivariate dependence problem into a univariate estimation problem, we can choose from them the best test procedures for our tail dependence parameter $\eta$. Balancing the prevention of type I and type II errors we opt for the recursive test from Quintos et al. Let $t$ denote the endpoint of a sub-sample of size $w_{t}<n$. The recursive estimator for $\eta$ is calculated from (3.6) for sub-samples $[1 ; t] \subset[1 ; n]$ :

$$
\widehat{\eta}_{t}=\frac{1}{m_{t}} \sum_{j=0}^{m_{t}-1} \ln \left(\frac{X_{t-j, t}}{X_{t-m_{t}, t}}\right),
$$

with $m_{t}=\kappa t^{2 / 3}$.

The value of the recursive test statistic equals the supremum of the following time series:

$$
Y_{n}^{2}(t)=\left(\frac{t m_{t}}{n}\right)\left(\frac{\widehat{\eta}_{n}}{\widehat{\eta}_{t}}-1\right)^{2} .
$$

Expression (4.2) compares the recursive value of the estimated tail parameter (3.6) to its full sample counterpart $\widehat{\eta}_{n}$. The null hypothesis of interest is that the tail dependence parameter does not exhibit any 
temporal changes. More specifically, let $\eta_{t}$ be the dependence in the left tail of $X$. The null hypothesis of constancy then takes the form

$$
H_{0}: \eta_{[n r]}=\eta, \quad \forall r \in R_{\varepsilon}=[\varepsilon ; 1-\varepsilon] \subset[0 ; 1],
$$

with $[n r]$ representing the integer value of $n r$. Without prior knowledge about the direction of a break, one is interested in testing the null against the two-sided alternative hypothesis $H_{A}: \eta_{[n r]} \neq \eta$. For practical reasons the above test is calculated over compact subsets of $[0 ; 1]$, i.e., $t$ equals the integer part of $n r$ for $r \in R_{\varepsilon}=[\varepsilon ; 1-\varepsilon]$ and for small $\varepsilon>0$. Sets like $R_{\varepsilon}$ are often used in the construction of parameter constancy tests (see, e.g., Andrews, 1993). ${ }^{15}$ In line with Quandt's (1960) pioneering work on endogenous breakpoint determination in linear time series models, the candidate break date $r$ can be selected as the maximum value of the test statistic (4.2), because at this point in time the constancy hypothesis is most likely to be violated.

Asymptotic critical values can be derived for the sup-value of 4.2, but if the data are temporally dependent the test sequence $Y_{n}^{2}$ needs to be scaled in order to guarantee convergence to the same limiting distribution function as in the case of absence of temporal dependence. It is well known that financial returns exhibit nonlinear dependencies like, e.g., ARCH effects (volatility clustering). It is likely that the loading variable $\widetilde{X}_{\min }$, previously defined as the cross-sectional minimum of the bank stock returns (transformed using their proper empirical distribution function), partly inherits these nonlinearities. The nonlinear dependence implies that the asymptotic variance of the Hill estimator $1 / \widehat{\eta}$ is $\frac{s^{2}}{\eta^{2}}$, with $s$ some scaling factor. If the scaling factor differs from 1 (presence of temporal dependence), the asymptotic critical values of the test statistic will depend on the scaling. Quintos et al. suggest to pre-multiply the test statistic with the inverse of the scaling factor in order to let it converge to the same critical values as in the i.i.d. case. However, their scaling estimator is based upon the ARCH assumption for univariate time series. As we do not want to make very specific assumptions on the precise structure of the nonlinear dependence in the marginals, we apply a block bootstrap to the asymptotic variance

\footnotetext{
${ }^{15}$ The restricted choice of $r$ implies that $\varepsilon n \leq t \leq(1-\varepsilon) n$. When the lower bound would be violated the recursive estimates might become too unstable and inefficient because of too small sub-sample sizes. On the other hand, the test will never find a break for $t$ equal or very close to $n$, because the test value (4.2) is close to zero in that latter case. Thus, for computational efficieny one might stop calculating the tests beyond the upper bound of $(1-\varepsilon) n<n$. In line with Andrews, we search for breaks in the $[0.15 n ; 0.85 n]$ subset of the total sample.
} 
of the Hill statistic $1 / \widehat{\eta}$ and thus the scaling factor $s .{ }^{16}$ Following Hall, Horowitz and Jing (1995), the optimal block length is set equal to $n^{1 / 3}$. One now selects $r$ for the recursive test such that $Y_{n}^{2}(t)$ - appropriately scaled - is maximal:

$$
\Omega_{r \in R_{\tau}}=\sup \widehat{s}^{-1} Y_{n}^{2}(t),
$$

with $\widehat{s}$ the estimate of the scaling factor. The null of parameter constancy is rejected if the sup-value exceeds the asymptotic critical values.

Quintos et al. provide a Monte Carlo study that shows convincingly the very good small sample power, size and bias properties of the recursive break test. Only in the case of a decrease of extreme tail dependence under the alternative hypothesis $\left(\eta_{1}>\eta_{2}\right)$ they detect less acceptable power properties. We solve this problem by executing the recursive test both in a "forward" version and a "backward" version. The forward version calculates $\eta_{t}$ in calender time, and the backward version in reverse calender time. If a downward break in $\eta$ occurs and the forward test does not pick it up, then the backward test corrects for this. Appendix A.2 provides a further Monte Carlo study of the small-sample properties of the recursive structural break test.

4.2. Cross-sectional variation. Apart from testing whether systemic banking risk is stable over time, we would also like to know whether cross-sectional differences between various groups of banks or different banking systems, say between the US and Europe or between different European countries, are statistically and economically significant. The asymptotic normality of tail dependence coefficient estimates $\widehat{\eta}$ referred to above enables some straightforward hypothesis testing. A test for the equality of tail dependence parameters between, e.g., Europe and the United States can thus be based on the following $T$-statistic:

$$
T=\frac{\widehat{\eta}_{1}-\widehat{\eta}_{2}}{\text { s.e. }\left(\widehat{\eta}_{1}-\widehat{\eta}_{2}\right)}
$$

which converges to a standard normal distribution in large samples. ${ }^{17}$ In the empirical applications below the asymptotic standard error in the test's denominator (4.5) is estimated using a block bootstrap with 1,000 replications. Again following Hall et al. (1995), we set the optimal block length equal to $n^{1 / 3}$. Similar to the structural stability

\footnotetext{
${ }^{16}$ The scale is estimated by $s=\widehat{\eta} m \widehat{\sigma}^{2}(1 / \widehat{\eta})$ with $\widehat{\sigma}^{2}$ the block bootstrapped variance of the Hill statistic.

${ }^{17}$ One can safely assume that $T$ comes sufficiently close to normality for empirical sample sizes as the one used in this paper (see, e.g., Hall, 1982, or Embrechts et al., 1997).
} 
test above, we opt for bootstrapping in blocks because of the nonlinear dependencies that might be present in the return data.

\section{DAtA AND DESCRIPTIVE STATistics}

We collected daily stock price data (total return indexes including dividends) for 25 euro area banks and 25 US banks. Excess returns are constructed by taking log first differences and deducting 3-month LIBOR rates (adjusted linearly to derive daily from annual rates). They are expressed in local currency, so that they do not vary directly with exchange rates. The market risk factor or aggregate shocks to the euro area and US banking systems are proxied by several measures with an eye toward some sensitivity analysis. First, we employ a general stock index and the banking sector sub-index for the euro area and the US, respectively. Second, we use the spread between below-investmentgrade and treasury bond yields for each of these economies. Finally, we use a global stock index and the global banking sector sub-index.

All series, except one, start on 2 April 1992 and end on 27 February 2004, rendering 3,106 return observations per bank. The euro area high-yield bond spread is only available from 1 January 1998 onwards, yielding 1,497 observations. All series are downloaded from Datastream, whose source for high-yield bond spreads is Merrill Lynch. ${ }^{18}$ The stock indices are the total return indices calculated by the data provider.

The following sub-section provides detailed information about how the 50 banks were chosen, based on balance sheet items for European and US banks. The subsequent section discusses the return data in greater depth, referring to the typical host of standard descriptive statistics.

5.1. Bank selection and balance sheet information. The time dimension of this dataset was very much constrained by the unavailability of longer stock price series for European banks. Before the 1990s fewer large European banks were privately quoted on stock exchanges and also many banks disappeared as a consequence of mergers. Ten out of 12 euro area countries have banks in our sample. There is no Austrian bank, as we could not construct a long enough stock price series for any of the two largest banks from this country. We deliberately excluded banks from Luxembourg, as they are considerably smaller than the larger banks from all other euro area countries. Roughly in proportion to the sizes of their economies in terms of GDP and the sizes of their

\footnotetext{
${ }^{18}$ See de Bondt and Marques (2004) for an in-depth discussion of high-yield bond spreads.
} 
banking systems in terms of assets, we have 6 banks from Germany, 4 banks from France, 4 banks from Italy, 3 banks from Spain, 2 banks each from the Netherlands and from Belgium and one bank from Finland, Greece, Ireland and Portugal, respectively. Appendix B contains the full list of banks, the abbreviations used in the tables and their country of origin.

Apart from the above constraints, banks were chosen on the basis of two main criteria: First, their size (as measured mainly by assets and deposits) and, second, their involvement in interbank lending (as measured by interbank loans, amounts due to and due from other banks and total money market funding). The necessary balance-sheet information was taken from Bureau van Dijk's Bankscope database (considering end of year values between 1992 and 2003). For the United States, the choice of banks was double-checked on the basis of the Federal Reserve Bank of Chicago commercial bank and bank holding company databases.

We used this balance-sheet information to identify the "systemically most important" banks across all the twelve years. By using several criteria, naturally some choices had to be made. This is illustrated in appendix $\mathrm{C}$, which reports data for one size (total assets) and one interbank trading ("due from banks") measure, all expressed in US dollars. Table C.2 displays the assets of all 25 US banks over the sample period, by declining order of average size. The corresponding table for "due from banks" is C.4. It turns out that the most important US bank according to the latter criterion is State Street, although in terms of assets it only comes at number 13 . Similar phenomena can also be observed for other "clearing banks", such as Northern Trust (5th by interbank linkages and only 24 th by assets), Bank of New York and Mellon, whose sizes are relatively poor indicators for their role in interbank relationships. We were particularly careful to have these banks that are most active in clearing and settlement in our sample. The justification for this is that failures of one or several main clearing banks may constitute a particularly severe source of contagion risk, even though they may not be very large compared to other players. ${ }^{19}$ Interestingly, as one can see by comparing tables C.1 and C.3 size and interbank activity are much more aligned for euro area banks.

Moreover, by comparing table C.1 with table C.2 we can see that the banks chosen for the euro area and the ones chosen for the US

\footnotetext{
${ }^{19}$ For example, the failure of Continental Illinois in 1983-84 and the computer problem of Bank of New York in 1985 raised major concerns and were accompanied by public action in order to prevent those incidents from spreading through the banking system.
} 
are of comparable size, even though the aggregate balance sheet of the euro area banks is overall larger than the US aggregate. The same similarity, however, does not apply to the "due from banks" measure of interbank relations, which is significantly larger in Europe than in the US (see tables C.3 and C.4). The larger interbank relationships in Europe compared to the US is an interesting finding in itself, which - to our knowledge - has not been emphasized in the literature on banking system risk before. ${ }^{20}$ It will be interesting to verify below whether this aggregate information from balance sheets is informative about the relative importance of systemic risk in the euro area as compared to the US banking system. In particular, does the greater amount of interbank lending in Europe translate into larger systemic risk?

\subsection{Descriptive statistics for stock returns and yield spreads.}

Appendix D presents the typical host of standard descriptive statistics for our 50 bank stock return series and three of the factors capturing aggregate risk (the banking sector indices, the general stock indices and the yield spread). Tables D.1 and D.2 report on the left-hand side mean excess returns, standard deviations, skew and kurtosis as well as on the right-hand side correlations between the individual bank stock returns and the three aggregate risk factors for the euro area and the United States, respectively. Mean returns are basically zero, as one would expect, whereas standard deviations of returns tend to be around 2 . Naturally, the volatility of the two stock indices is significantly lower than the one of the individual bank stocks. While there are little signs of skew, except for the troubled bank Banesto (see next sub-section for details) that shows some right skew, the high kurtosis signals that most series are leptokurtic.

As regards the correlations between bank stocks and aggregate risk factors, they are pretty high for the two stock indices, as could have been expected. Many correlation coefficients (though not all) reach levels of the order of 0.6 or higher, and plausibly the banking sector sub-index tends to be slightly more related to the individual stocks than the general stock market index. The picture is different for correlations between individual stock returns and the high-yield bond spread. First of all, correlation coefficients tend to be very low, varying between 0 and 0.05 in absolute value. Moreover, many of the US correlations have the "wrong" sign (a small positive correlation coefficient). This

\footnotetext{
${ }^{20} \mathrm{As}$ we were concerend about differences in reporting conventions or standards across the Atlantic, we discussed the difference with the data provider. No evidence of mistakes or different standards came out of this discussion.
} 
provides first evidence that the high-yield bond spread might not be a good predictor of aggregate banking system risk.

We complete the discussion of standard return statistics with the correlation matrices of individual bank stock returns. Table D.3 shows the correlation matrix for the euro area. Euro area bank returns seem to be generally positively correlated, with correlation coefficients varying between 0.05 and 0.77 . For the US, table D.4 provides a similar picture, although correlation coefficients appear to be more uniform (varying only between 0.32 and 0.66 ) and on average slightly higher.

For the purpose of the present paper, we are particularly interested in extreme negative returns. The left-hand sides of tables 1 and 2 report the three largest negative excess returns (in absolute value) for all the banks in the sample and for the two banking sector stock indices. Starting with Europe, the largest stock price decline in the sample (a massive daily collapse of 85\%) happens for Banesto (Banco Espanol de Credito) in February 1994. Around that time, this Spanish bank faced major difficulties and was rescued by an initial public intervention in December 1993. Another bank in major difficulties during our sample period is Berliner Bankgesellschaft from Germany. This is reflected in two consecutive stock price "crashes" of $38 \%$ and $27 \%$ during the summer of 2001. Ultimately, also this bank was saved by the federal state of Berlin. As regards the United States, the largest daily stock price slump happens to Unionbancal Corporation. The market value of this troubled Californian bank declined in June 2000 by as much as $36 \%$, as a consequence of credit quality problems. The next most significant corrections of just above $20 \%$ occur for Comerica Inc. and AmSouth Bancorporation. ${ }^{21}$ These examples illustrate that we have a number of individual bank crises in the sample.

[Insert table 1 about here]

Extreme negative returns of stock indices are obviously smaller than the ones for individual banks. In contrast to the stock returns, the high-yield bond spreads reported at the bottom of tables 1 and 2 are maxima, as extreme positive values indicate a situation of high risk. One can see that in times of stress non-investment grade corporate debt can trade at yields more than $10 \%$ above government debt.

There is also some first evidence of clustering in extreme bank stock declines, as many of them happen around a number of well-known crisis

\footnotetext{
${ }^{21}$ As we work with individual return data from Datastream, we screened our dataset for the problems described in Ince and Porter (2004). As one could probably expect for the relatively large banks and developed countries we are looking at, we did not find any signs of erroneous returns. For example, tables 1 and 2 suggest that stock splits or re-denominations did not artificially generate any huge returns.
} 
episodes. For example, a significant number European and US-based banks faced record downward corrections around the end of the summer 1998. This is the infamous episode related to the Long Term Capital Management (LTCM) collapse (and perhaps also to the Russian default). Another similar episode, very much limited to US banks, happened in spring and summer 2000, potentially related to the burst of the technology bubble. Interestingly, record bank stock crashes around 11 September 2001 - the time of the New York terrorist attack - are registered for a number of European banks, but not for US banks. ${ }^{22} \mathrm{Fi}$ nally, some American and European banks were hit significantly by the onset of the Asian crisis in fall 1997. These examples illustrate, first, that our sample covers a number of stress situations in global and national markets. ${ }^{23}$ Second, they also indicate the relevance of systematic shocks for banking stability, which motivates our tail- $\beta$ indicator.

[Insert table 2 about here]

As mentioned already above, many series indicate a high kurtosis, which might be caused by the fat tail property of bank stock returns. To address this issue more systematically, we report in tables 1 and 2 the estimated tail indexes $\widehat{\alpha}$ for individual banks and for the stock indices. It turns out that the tail indexes vary around 3, which is in line with the evidence presented in Jansen and De Vries (1991), further illustrating the non-normality of bank stock returns and the non-existence of higher-order moments. ${ }^{24}$ If anything, the tails of a number of European banks seem to be slightly fatter (smaller $\alpha$ ) than

\footnotetext{
${ }^{22}$ The less extreme reactions of US bank stocks may, however, also have to do with a four-day suspension of trading at the New York stock exchange.

${ }^{23}$ The presence of single and aggregate crisis situations in our sample is reassuring, as the interest of our paper is financial stability. At the same time, however, we would like to note that extreme-value methods do not require the presence of individual or aggregate failures in the sample. In contrast to fully non-parametric and parametric approaches, our semi-parametric approach allows to estimate reliably extremal behavior even beyond the sample boundaries.

A related issue is whether the absence of some banks from our sample, due to their failure or their merger with other banks, could imply sample selection bias. First of all, outright bank failures tend to be rare, so that related selection bias should be quite limited. A more intricate issue is banking consolidation. If mergers lead to the exlusion of relatively similar, highly connected banks, then a downward bias in measured systemic risk might occur. If they lead to the exclusion of different and little connected banks, then the amount of systemic risk in our sample should not be biased. As efficient mergers would often require the diversification of business, we might conclude that the overall room for sample selection bias in our sample is relatively contained.

${ }^{24}$ The non-normality of stock returns in general is a well-known fact in financial economics since at least the fundamental work by Mandelbrot (1963). For a related
} 
the ones of US banks. In addition to the larger interbank lending in Europe referred to above, this observation raises again the issue whether systemic risk on this side of the Atlantic is more pronounced than on the other. Another observation is that the yield spreads have much thinner tails than stock index returns.

The right-hand sides of tables 1 and 2 show the estimated quantiles for all the banks, when assuming a common percentile (or crash probability). In this paper, we experiment with percentiles $p$ between $0.02 \%$ and $0.05 \%$ (explicitly reporting results for the latter), as for these values the implied crisis levels tend to be close to or slightly beyond the historical extremes (see left-hand side). In other words, there cannot be any doubt about the fact that the phenomona considered constitute critical situations for banks. In terms of sensitivity analysis, all our qualitative results reported below are robust to varying the crash probability $p$ within this range. Finally, as was to be expected, the extreme quantiles implied by the common crash probability $p$ exhibit some variation across banks.

\section{BANK CONTAGION RISK}

In this section we report the results from our multivariate bank spillover measure. We are trying to answer two main sets of questions. 1) How large is bank contagion risk in euro area countries? And, in particular, what do our stock market indicators suggest about the relative importance of the risk of domestic spillovers between banks as compared to the risk of cross-border spillovers? Answers to the latter question are particularly important for macroprudential surveillance and for the ongoing debate about supervisory co-operation and the structure of supervisory authorities in Europe. 2) What do our indicators say about the relative size of bank contagion risk when comparing the euro area with the United States? Is one banking system more at risk than the other? The former set of questions is addressed in sub-section 6.1 and the latter in sub-section 6.2. In the present section we still abstract from extreme systematic risk for the euro area and US banking system, as this is addressed in the following section (section 7). For expositional reasons, we also abstract here from changes of spillover risk over time, which are addressed in section 8.

6.1. Euro area. In order to assess the exposure of euro area banks to each other, as derived from their extreme stock price co-movements, we

discussion of non-normality and the difficulty of parametric distributions to accurately capture the behavior of large bank stock returns for a wider cross-section of European banks, see Gropp and Moerman (2004). 
report in table 3 the estimation results for our measure (2.1). To keep the amount of information manageable, we do not show the extreme dependence parameters $\eta$ that enter in the estimation of (2.1) and we only display the spillovers to the largest banks of the countries listed on the left-hand side. We calculate the co-crash probabilities conditional on the second (column $\widehat{P}_{1}$ ), second and third (column $\widehat{P}_{2}$ ), second, third and fourth (column $\widehat{P}_{3}$ ) and so on largest banks from Germany (upper panel), from Spain (upper middle panel), from Italy (lower middle panel) and from France (lower panel). All probabilities refer to the crisis levels (extreme quantiles) reported in table 1 for $p=0.05 \%$.

For example, the value $22.4 \%$ in the row "Germany" and the column " $\widehat{P}_{1}$ " in the upper panel, refers to the probability that Deutsche Bank (the largest German bank) faces an extreme spillover from HypoVereinsbank (the second largest German bank). Going a few cells down, the value $11.2 \%$ describes the probability that Banco Santander Central Hispano (the largest Spanish bank) faces an extreme spillover from HypoVereinsbank. The difference between these two values would suggest that the likelihood of cross-border contagion could only be half of the likelihood of domestic contagion. When going through the table more systematically (in particular through the columns for more than one conditioning bank crash), it turns out that cross-border contagion risk is generally estimated to be smaller than domestic contagion risk in the euro area banking system, indeed. To pick just another example, the probability that the largest French bank (BNP Paribas) faces an extreme stock price slump given that the second (Crédit Agricole) and third largest French bank (Société Générale) have experienced one is a non-negligible $35.9 \%$ (see column $\widehat{P}_{2}$, upper middle panel, row France). The same probability for the largest Italian bank (Banca Intesa) is 7.5.\% (see column $\widehat{P}_{2}$, upper middle panel, row Italy). The probabilities in the first row of each panel are very often higher than the probabilities in the rows underneath.

There are also some exceptions, in particular among the bivariate probabilities reflecting linkages between two large banks (column $\widehat{P}_{1}$ ). This is not too surprising, as the largest players will have more extensive international operations, implying more scope for cross-border contagion. In particular, ABN AMRO - the largest Dutch bank - is more affected by problems of HypoVereinsbank than Deutsche Bank $(26.5 \%>22.4 \%)$. Actually, the linkages between Dutch and German banks tend to be among the largest cross-border linkages in our sample. Other important cross-border linkages exist between the top banks 
of France, Germany and the Netherlands and the top Spanish bank. Moreover, as in the case of BNP Paribas, Crédit Agricole and Société Générale, the largest institutions of a country must not always be very strongly interlinked in the home market. As a consequence, the French panel shows that ABN AMRO and Fortis - the largest Belgian bank - are more exposed to the second and third largest French bank than is BNP Paribas. The fact that Belgian and Dutch banks are associated with the largest cross-border spillover risks is also intuitive, since the banking sectors of these countries are dominated by a small number of very large international financial conglomerates. Also the results of Degryse and Nguyen (2004) and van Lelyveld and Liedorp (2004) suggest their special exposure to cross-border risk.

[Insert table 3 about here]

Another observation from table 3 is that the main Finnish and Greek banks, located in two countries next to the outside "border" of the euro area, tend to be least affected by problems of large banks from other euro area countries. Something similar, but to a lesser extent, can be observed for Ireland and, with exceptions, for Portugal. Apparently, smaller banking systems located more in the periphery of the euro area are more insulated from foreign spillovers than larger systems in the center. Overall, the level of spillover risk seems to be economically relevant, both domestically and across borders, in particular when more than one large bank face a stock price crash. Contagion risk for single crashes tends, however, to be markedly lower.

An interesting exception is Italy. While being a larger core country in the euro area, it is much less affected by problems in French, German or Spanish banks than other core countries. This is also consistent with the findings of Mistrulli (2005). In addition, spillovers from the largest Italian banks to other main banking systems in Europe seem also quite limited. One explanation for this phenomenon could be the low penetration of the Italian banking system from abroad and the limited number of acquisitions by Italian banks in other European countries. $^{25}$

The test results in table 4 show whether the differences between domestic and cross-country contagion risk are statistically significant or not. Rows and columns refer to the same banks as in table 3, but the cells now show T-statistics of the cross-sectional test described in sub-section 4.2. The null hypothesis is that domestic spillovers equal

\footnotetext{
${ }^{25}$ This must, however, not remain like this, as the recent acquisition of HypoVereinsbank by UniCredito suggests.
} 
cross-border spillovers. ${ }^{26}$ The test statistics partly qualify the interpretation of some of the contagion probabilities in table 3. Extreme crossborder linkages between Belgian, Dutch, French, German and Spanish banks are not (statistically) significantly different from domestic linkages within the major countries. In contrast, for Finland and Greece the null hypothesis is rejected in all cases. Moreover, the same happens in many cases for Ireland and Portugal. So, severe problems of larger French, German, Italian and Spanish banks may create similar problems for other large banks at home or in other central euro area countries, but often would do much less so for the largest banks of those smaller countries close to the outside "border" of the euro area. Hence, for the latter countries the tests of table 4 confirm the impression from the estimations in table 3.

[Insert table 4 about here]

The T-tests also confirm the special situation of Italy among the larger euro area countries. In many cases the exposure of Italian banks to foreign problems is significantly lower than domestic exposures in the other main countries. In addition, the greater exposure of ABN AMRO to Crédit Agricole (cross-border) than BNP Paribas to Crédit Agricole (domestic) is statistically significant at the 1\% level. And, similarly, the greater exposure of Fortis to Crédit Agricole (cross-border) than BNP Paribas to Crédit Agricole (domestic) is significant at the $10 \%$ level.

The probabilities in table 3 allow one to derive a relationship between the likelihood of a bank crash as a function of the number of other banks crashing. In our previous paper on currencies, we have denoted this relationship between the probability of crises and the number of conditioning events as "contamination function" (see Hartmann, et al., 2003, figures 1 to 7 ). Bae et al. (2003) speak in their international equity market contagion paper of "co-exceedance response curves". Gropp and Vesala (2004) apply the latter concept to European banks. While the results in table 3 suggest that most contamination functions in European banking are monotonously increasing (as for currencies), at least over certain ranges of conditioning events, there are also some

\footnotetext{
${ }^{26}$ The T-statistics result from comparing cross-border $\eta$-values with domestic $\eta$ values (ceteris paribus the number of conditioning banks), as used for the spillover probabilities of table 3. The estimation of tail dependence parameters $\eta$ have been described in equation (3.6). For example, the T-statistic in row Netherlands and column $T_{1}$ in table 4 results from testing whether the $\eta$-value for the largest Dutch bank (ABN AMRO) with respect to the second largest German bank (HypoVereinsbank) significantly differs from the domestic $\eta$-value of the largest German bank (Deutsche Bank) with respect to the second largest German bank (HypoVereinsbank).
} 
exceptions. Witness, for example, the exposure of Banco Commercial Portugues (the largest Portuguese bank) to problems of German banks. Going from $\widehat{P}_{4}$ to $\widehat{P}_{5}$ implies a reduction in the crash probability of BCP.

One potential explanation for this phenomenon is "flight to quality", "flight to safety" or "competitive effects". Some banks may benefit from the troubles at other banks, as e.g. depositors withdraw their funds from the bad banks to put them in good banks. Such behavior has been referred to by Kaufman (1988) in relation to US banking history, and Saunders and Wilson (1996) provided some evidence for it during two years of the Great Depression. For a more recent time period, Slovin, Sushka and Polonchek (1999) find regional "competitive effects" in response to dividend reduction and regulatory action announcements. Non-monotonicity of contamination functions might also occur for the curse of dimensionality, as very few observations may enter the joint failure area for more than two banks.

The finding of statistically similar spillover risk between major euro area banks within and between some large countries could be important for surveillance of the banking system and supervisory policies. One explanation for it may be the strong involvement of those banks in the unsecured euro interbank market. As these large players interact directly with each other, and in large amounts, one channel of contagion risk could be the exposures resulting from such trading. For example, Gropp and Vesala (2004) find interbank exposures at the country level to be a variable explaining part of spillovers in default risk between European banks. One implication of the similarity of domestic and cross-border spillover risks for some countries is that macroprudential surveillance and banking supervision need to have a cross-border dimension in the euro area. This is currently happening through the Eurosystem monitoring banking developments, through the application of the home-country principle (the home supervisor considers domestic and foreign operations of a bank), through the existence of various bilateral memoranda of understanding between supervisory authorities, through multilateral "colleges" of supervisors for specific groups and now also through the newly established "Lamfalussy Committees" in banking. The results could provide some arguments in favor of an increasing European-wide component in macroprudential surveillance and supervisory structures over time.

It is also interesting to see that in some smaller and less central countries in the area cross-border risk is more contained. This could suggest that even the larger players from those countries are still less interlinked 
with the larger players from the bigger countries. The existence of significant differences in the degree of cross-border risks between different groups of European countries could make the development of homogenous supervisory structures more complicated.

Overall, one could perhaps conclude that the results so far suggest that the still relatively limited cross-border integration of banking in the euro area does not seem to eliminate any contagion risk among the larger players from some key countries to levels that are so low that they can be simply ignored. This conclusion is also consistent with Degryse and Nguyen (2004) and Lelyveld and Liedorp (2004), whose analyses of interbank exposures suggest that risks from abroad may be larger than domestic risks in the Belgian and Dutch banking systems. One explanation for the relevance of cross-border bank risks could be that while bank mergers have been mainly national and traditional loan and deposit business of banks are only to a very limited extent expanding across national borders (see, e.g., the recent evidence provided in Hartmann, Maddaloni and Manganelli; 2003, figures 10 and 11), much of the wholesale business of these large players happens in international markets that are highly interlinked.

6.2. Cross-Atlantic comparison. Our final step to examine interbank spillovers consists of comparing them between the euro area and US banking systems. To do so, we calculate for each system the tail dependence parameter $\eta$ that governs the estimate of the multivariate contagion risk measure (2.1). Notice that for each continent $\eta_{U S}$ and $\eta_{E A}$ are derived from all the extreme stock return linkages (bilateral and multilateral) between the respective $N=25$ banks, following the estimation procedure described in section 3 .

As indicated in table 5 , we obtain $\widehat{\eta}_{U S}=0.39$ and $\widehat{\eta}_{E A}=0.17$. The evidence thus suggests that overall contagion risk in the US banking system is higher than contagion risk among euro area banks (about two times). ${ }^{27}$ Moreover, knowing that for the case of independence $\eta=1 / N=0.04$, the amount of multivariate linkage is of economically relevant magnitude. The $\widehat{P}$ values in the table describe the probability that all 25 banks in the euro area or the US crash, given that any of them crashes. These probabilities illustrate that overall systemic risk related to the crash of a single bank is extremely low. Of course, multivariate contagion risk increases for multiple bank crashes.

\footnotetext{
${ }^{27}$ Strictly speaking, this and related statements below make the plausible assumption that the dependence structure is sufficiently similar on both sides of the Atlantic for the slowly varying function $\ell(q)$ in 3.1 not to have a large impact on relative probabilities.
} 
[Insert table 5 about here]

Is this difference between the US and the euro area statistically significant? We apply the cross-sectional stability test (4.5) described in sub-section 4.2, with the following null hypothesis:

$$
H_{0}: \eta_{U S}=\eta_{E A} \text {. }
$$

It turns out that the $T$-statistic reaches $T=7.25$. In other words, our indicators and tests suggest that the difference in systemic spillover risk between the US and the euro area is statistically significant, way beyond the $1 \%$ confidence level.

One explanation could be that in a much more integrated banking system, such as the one of the United States, area-wide systemic risk is higher, as banking business is much more interconnected. We examine this hypothesis by also estimating the multivariate contagion risk for individual European countries. If the explanation above was true, then overall systemic spillover risk should not be lower within France, Germany or Italy than it is in the US. ${ }^{28}$ The bottom part of table 5 shows that this is actually the case. Overall domestic spillover risk in France and Germany is about the same as in the US; in Italy it is even larger than in the US (see also figure 1 in sub-section 8.1). Our crosssectional test cannot reject parameter equality between France and the US or between Germany and the US, but it rejects it between Italy and the US (as Italy is even more risky). In other words, the lower overall spillover risk in Europe is explained by the quite weak extreme cross-border linkages.

Having said all this, we need to note that there is some structural instability in the extreme dependence of bank stock returns on both sides of the Atlantic. As we will discuss in depth in section 8 below, the risk of spillovers has quite generally increased in the course of our sample period. We will, however, also show that all our conclusions here are robust to taking structural instability into account. The only caveat we have to keep in mind is that the probabilities in table 3 represent averages across the whole sample period, so that they tend to overestimate the risk of spillovers at the start of the sample and underestimate it towards the end of the sample.

Looking ahead, the analysis in the present section suggests that - as the European banking system integrates further over time - it could become more similar to the US system in terms of contagion risk. In other words, the ongoing and gradual integration process should be

\footnotetext{
${ }^{28}$ We thank Christian Upper for suggesting this exercise to us.
} 
accompanied by appropriate changes in macroprudential surveillance and supervisory structures.

\section{Aggregate Banking System RISK}

Next we turn to the analysis based on our measure of extreme systematic risk. We are interested in assessing to which extent individual banks and banking systems are vulnerable to an aggregate shock, as captured by an extreme downturn of the market risk factor or an extreme upturn of high-yield bond spreads. Across this section we assume stability of estimated tail- $\beta$ s over time. The same caveat applies as in the previous section, as structural breaks of extreme systematic banking system risk are only considered in section 8 .

The results are summarized in tables 6 and 7 for the euro area and the US, respectively, and for all measures of aggregate risk listed in sub-section 5.2. The different stock indices capture market risk, as in traditional asset pricing theory. The high-yield bond spread is also "tested" as a measure of aggregate risk. For example, Gertler and Lown (1999) have shown that it can be a good predictor of the business cycle, at least in the US, and fluctuations in economic activity are the most important determinant of banks' asset quality. Some might also regard high-yield spreads as a particularly suitable indicator for crisis situations.

[Insert table 6 about here]

The upper part of the tables report tail- $\beta$ s for individual banks. To take an example, the value 12.1 in the row "IRBAN" and column "stock index" of table 6 means that a very large downturn in the general euro area stock index is usually associated with a $12 \%$ probability that Allied Irish Banks, a top Irish bank, faces an extreme stock price decline. The value 30.2 in row "BNPPAR" and column "stock index" suggests that the same probability for the largest French bank is substantially higher. Going more systematically up and down the columns as well as right and left in the rows, one can see (i) that tail- $\beta$ s can be quite different across banks, both in Europe and in the US, and (ii) that the relative sizes of tail- $\beta$ s seem to be quite similar for different measures of aggregate risk. For example, a number of banks from some more peripheral and smaller euro area countries or smaller banks from large euro area countries can have quite low tail- $\beta$ s. One interpretation of this result is that the more local business of the latter banks exposes them less to aggregate euro area risk. Similar cases can be found for the US in table 7. For example, some players focussing on regional or local retail business, such as e.g. a savings\&loans association like 
Washington Mutual, have relatively low tail- $\beta$ s (in this specific case $3 \%$ for the US stock index as aggregate risk factor). In contrast, large and geographically broad banks - such as Deutsche Bank, BNP Paribas, Citigroup or JP Morgan Chase - exhibit larger tail- $\beta$ s, as they are much more diversified.

[Insert table 7 about here]

The bottom of tables 6 and 7 report the means and standard deviations of tail- $\beta$ s across the 25 banks for each continent. Overall, tail- $\beta \mathrm{s}$ in Europe and in the US are of similar order of magnitude, although the US $\beta$ s tend to be slightly less variable (except for yield spreads). We can use a cross-sectional T-test to compare aggregate banking risk across the Atlantic. Table 8 shows the average extreme dependence parameters $\bar{\eta}$ derived from the individual $\eta$ parameters governing the tail- $\beta \mathrm{s}$ of the 25 banks on each continent. It also shows the T-values for a test with the following null hypothesis:

$$
H_{0}: \bar{\eta}_{U S}=\bar{\eta}_{E A} \cdot
$$

The equality of extreme dependence between stock returns and the market risk factor in Europe and the United States cannot be rejected.

[Insert table 8 about here]

When turning to extreme systematic risk associated with high-yield bond spreads (see the right-hand side of tables 6 and 7 ), the results are somewhat different. Most importantly, tail- $\beta$ s for spreads are extremely small. Extreme positive levels of spreads on average do not seem to be associated with a high likelihood of banking problems. Quite the contrary, the probabilities are almost zero. This also confirms the simple correlation analysis reported in sub-section 5.2 and appendix D.

Accordingly, the tail dependence parameters $\bar{\eta}$ for spreads in table 8 are much smaller than the ones for stock indices. And note that the mean dependence parameters for yield spreads are all estimated to be quite close to the level associated with asymptotic independence for this two-dimensional measure, $\eta_{\text {indep }}=1 / N=0.5$. Then it does not come as a surprise that the T-tests show that - as for the market risk factor - the level of extreme aggregate risk in the US and in the euro area is statistically indistinguishable.

We conclude from this that high-yield bond spreads are not very informative about extreme aggregate banking system risk on both sides of the Atlantic. This finding could mean, for example, that credit spreads are a less good predictor of business cycle fluctuations - in particular of severe ones - than previously thought. It could also mean that the banks in our sample hold only a very limited amount of loans from 
borrowers that are rated below investment grade. Still, future research could address whether they have at least some incremental explanatory value for banking problems when other variables are controlled for as well.

\section{HAS SYSTEMIC RISK INCREASED?}

A crucial issue for macroprudential surveillance and supervisory policies is whether banking system risks change over time. In particular, it would be important to know whether they may have increased lately. Therefore, we apply in the present section our multivariate application of the structural stability test by Quintos, Fan and Phillips (2001; see sub-section 4.2) to the estimators of multivariate spillovers and systematic risk (sub-sections 8.1 and 8.2, respectively).

8.1. Time variation of bank contagion risk. We apply the recursive structural stability test described in equations (4.1), (4.2) and (4.4) to the extreme tail dependence parameters $\eta$ that govern the spillover probabilities reported in table 3 . The null hypothesis of constancy of $\eta$ for the cases in the table is given by (4.3). The test results are reported in table 9 , with the different cases structured in the same way as in tables 3 and 4.

[Insert table 9 about here]

Each entry first shows the endogenously estimated break point, if any, and then the value of the test statistic in parentheses. It turns out that the forward version of the recursive test discovers a significant upward break in spillover risk in almost every case, be it a domestic linkage or a cross-border linkage. For spillovers conditioned on German, Italian and Spanish banks almost all increases in risk occur some time during the year 1997. If crashes of French banks are the conditioning events, breaks tend to occur somewhat later, most often around the year 2000. While there have been economic events in the vicinity of the break point times found by the test that could have contributed to increases in spillover risks (e.g. the Asian financial crisis or the end of the technology boom), we would not pay too much attention to the exact dates. The reason is that further evidence presented below suggests that changes in risk exhibit a fairly gradual patterns, so that just singling out the most important break point could be misleading.

[Insert table 10 about here]

These results suggest that there was also an increase in system-wide spillover risks. We examine this question in table 10. We first calculate the 25-dimensional $(N=25)$ tail dependence parameter values that span 
the whole US block $\widehat{\eta}_{U S}$ and the whole euro area block $\widehat{\eta}_{E A}$ (as in subsection 6.2, table 5) and test for structural change. The same we do for Germany $(N=6)$, France $(N=4)$ and Italy $(N=4)$, separately. The null is again like in (4.3). The table shows on the left-hand side break points and test statistics for the full sample; in the middle of table 10 estimated sub-sample values for the different $\eta$ s are reported. Finally, the right-hand side of the table also displays the results of two further structural stability tests, limited to the second half of the sample after the first endogenous break. The first test is another Quintos et al. endogenous stability test, and the second an exogenous stability test $\left(T_{\mathrm{EMU}}\right)$, in which the break point is chosen to be 1 January 1999, the start of Economic and Monetary Union in Europe.

The tests indicate a significant upward break in euro area systemic risk around mid 1996 (test value 4.9) and in US systemic risk at the end of 1995 (test value 18.5). These breaks are both slightly earlier than the lower-dimensional ones in table $9 .^{29} \widehat{\eta}_{U S}$ increases from 0.20 to 0.41 and $\widehat{\eta}_{E A}$ from 0.13 to 0.20 . Gropp and Vesala (2004) also find an increase in bank spillover risk in Europe, using a different methodology, but they impose the break point at the time of the introduction of the euro. For France, Germany and Italy, our test also indicates strong domestic upward breaks, but in addition France and Germany experience a (weaker) downward break (as indicated by the backward version of the test). In sum, we detect a significant increase of multivariate spillover risk both in the euro area and in the US banking system. Both systems seem to be more vulnerable to contagion risk today than they have been in the early 1990s, the US even more so than the euro area.

The increase of spillover risk found for the US is consistent with the findings of de Nicolo and Kwast (2002), who detect an upward trend of regular correlations between US large and complex banking organizations (LCBOs) during the period 1988 to 1999 and interpret it as a sign of increasing systemic risk. ${ }^{30}$ The authors estimate that part of the increase is likely to be related to consolidation among LCBOs. The timing of structural change in de Nicolo and Kwast's paper is not exactly the same as in ours but quite similar, as they find most correlation changes during 1996 and perhaps 1997. Mistrulli (2005)

\footnotetext{
${ }^{29}$ Quintos et al. (2001) report critical values in the table of their appendix A (p. $662)$, which are reproduced in the notes to our tables 9 and 10.

One explanation for the earlier increase in fully systemic risk could be that the (many) cases not covered in table 9 have earlier breaks than the ones shown.

${ }^{30}$ Within the group of about 22 LCBOs, however, most of the increase in correlations is concentrated among the less complex banks.
} 
argues that some increase in domestic contagion risk in the Italian banking sector has been caused by new interbank lending structures that emerged from consolidation. And the risk seems to pick up around 1997, similar to our break points. Hence, banking consolidation may be one important explanation for a higher contagion risk within the countries dicussed. It is, however, a less likely explanation for the increase in $\eta$ for the euro area banking system as a whole. The reason is that cross-border bank mergers are still relatively rare in Europe (see, e.g., Hartmann et al., 2003, figure 10).

In order to get a better view of the evolution of multivariate contagion risk over time, we plot in figure 1 the recursive estimates of $\eta$ for the euro area, the US, France, Germany and Italy. In addition to unfiltered results (solid lines), we also display results for GARCHfiltered return data (dotted lines). For the reasons given in appendix E, however, we mainly focus on the unfiltered results. Comparing the two upper panels of the figure, we can see the smaller and gradual character of the increase in spillover risk in the euro area. Notice the consistency of this evolution with a slowly advancing integration process. Multivariate risk in the US starts at a higher level and begins to rise later but at a much faster pace. The lower panels of the figure confirm the results discussed in sub-section 6.2 , in so far as general spillover risk within France, Germany and Italy is higher than in the euro area as a whole and, on average, of a similar order of magnitude as within the United States. (The results are qualitatively the same for filtered data, although the strength of changes is sometimes muted. ${ }^{31}$ ) All these findings are consistent with the hypothesis advanced in section 6 that banks are more exposed to each other within a country than across borders. So far, this even remains true in the euro area, which shares a common currency and a common interbank market.

[Insert figure 1 about here]

Figure 2 shows then the recursive statistics of the cross-sectional tests comparing US multivariate spillover risk with euro area, French, German and Italian spillover risk. We would like to learn from this whether the similarities and differences in multivariate risk across those banking systems established in section 6 generally hold across our sample period. Each panel exhibits the difference in $\eta$ between the first country (always the US) and the second area or country. The straight dashed lines describe two standard deviation confidence intervals. So, when a solid curve moves out of a confidence interval, then the test rejects

\footnotetext{
${ }^{31} \mathrm{~A}$ similar phenomenon for general stock market data has already been observed by Poon et al. (2004).
} 
the equality of multivariate tail dependence parameters between the two countries. If a curve is above the confidence interval, then the first country is more susceptible to contagion. In the opposite case, the second country is the more risky one. We can immediately confirm from the upper left-hand chart in figure 2 that the US is more risky than the euro area, except for the very start of the sample. The lower right-hand chart illustrates that Italy is more risky than the US.

[Insert figure 2 about here]

Finally, we turn to the results of the two structural stability tests for the second half of the sample on the right of table 10. Interestingly enough, the endogenous test (backward version) finds a second break point for the euro area in January 1999 reducing $\eta$ (test value $3.2 \mathrm{com}$ pared to a critical value of 2.6 for a significant change at the $1 \%$ level). In other words, it indicates that multivariate contagion risk decreased in parallel with the introduction of the euro. As we are concerned about the validity of the asymptotic properties of the Quintos et al. test when it is applied in a sequential way, we also conduct an exogenous stability test for which we impose 1 January 1999 as the break point. This test exploits the asymptotic normality of the tail dependence parameter, as in the case of cross-sectional differences discussed earlier. It confirms that there is some decline in $\eta_{E A}$ at the time of the euro changeover, but this decline is not statistically significant (test value 1.4 compared to a critical value of 1.9 for a significant change at the $5 \%$ level).

While it is often assumed that the introduction of the euro with a common money market should have led to an increase in contagion risk in the euro area, our results do not provide any evidence of that actually happening. On the contrary, if anything there was a slight decrease of multivariate extreme dependence between all euro area banks. One explanation for such a development would be as follows. Whereas the introduction of a single currency with a common (and fully integrated) money market could increase the interbank linkages between banks across borders, and thereby the risk of contagion, on the other hand the much larger and more liquid money market as well as the wider access to different contingent claims under a single currency could also increase the money market's resilience against shocks and improve risk sharing. If the latter effects dominate the former, then the banking system could well become less prone to extreme spillovers.

As for the three larger euro area countries, Germany experiences a similar reduction in risk as the area as a whole. But in this case the reduction is also statistically significant for the exogenous break test, at least at the $10 \%$ level. France and Italy also have some further breaks. While statistically significant, they do not happen in the vicinity of the 
euro changeover. The United States banking system faces a further increase in multivariate spillover risk at the end of 1997.

We close this sub-section with a word of caution. While the evidence supporting increases in multivariate extreme dependencies among banks in both the euro area and the United States seems statistically relatively strong, we should not forget that our sample period extends "only" over 12 years. This means, first, that we cover only a small number of economic cycles. ${ }^{32}$ Since there was a relatively long upturn during the 1990s, there may be a risk that this had an impact on extreme bank stock return dependence. More generally, similar to correlation extreme dependence can oscillate over time. Obviously, we cannot know whether there was already a period of higher extreme linkages between banks before our sample starts or whether the high linkages observed towards the end of our sample will come down again in the future.

8.2. Time variation of aggregate banking system risk. Now we apply the structural stability test to extreme systematic risk in banking systems. More precisely, we study whether the bivariate extreme dependence parameters $\eta$ that enter our estimates of tail- $\beta$ s have changed between 1992 and 2004. Table 11 reports the results for each euro area bank in our sample and table 12 for each US bank. Each table shows for the respective banks the estimated break points, if any, with test values in parentheses. Tests are performed for all aggregate risk measures on which we condition the tail- $\beta$ s.

[Insert table 11 about here]

The general result is that extreme systematic risk has increased over time. In other words, both the euro area and the US banking system seem to be more exposed to aggregate shocks today than they were in the early 1990s. We further illustrate this at the system-wide level in figure 3, which gives us a better insight into the time evolution of extreme systematic risk. The lines in the two panels refer to averages of $\eta \mathrm{s}$ across the 25 euro area and 25 US banks, respectively. We choose the general local stock indices as aggregate risk factors, but the picture is unchanged for other stock indices. Similar to figure 1 above for interbank spillover risk, the $\eta$-values entering the figure are calculated recursively. One can see that the increase in aggregate banking system risk

\footnotetext{
${ }^{32}$ Following the NBER and CEPR business cycle dating programs, we cover at most two full cycles; see http://www.nber.org/cycles.html and http://www.cepr.org/data/Dating/.
} 
is also economically significant, both in the euro area and in the US. ${ }^{33}$ While results corrected for time-varying volatility (GARCH-filtered returns) are somewhat more muted, qualitatively they are unchanged. Moreover, the similarity of extreme aggregate banking system risk in the euro area and the US established in section 7 seems to be valid for the entire sample period.

[Insert figure 3 about here]

Table 11 locates the timing of most European break points for the stock indices around 1997 and for some cases in 1996. In the US they happen somewhat earlier, with many breaks in 1996 (table 12). For Europe the timing is roughly in line with, but not identical to interbank spillover risks (see the previous sub-section), for the US the tail- $\beta$ breaks happen somewhat later than the contagion breaks. Similar to the spillover risks discussed earlier, the time evolution visible in figure 3 , however, suggests that not too much importance should be given to the exact break dates.

We do not report the pre- and post-break tail- $\beta$ and $\eta$ values in the tables in order to save space and since figure 3 provided already a good general impression. ${ }^{34}$ We just mention that economically relevant changes apply also to some of the most important players, such as the largest US banks (Citigroup and JP Morgan Chase). The $\beta$ s of important clearing banks, such as Bank of New York, State Street or Northern Trust, changed as well, sometimes by even more than the former. The main US clearers have also some of the statistically most significant breaks (table 12). Similarly significant changes can also be observed for the euro area.

[Insert table 12 about here]

Both in Europe and in the US there are also breaks in tail- $\beta$ s for yield spreads. They happen, however, with surprising regularity in 2000, the time of the burst of the technology bubble. In any case, given the very low extreme systematic risk associated with yield spreads, not too much importance should be given to this result. Finally, the same words of caution about business cycles and time-varying co-movements should be kept in mind as for the previous sub-section.

\footnotetext{
${ }^{33}$ Notice that these results are different from the ones by de Nicolo and Kwast (2002) using standard market model $\beta$ s among US LCBOs. They do not identify any increase of the impact of the general market index on LCBO stock returns between 1992 and 1999. They only observe an increase of the impact of a special sectoral LCBO index in late 1992/early 1993, conditional on the general market index.

${ }^{34}$ They are available from the authors on request.
} 


\section{Conclusions}

In this paper we made a new attempt to assess banking system risk, by applying recent multivariate extreme-value estimators and tests to excess returns of the major banks in the euro area and the United States. We distinguish two types of measures, one capturing extreme spillovers among banks ("contagion risk") and another capturing the exposure of banks to extreme systematic shocks (which we denote as tail- $\beta$ ). We compare the importance of those forms of systemic risk across countries and over time.

Our results suggest that bank spillover risk in the euro area seems to be significantly lower than in the US. As domestic linkages in the euro area are comparable to extreme linkages among US banks, this finding seems to be related to weak cross-border linkages in Europe. For example, the largest banks of some smaller countries at the periphery of the area seem to be more protected from cross-border contagion risk than some of the major European banks originating from some central European countries. Extreme systematic risk for banks seems to be roughly comparable across the Atlantic. In contrast to stock indices, high-yield bond spreads in general do not seem to be very informative about aggregate banking risks. Structural stability tests for both our banking system risk indicators suggest a general increase in systemic risk taking place over the second half of the 1990s, both in Europe and the US. We do not find, however, that the introduction of the euro had any adverse effect on cross-border banking risks, quite the contrary. Overall, the increase of risk in the euro area as a whole seems to have happened extremely gradually, as one would expect from the slow integration of traditional banking business. For the US it may be noteworthy that some of the strongest increases in extreme systematic risk seem to be concentrated among the largest players and the main clearing banks.

Our results provide some interesting perspectives on the ongoing debate on financial stability policies in Europe. For example, the benchmark of the US seems to indicate that cross-border risks may further increase in the future, as banking business becomes better integrated. At the same time, it should be recognized that the direction of this process is not unique to Europe. And in addition, our twelve-year sample period includes one long economic cycle that may have overemphasized commonality in banking risks. Keeping these caveats in mind, the results in this paper underline the importance of macroprudential surveillance that takes a cross-border perspective, in particular 
in Europe. They also encourage further thinking about the best institutional structures for supervision in a European banking system that slowly overcomes the barriers imposed by national and economic borders. While important steps have already been taken in this regard, if one thinks for example of the newly established Lamfalussy Committees in banking, it is nevertheless important to prepare for a future that may be different from the status quo.

\section{REFERENCES}

[1] Aharony, J., and I. Swary (1983), 'Contagion effects of bank failures: Evidence from capital markets', Journal of Business, 56(3), 305-317.

[2] Allen, F., and D. Gale (2000), 'Financial contagion', Journal of Political Economy, 108(1), 1-33.

[3] Andrews, D. (1993), 'Tests for parameter stability and structural change with unknown change point', Econometrica, 59, 817-858.

[4] Bae, K., A. Karolyi and R. Stulz (2003), 'A new approach to measuring financial contagion', Review of Financial Studies, 16(3), 717-763.

[5] Beirlant, J., and B. Vandewalle (2002), 'Some comments on the estimation of a dependence index in bivariate extreme values statistics', Statistics and Probability Letters, 60, 265-278.

[6] Bekaert, G., C. Harvey and A. Ng (forthcoming), 'Market integration and contagion', forthcoming in 2005 in Journal of Business, 78(1).

[7] Blavarg, M., and P. Nimander (2002), 'Interbank exposures and systemic risk', Risk Measurement and Systemic Risk - Proceedings of the Third Joint Central Bank Research Conference (Basel, Bank for International Settlements), 287305.

[8] Calomiris, C., and J. Mason (1997) 'Contagion and bank failures during the Great Depression: The June 1932 Chicago banking panic', American Economic Review, 87(5), 863-883.

[9] Calomiris, C. and J. Mason (2000), 'Causes of U.S. bank distress during the Depression', NBER Working Paper, no. 7919, September.

[10] Chen, Y. (1999), 'Banking panics: The role of the first-come, first-served rule and information externalities', Journal of Political Economy, 107(5), 946-968.

[11] Cooperman, E., W. Lee and G. Wolfe (1992), 'The 1985 Ohio thrift crisis, the FSLIC's solvency, and rate contagion for retail CDs', Journal of Finance, 47(3), 919-941.

[12] Cornell, B., and A. Shapiro (1986) 'The reaction of bank stock prices to the international debt crisis', Journal of Banking and Finance, 10, 55-73.

[13] Danielsson, J., and C. de Vries (1997), 'Tail index and quantile estimation with very high frequency data', Journal of Empirical Finance, 4, 241-257.

[14] Danielsson, J., L. de Haan, L. Peng and C. de Vries (2001), 'Using a bootstrap method to choose the sample fraction in tail index estimation', Journal of Multivariate Analysis, 76, 226-248.

[15] De Bandt, O., and P. Hartmann (2000), 'Systemic risk: A survey', ECB Working Paper, no. 35, November. 
[16] de Bondt, G., and D. Marques (2004), 'The high-yield segment of the corporate bond market: A diffusion modelling approach for the United States, the United Kingdom and the euro area', ECB Working Paper, no. 313, February, forthcoming in the Journal of Financial Markets Research.

[17] Degryse, H., and G. Nguyen (2004), 'Interbank exposures: An empirical examination of systemic risk in the Belgian banking system', paper presented at the Symposium of the ECB-CFS research network on 'Capital Markets and Financial Integration in Europe', European Central Bank, Frankfurt am Main, 10-11 May.

[18] Demirgüc-Kunt, A., and E. Detragiache (1998), 'The determinants of banking crises in developing and developed countries', IMF Staff Papers, 45, 81-109.

[19] De Nicolo, G. and M. Kwast (2002), 'Systemic risk and financial consolidation: Are they related?', Journal of Banking and Finance, 26, 861-880.

[20] Docking, D., M. Hirschey and E. Jones (1997), 'Information and contagion effects of bank loan-loss reserve announcements', Journal of Financial Economics, 43(2), 219-240.

[21] Draisma, G., H. Drees, A. Ferreira and L. de Haan (2001), 'Tail dependance in independance', EURANDOM report 2001-014.

[22] Eichengreen, B., A. Rose and C. Wyplosz (1996), 'Contagious currency crises: first tests', Scandinavian Journal of Economics, 98, 463-484.

[23] Elsinger, H., A. Lehar and M. Summer (2002), 'Risk assessment for banking systems', Oesterreichische Nationalbank, Working Paper, no. 79, October.

[24] Embrechts, P., C. Klüppelberg and T. Mikosch (1997), Modelling Extremal Events (Berlin: Springer).

[25] Forbes, K., and R. Rigobon (2002), 'No contagion, only interdependence: measuring stock market comovements', Journal of Finance, 57, 2223-2262.

[26] Freixas, X., B. Parigi and J.-C. Rochet (2002), 'Systemic risk, interbank relations and liquidity provision by the central bank', Journal of Money, Credit, and Banking, 32(3/2), 611-640.

[27] Furfine, C. (2003), 'Interbank exposures: Quantifying the risk of contagion', Journal of Money, Credit, and Banking, 35(1), 111-128.

[28] Gertler, M., and C. Lown (1999), 'The information in the high-yield bond spread for the business cycle: Evidence and some implications', Oxford Review of Economic Policy, 15(3), 132-150.

[29] Goldie, C., and R. Smith (1987), 'Slow variation with remainder: Theory and applications', Quarterly Journal of Mathematics, 38, 45-71.

[30] Gomes, I., L. de Haan, and L. Peng (2002), 'Semi-parametric estimation of the second order parameter in statistics of extremes', Extremes, 5(4), 387-414.

[31] Gonzalez-Hermosillo, B., C. Pazarbasioglu and R. Billings (1997), 'Banking system fragility: Likelihood versus timing of failure - An application to the Mexican financial crisis', IMF Staff Papers, 44(3), 295-314.

[32] Gorton, G. (1988), 'Banking panics and business cycles', Oxford Economic Papers, 40, 751-781.

[33] Gropp, R., and G. Moerman (2004), 'Measurement of contagion in banks' equity prices ', in I. Hasan and J. Tarkka (eds.), Banking, Development and Structural Change, Special Issue of the Journal of International Money and Finance, 23(3), 405-459. 
[34] Gropp, R., and J. Vesala (2004), 'Bank contagion in Europe', paper presented at the Symposium of the ECB-CFS research network on 'Capital Markets and Financial Integration in Europe', European Central Bank, Frankfurt am Main, 10-11 May.

[35] Grossman, R. (1993), 'The macroeconomic consequences of bank failures under the National Banking System', Explorations in Economic History, 30, 294-320.

[36] Haan, L. de, Jansen, D.W., Koedijk, K. and C.G. de Vries (1994), 'Safety first portfolio selection, extreme value theory and long run asset risks', in J. Galambos, J. Lechner and E. Simiu (eds.), Extreme Value Theory and Applications (Dordrecht: Kluwer Academic Publishers), 471-487.

[37] Hall, P. (1982), 'On some simple estimates of an exponent of regular variation', Journal of the Royal Statistical Society B, 44(1), 37-42.

[38] Hall, P., J. Horowitz and B. Jing (1995), 'On blocking rules for the bootstrap with dependent data', Biometrika, 82(3), 561-574.

[39] Hartmann, P., A. Maddaloni and S. Manganelli (2003), 'The euro area financial system: Structure, integration and policy initiatives', Oxford Review of Economic Policy, 19(1), 180-213.

[40] Hartmann, P., S. Straetmans and C.G. de Vries (2003a), 'A global perspective on extreme currency linkages', in W. Hunter, G. Kaufman and M. Pomerleano (eds.), Asset Price Bubbles: The Implications for Monetary, Regulatory and International Policies (Cambridge (MA): MIT Press), 361-382.

[41] Hartmann, P., S. Straetmans and C.G. de Vries (2003b), 'The breadth of currency crises', paper presented at the Center for Financial Studies/Wharton School conference on 'Liquidity concepts and financial instabilities', Eltville, June.

[42] Hartmann, P., S. Straetmans and C.G. de Vries (2004), 'Asset market linkages in crisis periods', Review of Economics and Statistics, 86(1), 313-326.

[43] Hasan, I., and G. Dwyer (1994), 'Bank runs in the free banking period', Journal of Money, Credit, and Banking, 26, 271-288.

[44] Hellwig, M. (1994), 'Liquidity provision, banking, and the allocation of interest rate risk', European Economic Review, 38(7), 1363-1389.

[45] Hill, B. (1975), 'A simple general approach to inference about the tail of a distribution', The Annals of Statistics, 3(5), 1163-1173.

[46] Ince, O., and R. Porter (2004), 'Individual equity return data from Thomson Datastream: Handle with care!', University of Florida Working Paper, March.

[47] Jansen, D., and C. de Vries (1991), 'On the frequency of large stock returns: Putting booms and busts into perspective', Review of Economics and Statistics, 73, 19-24.

[48] J.P. Morgan (1999), CreditMetrics (4th edition), www.creditmetrics.com.

[49] Kaufman, G. (1988), 'Bank runs: Causes, benefits and costs', Cato Journal, $7(3), 559-587$.

[50] Kho, B.-C., D. Lee and R. Stulz (2000), 'U.S. banks, crises, and bailouts: From Mexico to LTCM', American Economic Review Papers and Proceedings, 90(2), $28-31$.

[51] Ledford, A., and J. Tawn (1996), 'Statistics for near independence in multivariate extreme values', Biometrika, 83(1), 169-187.

[52] Lelyveld, I. van, and F. Liedorp (2004), 'Interbank contagion in the Dutch banking sector', De Nederlandsche Bank Working Paper, no. 005, July. 
[53] Longin, F., and B. Solnik (2001), 'Extreme correlation of international equity markets', Journal of Finance, 56, 649-676.

[54] Mandelbrot, B. (1963), 'The variation of certain speculative prices', Journal of Business, 36, 394-419.

[55] Merton, R. (1974), On the pricing of corporate debt: the risk structure of interest rates, Journal of Finance, 29, 449-470.

[56] Mistrulli, P. (2005), 'Interbank lending patterns and financial contagion', mimeo., Banca d'Italia, May.

[57] Morgenstern, D. (1956), 'Einfache Beispiele zweidimensionaler Verteilungen', Mitteilungsblatt fur Mathematische Statistik, 8, 234-235.

[58] Musumeci, J. and J. Sinkey (1990), 'The international debt crisis, investor contagion, and bank security returns in 1987: The Brazilian experience', Journal of Money, Credit, and Banking, 22(2), 210-233.

[59] Peng, L. (1999), 'Estimation of the coefficient of tail dependence in bivariate extremes', Statistics and Probability Letters, 43, 399-409.

[60] Pindyck, R., and J. Rotemberg (1993), 'The comovements of stock prices', Quarterly Journal of Economics, 108, 1073-1104.

[61] Poon, S.-H., M. Rockinger and J. Tawn (2004), 'Extreme value dependence in financial markets: Diagnostics, models, and financial implications', Review of Financial Studies, 17(2), 581-610.

[62] Pritsker, M. (2001), 'The channels for financial contagion', in S. Claessens and K. Forbes (eds.), International Financial Contagion (Dordrecht: Kluwer Academic Publishers), 67-95.

[63] Quandt, R. (1960), 'Test of the hypothesis that a linear regression system obeys two separate regimes', Journal of the American Statistical Association, $55,324-330$.

[64] Quintos, C., Z. Fan and P. Phillips (2001), 'Structural change tests in tail behaviour and the Asian crisis', Review of Economic Studies, 68, 633-663.

[65] Saunders, A. (1986), 'An examination of the contagion effect in the international loan market', Studies in Banking and Finance, 3, 219-247.

[66] Saunders, A., and B. Wilson (1996), 'Contagious bank runs: Evidence from the 1929-33 period', Journal of Financial Intermediation, 5(4), 409-423.

[67] Shiller, R. (1989), 'Comovements in stock prices and comovements in dividends', Journal of Finance, 44, 719-729.

[68] Slovin, M., M. Sushka and J. Polonchek (1999), 'An analysis of contagion and competitive effects at commercial banks', Journal of Financial Economics, 54, 197-225.

[69] Smirlock, M., and H. Kaufold (1987), 'Bank foreign lending, mandatory disclosure rules, and the reaction of bank stock prices to the Mexican debt crisis', Journal of Business, 60(3), 347-364.

[70] Straetmans, S. (2000), Extremal spill-overs in equity markets, in P. Embrechts (ed.), Extremes and Integrated Risk Management (London: Risk Books), 187204.

[71] Straetmans, S., W. Verschoor and C. Wolff (2003), 'Extreme US stock market fluctuations in the wake of 9/11', paper presented at the 2004 American Finance Assocation Meetings, San Diego (CA), 3-5 January.

[72] Swary, I. (1986), 'Stock market reaction to regulatory action in the Continental Illinois crisis', Journal of Business, 59(3), 451-473. 
[73] Upper, C., and A. Worms (2004), 'Estimating bilateral exposures in the German interbank market: Is there a danger of contagion?', European Economic Review, 48(4), 827-849.

[74] Wall, L., and D. Peterson (1990) 'The effect of Continental Illinois' failure on the financial performance of other banks', Journal of Monetary Economics, 26, 77-99. 
TABLE 1. Historical minima, tail indexes and quantile estimates for excess stock returns of euro area banks

\begin{tabular}{|c|c|c|c|c|c|c|}
\hline \multirow[t]{2}{*}{ Bank } & \multicolumn{3}{|c|}{ |Extreme negative returns| in \% } & \multirow[t]{2}{*}{$\widehat{\alpha}$} & $\widehat{Q}(p)$ & in $\%$ \\
\hline & $X_{1, n}$ (date) & $X_{2, n}$ (date) & $X_{3, n}$ (date) & & $p=0.05 \%$ & $p=0.02 \%$ \\
\hline DEUTSCHE & $12.4(09 / 11 / 01)$ & $12.0(03 / 09 / 00)$ & $10.1(09 / 19 / 01)$ & 3.3 & 13.8 & 18.2 \\
\hline HYPO & $17.3(10 / 23 / 02)$ & $14.3(09 / 30 / 02)$ & $11.5(09 / 11 / 01)$ & 3.1 & 17.9 & 24.0 \\
\hline DRESDNER & $11.1(10 / 28 / 97)$ & $9.9(07 / 22 / 02)$ & $9.7(03 / 09 / 00)$ & 3.2 & 16.1 & 21.5 \\
\hline COMMERZ & $13.3(09 / 11 / 01)$ & $13.1(09 / 20 / 01)$ & $13.1(10 / 23 / 02)$ & 2.9 & 15.9 & 21.9 \\
\hline BGBERLIN & $37.9(08 / 30 / 01)$ & $27.0(09 / 10 / 01)$ & $17.1(01 / 17 / 94)$ & 2.4 & 23.4 & 34.2 \\
\hline DEPFA & $16.5(11 / 29 / 00)$ & $10.4(10 / 08 / 98)$ & $10.3(07 / 23 / 02)$ & 3.2 & 13.4 & 17.6 \\
\hline BNPPAR & $12.5(09 / 30 / 98)$ & $11.2(09 / 30 / 02)$ & $11.0(10 / 04 / 02)$ & 3.0 & 15.4 & 20.8 \\
\hline $\mathrm{CA}$ & $19.6(11 / 19 / 01)$ & $12.4(07 / 12 / 01)$ & $10.5(09 / 12 / 02)$ & 2.4 & 13.3 & 19.4 \\
\hline SGENERAL & $12.5(09 / 10 / 98)$ & $11.6(09 / 30 / 02)$ & $10.4(07 / 19 / 02)$ & 2.7 & 17.1 & 23.6 \\
\hline NATEXIS & $13.6(10 / 08 / 97)$ & $10.8(09 / 25 / 96)$ & $10.6(03 / 25 / 94)$ & 3.6 & 9.6 & 12.3 \\
\hline INTESA & $12.7(11 / 07 / 94)$ & $12.2(09 / 20 / 01)$ & $11.6(10 / 28 / 97)$ & 3.9 & 13.7 & 17.4 \\
\hline UNICREDIT & $10.9(07 / 20 / 92)$ & $10.3(09 / 10 / 98)$ & $9.9(10 / 21 / 92)$ & 3.6 & 12.9 & 16.7 \\
\hline PAOLO & $9.9(12 / 04 / 00)$ & $9.7(09 / 10 / 98)$ & $9.5(09 / 20 / 01)$ & 3.5 & 13.3 & 17.3 \\
\hline CAPITA & $18.2(03 / 07 / 00)$ & $12.0(10 / 01 / 98)$ & $11.5(06 / 20 / 94)$ & 3.3 & 16.7 & 24.6 \\
\hline SANTANDER & $15.9(10 / 01 / 98)$ & $12.8(01 / 13 / 99)$ & $11.4(07 / 30 / 02)$ & 3.0 & 15.8 & 21.4 \\
\hline BILBAO & $14.5(01 / 13 / 99)$ & $11.8(09 / 10 / 98)$ & $10.7(09 / 24 / 92)$ & 2.6 & 17.4 & 24.8 \\
\hline BANESP & $84.8(02 / 02 / 94)$ & $18.9(11 / 27 / 02)$ & $15.5(08 / 28 / 98)$ & 2.2 & 20.1 & 30.6 \\
\hline ING & $16.1(10 / 15 / 01)$ & $14.0(10 / 02 / 98)$ & $13.9(09 / 11 / 01)$ & 2.4 & 23.4 & 34.4 \\
\hline ABNAMRO & $12.6(09 / 14 / 01)$ & $11.9(09 / 11 / 01)$ & $11.3(09 / 30 / 02)$ & 2.5 & 19.6 & 28.3 \\
\hline FORTIS & $11.0(08 / 01 / 02)$ & $10.6(09 / 30 / 02)$ & $10.6(09 / 11 / 01)$ & 3.1 & 14.6 & 19.7 \\
\hline ALMANIJ & $8.7(11 / 26 / 99)$ & $8.0(04 / 30 / 92)$ & $6.2(08 / 01 / 02)$ & 3.8 & 9.7 & 12.4 \\
\hline ALPHA & $9.4(04 / 27 / 98)$ & $9.4(09 / 09 / 93)$ & $9.1(01 / 13 / 99)$ & 3.1 & 14.4 & 19.3 \\
\hline $\mathrm{BCP}$ & $17.1(10 / 23 / 02)$ & $9.9(02 / 25 / 03)$ & $9.1(04 / 16 / 99)$ & 2.5 & 13.8 & 19.8 \\
\hline SAMPO & $20.7(08 / 17 / 92)$ & $18.3(12 / 21 / 92)$ & $15.6(08 / 26 / 92)$ & 2.6 & 23.8 & 33.7 \\
\hline IRBAN & $18.2(02 / 06 / 02)$ & $10.3(10 / 08 / 98)$ & $10.1(10 / 28 / 97)$ & 2.9 & 12.7 & 17.4 \\
\hline BANK INDEX & $6.9(09 / 11 / 01)$ & $6.7(10 / 01 / 98)$ & $6.3(09 / 10 / 98)$ & 2.5 & 11.2 & 16.1 \\
\hline STOCK INDEX & $6.3(09 / 11 / 01)$ & $5.3(10 / 28 / 97)$ & $5.0(09 / 14 / 01)$ & 3.2 & 7.7 & 10.2 \\
\hline YIELD SPREAD & $16.6(10 / 02 / 01)$ & $16.5(10 / 03 / 01)$ & $16.3(10 / 01 / 01)$ & 9.1 & 22.3 & 24.7 \\
\hline
\end{tabular}

Note: Returns and quantiles are reported in absolute values and therefore positive. $X_{1, n}, X_{2, n}$ and $X_{3, n}$ are the three smallest daily excess returns in the sample for each bank or each index. The last line describes the largest values (maxima) for high-yield bond spreads. Dates in parentheses are denoted $\mathrm{XX} / \mathrm{YY} / \mathrm{ZZ}$, where $\mathrm{XX}=$ month, $\mathrm{YY}=$ day and $\mathrm{ZZ}=$ year. $\widehat{\alpha}$ is the tail index, estimated with the method by Hill (1975). $\widehat{Q}(p)$ is the estimated quantile (crisis level) for each bank, as implied by the estimated tail index and the assumed percentile (crisis probability). The quantiles are calculated for two percentiles $p$ that correspond to an in-sample quantile $(p=0.05 \%)$ and an out-of-sample quantile $(p=0.02 \%)$. Data are from 2 April 1992 to 27 February 2004. The source of raw data is Datastream. 
TABLE 2. Historical minima, tail indexes and quantile estimates for excess stock returns of US banks

\begin{tabular}{|c|c|c|c|c|c|c|}
\hline \multirow[t]{2}{*}{ Bank } & \multicolumn{3}{|c|}{ |Extreme negative returns| in \% } & \multirow[t]{2}{*}{$\widehat{\alpha}$} & \multirow{2}{*}{$\frac{\widehat{Q}(p)}{.05 \%}$} & \multirow{2}{*}{$\begin{array}{l}\text { in } \% \\
p=0.02 \%\end{array}$} \\
\hline & $X_{1, n}$ (date) & $X_{2, n}$ (date) & $X_{3, n}$ (date) & & & \\
\hline CITIG & $17.1(07 / 23 / 02)$ & $11.7(07 / 22 / 02)$ & $11.5(10 / 27 / 97)$ & 3.3 & 13.7 & 18.0 \\
\hline JP MORGAN & $20.0(07 / 23 / 02)$ & $10.8(09 / 03 / 98)$ & $10.1(09 / 13 / 00)$ & 3.7 & 12.9 & 16.6 \\
\hline BAMERICA & $11.6(10 / 14 / 98)$ & $10.7(10 / 27 / 03)$ & $9.1(06 / 16 / 00)$ & 3.6 & 12.0 & 15.5 \\
\hline WACHOVIA & $9.2(11 / 14 / 00)$ & $9.1(05 / 25 / 99)$ & $9.0(01 / 27 / 99)$ & 3.5 & 10.9 & 14.1 \\
\hline FARGO & $9.2(06 / 16 / 00)$ & $7.5(06 / 08 / 98)$ & $7.3(04 / 14 / 00)$ & 3.7 & 9.6 & 12.3 \\
\hline BONE & $25.8(08 / 25 / 99)$ & $11.4(11 / 10 / 99)$ & $9.5(10 / 27 / 97)$ & 3.0 & 13.5 & 18.4 \\
\hline WASHING & $11.7(10 / 17 / 01)$ & $10.3(09 / 04 / 98)$ & $9.3(12 / 09 / 03)$ & 3.5 & 12.7 & 16.5 \\
\hline FLEET & $11.2(07 / 16 / 02)$ & $10.2(02 / 21 / 95)$ & $8.0(07 / 23 / 02)$ & 3.7 & 11.7 & 15.0 \\
\hline BNYORK & $16.9(12 / 18 / 02)$ & $13.9(07 / 16 / 01)$ & $11.1(10 / 03 / 02)$ & 3.4 & 12.6 & 16.5 \\
\hline SSTREET & $19.7(04 / 14 / 93)$ & $12.1(03 / 21 / 03)$ & $11.9(10 / 12 / 00)$ & 3.0 & 14.8 & 20.0 \\
\hline NTRUST & $10.6(10 / 03 / 02)$ & $9.1(04 / 14 / 00)$ & $8.5(05 / 25 / 00)$ & 3.5 & 11.8 & 15.4 \\
\hline MELLON & $13.0(10 / 27 / 97)$ & $10.6(01 / 22 / 03)$ & $9.8(03 / 08 / 96)$ & 3.3 & 12.7 & 16.7 \\
\hline BCORP & $17.4(10 / 05 / 01)$ & $15.9(06 / 30 / 92)$ & $10.7(10 / 04 / 00)$ & 2.9 & 14.4 & 19.8 \\
\hline CITYCO & $9.5(04 / 14 / 00)$ & $8.2(10 / 27 / 97)$ & $7.7(02 / 04 / 00)$ & 3.1 & 11.3 & 15.2 \\
\hline $\mathrm{PNC}$ & $16.1(07 / 18 / 02)$ & $10.3(10 / 17 / 02)$ & $9.8(01 / 29 / 02)$ & 3.4 & 10.9 & 14.3 \\
\hline KEYCO & $8.9(08 / 31 / 98)$ & $8.3(03 / 07 / 00)$ & $8.2(06 / 30 / 00)$ & 3.4 & 11.4 & 14.9 \\
\hline SOTRUST & $10.6(04 / 26 / 93)$ & $10.3(01 / 03 / 00)$ & $9.7(03 / 17 / 00)$ & 3.1 & 12.0 & 16.2 \\
\hline COMERICA & $22.7(10 / 02 / 02)$ & $9.1(04 / 17 / 01)$ & $9.1(04 / 14 / 00)$ & 3.4 & 10.7 & 14.0 \\
\hline UNIONBANK & $36.4(06 / 16 / 00)$ & $15.5(03 / 17 / 00)$ & $10.9(12 / 15 / 00)$ & 3.0 & 15.1 & 20.6 \\
\hline AMSOUTH & $20.9(09 / 22 / 00)$ & $15.0(06 / 01 / 99)$ & $6.9(01 / 10 / 00)$ & 3.5 & 9.4 & 12.2 \\
\hline HUNTING & $18.3(09 / 29 / 00)$ & $10.4(01 / 18 / 01)$ & $10.0(08 / 31 / 98)$ & 3.1 & 13.2 & 17.8 \\
\hline $\mathrm{BBT}$ & $8.2(01 / 21 / 03)$ & $7.2(06 / 15 / 00)$ & $7.0(04 / 14 / 00)$ & 3.4 & 10.1 & 13.2 \\
\hline $53 \mathrm{BANCO}$ & $8.5(11 / 15 / 02)$ & $7.3(01 / 14 / 99)$ & $7.0(04 / 14 / 00)$ & 3.8 & 9.6 & 12.3 \\
\hline SUTRUST & $10.2(07 / 20 / 98)$ & $9.5(04 / 14 / 00)$ & $8.9(06 / 16 / 00)$ & 3.2 & 10.6 & 14.2 \\
\hline REGIONS & $11.2(12 / 15 / 03)$ & $9.1(08 / 31 / 98)$ & $8.5(06 / 15 / 00)$ & 3.5 & 10.2 & 13.2 \\
\hline BANK INDEX & $7.0(04 / 14 / 00)$ & $6.8(07 / 23 / 02)$ & $6.7(10 / 27 / 97)$ & 3.4 & 9.1 & 12.0 \\
\hline STOCK INDEX & $7.0(08 / 31 / 98)$ & $6.8(04 / 14 / 00)$ & $6.8(10 / 27 / 97)$ & 3.7 & 6.3 & 8.0 \\
\hline YIELD SPREAD & $10.8(10 / 10 / 02)$ & $10.7(10 / 09 / 02)$ & $10.7(10 / 11 / 02)$ & 15.8 & 12.1 & 12.9 \\
\hline
\end{tabular}

Note: Returns and quantiles are reported in absolute values and therefore positive. $X_{1, n}, X_{2, n}$ and $X_{3, n}$ are the three smallest daily excess returns in the sample for each bank or each index. The last line describes the largest values (maxima) for high-yield bond spreads. Dates in parentheses are denoted $\mathrm{XX} / \mathrm{YY} / \mathrm{ZZ}$, where $\mathrm{XX}=$ month, $\mathrm{YY}=$ day and $\mathrm{ZZ}=\mathrm{year} . \widehat{\alpha}$ is the tail index, estimated with the method by Hill (1975). $\widehat{Q}(p)$ is the estimated quantile (crisis level) for each bank, as implied by the estimated tail index and the assumed percentile (crisis probability). The quantiles are calculated for two percentiles $p$ that correspond to an in-sample quantile $(p=0.05 \%)$ and an out-of-sample quantile $(p=0.02 \%)$. Data are from 2 April 1992 to 27 February 2004. The source of raw data is Datastream. 
TABLE 3. Domestic versus cross-border extreme spillover risk among euro area banks: Estimations

\begin{tabular}{|c|c|c|c|c|c|}
\hline \multirow[t]{2}{*}{ Largest bank } & $\widehat{P_{1}}$ & $\widehat{P_{2}}$ & $\widehat{P_{3}}$ & $\widehat{P_{4}}$ & $\widehat{P_{5}}$ \\
\hline & \multicolumn{5}{|c|}{ Conditioning banks: German } \\
\hline Germany & 22.4 & 65.1 & 74.3 & 72.7 & 55.4 \\
\hline Netherlands & 26.5 & 54.1 & 70.1 & 43.0 & 34.2 \\
\hline France & 8.2 & 25.2 & 35.8 & 31.0 & 16.2 \\
\hline Spain & 11.2 & 17.4 & 24.2 & 44.1 & 40.3 \\
\hline Italy & 7.5 & 13.6 & 12.9 & 7.5 & 10.8 \\
\hline Belgium & 16.1 & 44.2 & 42.6 & 28.5 & 9.2 \\
\hline Ireland & 4.0 & 5.5 & 5.4 & 24.7 & 16.5 \\
\hline Portugal & 7.7 & 13.6 & 21.7 & 25.1 & 18.0 \\
\hline Finland & 0.9 & 1.7 & 2.3 & 4.0 & 4.5 \\
\hline \multirow[t]{2}{*}{ Greece } & 0.9 & 1.4 & 1.3 & 1.3 & 2.1 \\
\hline & \multicolumn{5}{|c|}{ Conditioning banks: French } \\
\hline France & 2.9 & 35.9 & 76.6 & & \\
\hline Germany & 3.1 & 23.9 & 69.5 & & \\
\hline Netherlands & 8.2 & 48.7 & 71.8 & & \\
\hline Italy & 1.5 & 7.5 & 13.1 & & \\
\hline Spain & 3.3 & 27.4 & 70.1 & & \\
\hline Belgium & 6.7 & 38.0 & 56.3 & & \\
\hline Ireland & 1.0 & 1.8 & 6.9 & & \\
\hline Portugal & 2.5 & 6.5 & 26.5 & & \\
\hline Finland & 0.0 & 0.2 & 0.7 & & \\
\hline \multirow[t]{2}{*}{ Greece } & 0.2 & 0.3 & 0.6 & & \\
\hline & \multicolumn{5}{|c|}{ Conditioning banks: Italian } \\
\hline Italy & 9.6 & 16.4 & 16.6 & & \\
\hline Germany & 5.1 & 12.4 & 18.8 & & \\
\hline Netherlands & 7.2 & 16.1 & 18.0 & & \\
\hline Spain & 4.6 & 11.7 & 14.6 & & \\
\hline France & 5.2 & 7.3 & 8.6 & & \\
\hline Belgium & 4.7 & 12.0 & 11.4 & & \\
\hline Ireland & 1.6 & 2.6 & 5.1 & & \\
\hline Portugal & 1.8 & 2.5 & 3.3 & & \\
\hline Finland & 1.9 & 3.2 & 2.5 & & \\
\hline \multirow[t]{2}{*}{ Greece } & 0.8 & 0.8 & 0.7 & & \\
\hline & \multicolumn{5}{|c|}{ Conditioning banks: Spanish } \\
\hline Spain & 45.4 & 31.6 & & & \\
\hline Germany & 22.4 & 13.9 & & & \\
\hline Netherlands & 26.5 & 15.6 & & & \\
\hline France & 25.8 & 21.6 & & & \\
\hline Italy & 8.3 & 9.0 & & & \\
\hline Belgium & 13.7 & 5.6 & & & \\
\hline Ireland & 4.1 & 3.3 & & & \\
\hline Portugal & 6.2 & 6.5 & & & \\
\hline Finland & 1.1 & 1.4 & & & \\
\hline Greece & 1.7 & 1.1 & & & \\
\hline
\end{tabular}

Note: The table reports estimated extreme spillover probabilities between banks, as defined in (2.1). Each column $\widehat{P}_{j}$ shows the spillover probabilities for the largest bank of the country mentioned on the left-hand side conditional on a set of banks $j$ from either the same country or other countries. The number of conditioning banks varies from 1 to 5 for Germany (top panel), 1 to 3 for France (upper middle panel), 1 to 3 for Italy (lower middle panel) and 1 to 2 for Spain (bottom panel). For example, the $\widehat{P}_{2}$ column contains probabilities for a stock market crash of the largest bank in each country, conditional on crashes of the 2nd and 3rd largest bank in Germany, France, Italy or Spain. All probabilities are estimated with the extension of the approach by Ledford and Tawn (1996) described in section 3 and reported in \%. Univariate crash probabilities (crisis levels) are set to $p=0.05 \%$. 
TABLE 4. Domestic versus cross-border extreme spillover risk among euro area banks: Tests

\begin{tabular}{|c|c|c|c|c|c|}
\hline \multirow[t]{2}{*}{ Largest bank } & $T_{1}$ & $T_{2}$ & $T_{3}$ & $T_{4}$ & $T_{5}$ \\
\hline & \multicolumn{5}{|c|}{ Conditioning banks: German } \\
\hline Netherlands & -1.01 & 0.00 & -0.50 & 0.66 & 0.59 \\
\hline France & 1.61 & 1.58 & 1.20 & 0.83 & 1.52 \\
\hline Spain & 0.98 & $* * 2.51$ & $* * 2.19$ & 0.50 & 0.21 \\
\hline Italy & 1.56 & $* * * 2.58$ & $* * * 3.10$ & $* * * 2.59$ & $* 1.91$ \\
\hline Belgium & 0.12 & 0.26 & 0.83 & 0.98 & *1.86 \\
\hline Ireland & $* * 2.08$ & $* *-2.15$ & $* * * 3.78$ & 1.36 & 1.51 \\
\hline Portugal & 1.28 & $* * 2.49$ & $* 1.90$ & 0.91 & 1.17 \\
\hline Finland & $* * * 3.93$ & $* * * 4.82$ & $* * * 4.32$ & $* * * 3.09$ & $* * * 2.62$ \\
\hline \multirow[t]{2}{*}{ Greece } & $* * * 3.61$ & $* * * 4.47$ & $* * * 4.44$ & $* * * 3.28$ & $* * * 2.66$ \\
\hline & \multicolumn{5}{|c|}{ Conditioning banks: French } \\
\hline Germany & -0.31 & 0.86 & -0.39 & & \\
\hline Netherlands & $* *_{-} 2.50$ & -1.11 & -0.75 & & \\
\hline Spain & -0.24 & 0.48 & 0.08 & & \\
\hline Italy & 1.03 & $* * * 2.75$ & *1.92 & & \\
\hline Belgium & $*_{-}-1.85$ & -0.51 & 0.37 & & \\
\hline Ireland & 1.32 & $* * * 3.20$ & $* * * 2.58$ & & \\
\hline Portugal & 0.11 & $* * 2.36$ & 1.04 & & \\
\hline Finland & $* * * 3.56$ & $* * * 3.96$ & $* * * 3.93$ & & \\
\hline \multirow[t]{2}{*}{ Greece } & $* * 2.56$ & $* * * 3.73$ & $* * * 3.65$ & & \\
\hline & \multicolumn{5}{|c|}{ Conditioning banks: Italian } \\
\hline Germany & 1.11 & 0.42 & -0.09 & & \\
\hline Netherlands & 0.41 & -0.17 & -0.56 & & \\
\hline Spain & 1.33 & 0.45 & -0.01 & & \\
\hline France & 0.96 & 1.27 & -0.09 & & \\
\hline Belgium & 1.01 & 0.31 & -0.36 & & \\
\hline Ireland & $* * 2.50$ & $* * 2.52$ & 1.46 & & \\
\hline Portugal & $* * * 2.70$ & $* * 2.57$ & $* * 2.07$ & & \\
\hline Finland & $* * 2.33$ & $* * 2.10$ & $* * 2.16$ & & \\
\hline \multirow[t]{2}{*}{ Greece } & $* * * 3.90$ & $* * * 3.59$ & $* * * 3.34$ & & \\
\hline & \multicolumn{5}{|c|}{ Conditioning banks: Spanish } \\
\hline Germany & 1.41 & 1.04 & & & \\
\hline Netherlands & 0.89 & 1.00 & & & \\
\hline France & 0.68 & 0.31 & & & \\
\hline Italy & $* * * 2.83$ & 1.51 & & & \\
\hline Belgium & $* 1.83$ & *1.91 & & & \\
\hline Ireland & $* * * 4.21$ & $* * * 3.00$ & & & \\
\hline Portugal & $* * * 3.47$ & $* * 2.05$ & & & \\
\hline Finland & $* * * 5.40$ & ***3.92 & & & \\
\hline Greece & $* * * 4.58$ & ***3.39 & & & \\
\hline
\end{tabular}

Note: The table reports the statistics for the cross sectional test (4.5). Within each panel the degree of extreme domestic spillover risk is compared with the degree of extreme cross-border spillover risk for a given fixed number of conditioning banks. So, each T-statistic describes whether the differences between domestic and cross-border values of $\eta$ that entered the estimations in table 3 are statistically significant. For example, in the top panel the test statistic in the row "Netherlands" and the column $T_{1}$ indicates whether the difference between the $\eta$ for the spillover probability between ABN AMRO and HypoVereinsbank and the $\eta$ between Deutsche Bank and HypoVereinsbank is statistically signifcant. The null hypothesis is that the respective two $\eta$ s are equal. Insignificant T-statistics imply that the domestic and cross-border spillover risks are indistinguishable. A significant rejection with positive sign implies that cross-border spillover risk is statistically smaller than its domestic counterpart; and a rejection with negative sign implies that crossborder risk is larger than domestic risk. The critical values of the test are 1.65, 1.96 and 2.58 for the $10 \%$, $5 \%$ and $1 \%$ levels, respectively. Asterisks $* * *$ and $* * *$ indicate rejections of the null hypothesis at $10 \%$, $5 \%$ and $1 \%$ significance. 


\section{TABLE 5. Multivariate extreme spillover risk among euro area and US banks}

\begin{tabular}{lcrrr}
\hline \hline \multicolumn{2}{c}{ Country/Area } & \multicolumn{2}{c}{ Estimations } & \multicolumn{2}{c}{$\begin{array}{c}\text { Cross-sectional } \\
\text { nyynn}\end{array}$} & $\widehat{\eta}$ & \multicolumn{1}{c}{$\widehat{P}$} & test $T$ \\
\hline United States & $(N=25)$ & 0.39 & $2.8 \mathrm{E}-4$ & $H_{0}: \eta_{U S}=\eta_{E A}$ \\
Euro area & $(N=25)$ & 0.17 & $6.7 \mathrm{E}-15$ & $T=7.25$ \\
\hline Germany & $(N=6)$ & 0.42 & $1.5 \mathrm{E}-3$ & \\
France & $(N=4)$ & 0.48 & $1.4 \mathrm{E}-2$ & \\
Italy & $(N=4)$ & 0.62 & 0.6 & \\
\hline \hline
\end{tabular}

Note: The table reports in the column $\widehat{\eta}$ the coefficient that governs the multivariate extreme tail dependence for all the banks of the countries/areas detailed on the left-hand side. In the column $\widehat{P}$ it shows the probabililty that all banks of a specific country/area crash given that one of them crashes. Both statistics are estimates of system-wide extreme spillover risks. Univariate crash probabilities (crisis levels) are set to $p=0.05 \%$. The right-hand column describes the cross-sectional test (4.5) for the whole US and euro area banking systems. A positive (negative) test statistic indicates that the US (euro area) $\eta$ is larger than the euro area (US) $\eta$. The critical values of the test are 1.65, 1.96 and 2.58 for the $10 \%, 5 \%$ and $1 \%$ levels, respectively. Note that $\eta$ values for countries/areas with different numbers of banks may not be comparable. 
TABLE 6. Extreme systematic risk (tail- $\beta$ s) of euro area banks

\begin{tabular}{|c|c|c|c|c|c|}
\hline \multirow[t]{2}{*}{$\overline{\text { Bank }}$} & \multicolumn{5}{|c|}{ Aggregate risk factor } \\
\hline & Bank index & Stock index & Global bank & Global stock & Yield spread \\
\hline DEUTSCHE & 51.1 & 35.0 & 25.6 & 13.0 & $3.8 \mathrm{E}-5$ \\
\hline HYPO & 22.3 & 20.8 & 9.3 & 5.5 & 0.1 \\
\hline DRESDNER & 37.9 & 27.7 & 19.1 & 11.6 & 0.3 \\
\hline COMMERZ & 39.5 & 30.8 & 15.2 & 13.9 & 0.2 \\
\hline BGBERLIN & 2.8 & 1.6 & 0.8 & 0.7 & 0.8 \\
\hline DEPFA & 6.2 & 7.3 & 3.0 & 2.9 & $3.4 \mathrm{E}-2$ \\
\hline BNPPAR & 42.1 & 30.2 & 23.2 & 13.2 & $2.7 \mathrm{E}-2$ \\
\hline $\mathrm{CA}$ & 9.2 & 6.7 & 1.6 & 2.0 & 0.4 \\
\hline SGENERAL & 45.8 & 30.0 & 22.7 & 16.0 & $6.9 \mathrm{E}-2$ \\
\hline NATEXIS & 1.8 & 1.9 & 2.2 & 1.7 & $9.1 \mathrm{E}-3$ \\
\hline INTESA & 19.1 & 11.2 & 7.2 & 5.9 & 0.4 \\
\hline UNICREDIT & 14.5 & 9.5 & 10.5 & 5.0 & 0.3 \\
\hline PAOLO & 36.7 & 28.5 & 15.2 & 10.2 & 0.3 \\
\hline CAPITA & 16.5 & 9.3 & 9.4 & 6.4 & 0.3 \\
\hline SANTANDER & 36.4 & 33.4 & 17.4 & 14.5 & 0.6 \\
\hline BILBAO & 41.6 & 31.1 & 20.4 & 13.4 & 0.6 \\
\hline BANESP & 2.6 & 1.2 & 1.4 & 0.6 & $2.7 \mathrm{E}-3$ \\
\hline ING & 61.7 & 46.0 & 23.1 & 14.1 & 0.5 \\
\hline ABNAMRO & 50.3 & 46.3 & 23.7 & 13.9 & 0.2 \\
\hline FORTIS & 48.5 & 36.3 & 11.8 & 10.9 & 0.1 \\
\hline ALMANIJ & 11.9 & 11.1 & 7.4 & 4.5 & 0.2 \\
\hline ALPHA & 3.7 & 4.1 & 1.5 & 1.2 & $8.0 \mathrm{E}-3$ \\
\hline $\mathrm{BCP}$ & 17.0 & 11.9 & 9.3 & 7.5 & 0.3 \\
\hline SAMPO & 2.7 & 2.2 & 3.4 & 1.4 & $2.1 \mathrm{E}-2$ \\
\hline IRBAN & 13.9 & 12.1 & 6.9 & 4.6 & 0.1 \\
\hline average & 25.4 & 19.4 & 11.6 & 7.8 & 0.2 \\
\hline st. dev. & 18.8 & 14.5 & 8.3 & 5.3 & 0.2 \\
\hline
\end{tabular}

Note: The table exhibits the estimates of extreme systematic risk (2.2) (tail- $\beta \mathrm{s}$ ) for individual euro area banks and for the euro area banking system as a whole. The entries show the probability that a given bank crashes given that a market indicator of aggregate risk crashes (or in the case of the yield spread booms). Results are reported for five different aggregate risk factors: The euro area banking sector sub-index, the euro area stock index, the world banking sector sub-index, the world stock index and the euro area high-yield bond spread. Data for the euro area yield spread are only available from 1998 to 2004 . All probabilities are estimated with the extension of the approach by Ledford and Tawn (1996) described in section 3 and reported in \%. Univariate crash probabilities (crisis levels) are set to $p=0.05 \%$. The average and the standard deviation at the bottom of the table are calculated over the 25 individual tail- $\beta \mathrm{s}$ in the upper rows, respectively. 
TABLE 7. Extreme systematic risk (tail- $\beta$ s) of US banks

\begin{tabular}{|c|c|c|c|c|c|}
\hline \multirow[t]{2}{*}{$\overline{\text { Bank }}$} & \multicolumn{5}{|c|}{ 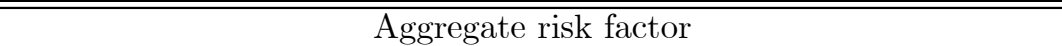 } \\
\hline & Bank index & Stock index & Global bank & Global stock & Yield spread \\
\hline CITIG & 41.1 & 26.5 & 16.5 & 17.4 & 0.3 \\
\hline JPMORGAN & 39.4 & 18.0 & 15.2 & 16.4 & 1.3 \\
\hline $\mathrm{BOA}$ & 37.7 & 12.4 & 6.4 & 7.1 & 0.2 \\
\hline WACHO & 27.2 & 9.6 & 8.6 & 9.3 & 0.5 \\
\hline FARGO & 17.1 & 7.1 & 4.5 & 3.8 & $2.4 \mathrm{E}-2$ \\
\hline BONEC & 31.0 & 14.0 & 9.7 & 10.0 & 0.4 \\
\hline WASHMU & 9.5 & 2.8 & 4.7 & 1.8 & 0.1 \\
\hline FLEET & 38.8 & 13.1 & 10.6 & 10.1 & 0.6 \\
\hline BNYORK & 25.2 & 12.9 & 10.9 & 11.3 & 1.0 \\
\hline STATEST & 26.8 & 19.0 & 10.9 & 18.3 & 1.0 \\
\hline NOTRUST & 26.7 & 17.4 & 12.0 & 10.0 & 0.9 \\
\hline MELLON & 29.4 & 16.4 & 10.6 & 10.4 & 0.8 \\
\hline USBANC & 19.6 & 6.6 & 7.8 & 4.8 & 0.3 \\
\hline CITYCO & 32.3 & 8.9 & 7.4 & 6.7 & 0.2 \\
\hline $\mathrm{PNC}$ & 25.8 & 12.7 & 10.2 & 8.9 & 0.3 \\
\hline KEYCO & 24.9 & 8.4 & 6.1 & 6.1 & 0.2 \\
\hline SUNTRUST & 32.0 & 11.7 & 8.9 & 7.8 & 0.3 \\
\hline COMERICA & 24.0 & 13.5 & 7.1 & 7.1 & 0.5 \\
\hline UNIONBAN & 11.2 & 3.9 & 5.9 & 3.8 & 0.1 \\
\hline AMSOUTH & 15.1 & 7.5 & 8.7 & 6.4 & 0.3 \\
\hline HUNTING & 17.5 & 7.0 & 8.3 & 6.0 & 0.1 \\
\hline $\mathrm{BBT}$ & 19.9 & 6.6 & 5.3 & 5.4 & 0.2 \\
\hline $53 \mathrm{BANCO}$ & 21.7 & 8.6 & 4.9 & 3.6 & 0.2 \\
\hline SOTRUST & 33.3 & 7.3 & 6.8 & 4.4 & 0.3 \\
\hline RFCORP & 26.5 & 11.6 & 8.4 & 7.8 & 0.2 \\
\hline average & 26.2 & 11.3 & 8.6 & 8.2 & 0.4 \\
\hline st. dev. & 8.5 & 4.4 & 3.0 & 4.2 & 0.3 \\
\hline
\end{tabular}

Note: The table exhibits the estimates of extreme systematic risk (2.2) (tail- $\beta \mathrm{s})$ for individual US banks and for the US banking system as a whole. The entries show the probability that a given bank crashes given that a market indicator of aggregate risk crashes (or in the case of the yield spread booms). Results are reported for five different aggregate risk factors: The US banking sector sub-index, the US stock index, the world banking sector sub-index, the world stock index and the US high-yield bond spread. All probabilities are estimated with the extension of the approach by Ledford and Tawn (1996) described in section 3 and reported in \%. Univariate crash probabilities (crisis levels) are set to $p=0.05 \%$. The average and the standard deviation at the bottom of the table are calculated over the 25 individual tail- $\beta$ s in the upper rows, respectively. 
TABLE 8. Comparisons of extreme systematic risk across different banking systems

\begin{tabular}{cccccc}
\hline \hline & \multicolumn{5}{c}{ Aggregate risk factor } \\
\cline { 2 - 6 } Banking system & Bank index & Stock index & Global bank & Global stock & Yield spread \\
\hline $\bar{\eta}_{U S}$ & 0.87 & 0.79 & 0.78 & 0.77 & 0.55 \\
$\bar{\eta}_{E A}$ & 0.86 & 0.83 & 0.80 & 0.76 & 0.53 \\
\hline $\bar{\eta}_{F R}$ & 0.85 & 0.82 & 0.79 & 0.76 & 0.50 \\
$\bar{\eta}_{G E}$ & 0.86 & 0.84 & 0.80 & 0.76 & 0.53 \\
$\bar{\eta}_{I T}$ & 0.88 & 0.83 & 0.82 & 0.78 & 0.57 \\
\hline Null hypothesis & & & & & 0.30 \\
\hline $\bar{\eta}_{U S}=\bar{\eta}_{E A}$ & 0.19 & -0.94 & -0.44 & 0.21 & 1.18 \\
$\bar{\eta}_{U S}=\bar{\eta}_{F R}$ & 0.34 & -0.59 & -0.32 & 0.14 & 0.48 \\
$\bar{\eta}_{U S}=\bar{\eta}_{G E}$ & 0.20 & -1.05 & -0.47 & 0.30 & -0.48 \\
$\bar{\eta}_{U S}=\bar{\eta}_{I T}$ & -0.08 & -0.63 & -0.81 & -0.16 & \\
\hline \hline
\end{tabular}

Note: the table exhibits the average tail dependence parameters $\eta$ that govern the tail- $\beta$ estimates reported in tables 6 and 7 for the US, euro area, French, German and Italian banking system (upper panel) and the statistics of tests examining differences in extreme systematic risk between the US and euro area banking systems (lower panel). Each $\bar{\eta}$ is calculated as the mean of tail- $\beta$ dependence parameters across all the banks in our sample for the respective country/area. The tests are applications of the cross-sectional test (4.5). The null hypothesis is that extreme systematic risk in the US banking system is the same as in the other banking systems. A positive (negative) test statistic indicates that extreme systematic risk in the US banking system (in the respective euro area banking system) is larger than in the respective euro area (US) banking system. The critical values of the test are $1.65,1.96$ and 2.58 for the $10 \%, 5 \%$ and $1 \%$ levels, respectively. All results are reported for the five different aggregate risk factors: The euro area/US banking sector sub-index, the euro area/US stock index, the world banking sector sub-index, the world stock index and the euro area/US high-yield bond spread. Univariate crash probabilities (crisis levels) are set to $p=0.05 \%$. 
TABle 9. Domestic and cross-border extreme spillover risk among euro area banks: Time variation

\begin{tabular}{|c|c|c|c|c|c|}
\hline \multirow[t]{2}{*}{ Largest bank } & $\widehat{\eta}_{1}$ & $\widehat{\eta}_{2}$ & $\widehat{\eta}_{3}$ & $\widehat{\eta}_{4}$ & $\widehat{\eta}_{5}$ \\
\hline & \multicolumn{5}{|c|}{ Conditioning banks: German } \\
\hline Germany & $3 / 31 / 97(43.5)$ & $8 / 1 / 97(62.0)$ & $4 / 2 / 97(38.4)$ & $8 / 15 / 97(7.2)$ & $7 / 23 / 97(17.3)$ \\
\hline Netherlands & $3 / 31 / 97(81.1)$ & 4/2/97 (77.9) & $4 / 2 / 97(66.2)$ & 8/21/97 (16.9) & $4 / 2 / 97(7.3)$ \\
\hline France & $7 / 23 / 97(25.6)$ & $8 / 1 / 97(37.5)$ & $9 / 9 / 97(41.2)$ & 7/23/97 (19.3) & $8 / 15 / 97(8.4)$ \\
\hline Spain & $7 / 21 / 97(68.8)$ & $5 / 27 / 97(39.7)$ & $5 / 29 / 97(55.9)$ & $7 / 23 / 97(18.9)$ & $8 / 14 / 97(5.5)$ \\
\hline Italy & $7 / 21 / 97(49.2)$ & $9 / 9 / 97(46.2)$ & $9 / 9 / 97(41.4)$ & $8 / 21 / 97(20.2)$ & $8 / 21 / 97(9.3)$ \\
\hline Belgium & $8 / 21 / 97(62.2)$ & $4 / 2 / 97(50.1)$ & $3 / 27 / 97(56.7)$ & $7 / 23 / 97(25.9)$ & $6 / 12 / 98(6.9)$ \\
\hline Ireland & $8 / 20 / 97(43.0)$ & $10 / 16 / 97(24.3)$ & $8 / 15 / 97(21.9)$ & 8/14/97 (11.3) & $8 / 15 / 97(4.7)$ \\
\hline Portugal & $9 / 9 / 97(27.5)$ & $1 / 14 / 94(37.1)$ & $1 / 25 / 94(50.1)$ & $7 / 23 / 97(23.2)$ & $7 / 23 / 97(7.5)$ \\
\hline Finland & $10 / 16 / 97(30.5)$ & 10/16/97 (26.3) & $5 / 23 / 94(37.2)$ & $8 / 22 / 97(23.6)$ & $7 / 23 / 97(9.6)$ \\
\hline \multirow[t]{2}{*}{ Greece } & $3 / 27 / 97(64.0)$ & $3 / 27 / 97(58.8)$ & $4 / 2 / 97(47.8)$ & $3 / 27 / 97(18.8)$ & $8 / 15 / 97(7.4)$ \\
\hline & \multicolumn{5}{|c|}{ Conditioning banks: French } \\
\hline France & $2 / 15 / 02(25.3)$ & $9 / 19 / 00(32.8)$ & $6 / 17 / 94(22.5)$ & & \\
\hline Germany & $10 / 9 / 00(52.6)$ & $11 / 21 / 00(36.3)$ & $5 / 21 / 96(4.4)$ & & \\
\hline Netherlands & $10 / 10 / 00(54.4)$ & $9 / 20 / 00(44.9)$ & $10 / 22 / 97(39.0)$ & & \\
\hline Italy & $1 / 11 / 02(20.1)$ & $1 / 31 / 01(37.8)$ & $10 / 22 / 97(32.5)$ & & \\
\hline Spain & $10 / 10 / 00(34.3)$ & $9 / 19 / 00(40.6)$ & $10 / 13 / 97(32.1)$ & & \\
\hline Belgium & $9 / 1 / 00(47.7)$ & $11 / 27 / 01(52.4)$ & $6 / 9 / 98(40.8)$ & & \\
\hline Ireland & $9 / 20 / 00(13.8)$ & $11 / 21 / 00(19.4)$ & $12 / 7 / 01(12.2)$ & & \\
\hline Portugal & $1 / 25 / 02(24.8)$ & $1 / 29 / 02(30.4)$ & $10 / 22 / 97(20.4)$ & & \\
\hline Finland & $4 / 14 / 00(6.1)$ & $5 / 31 / 94(26.0)$ & $11 / 4 / 96(27.5)$ & & \\
\hline \multirow[t]{2}{*}{ Greece } & $6 / 11 / 98(15.5)$ & $2 / 28 / 97(32.5)$ & $2 / 28 / 97(19.2)$ & & \\
\hline & \multicolumn{5}{|c|}{ Conditioning banks: Italian } \\
\hline Italy & $9 / 30 / 97(5.4)$ & $9 / 25 / 97(9.0)$ & $9 / 30 / 97(3.6)$ & & \\
\hline Germany & $7 / 25 / 97(23.9)$ & $7 / 25 / 97(31.7)$ & $10 / 8 / 97(18.8)$ & & \\
\hline Netherlands & $10 / 7 / 97(16.6)$ & $8 / 1 / 97(27.7)$ & $8 / 7 / 97(18.7)$ & & \\
\hline Spain & $6 / 27 / 97(7.6)$ & 7/14/97 (19.9) & $9 / 9 / 97(12.1)$ & & \\
\hline France & $10 / 8 / 97(9.9)$ & $10 / 22 / 97(8.3)$ & $9 / 9 / 97(7.9)$ & & \\
\hline Belgium & $7 / 31 / 97(25.8)$ & $8 / 1 / 97(44.8)$ & $10 / 8 / 97(30.2)$ & & \\
\hline Ireland & $8 / 22 / 97(4.9)$ & $10 / 8 / 97(7.0)$ & $8 / 7 / 97(6.7)$ & & \\
\hline Portugal & $8 / 1 / 97(9.1)$ & $8 / 1 / 97(18.2)$ & $8 / 7 / 97(13.6)$ & & \\
\hline Finland & - & $7 / 25 / 97(8.5)$ & $10 / 24 / 97(5.9)$ & & \\
\hline \multirow[t]{2}{*}{ Greece } & $9 / 9 / 97(15.3)$ & $10 / 17 / 97(19.2)$ & $8 / 15 / 97(13.4)$ & & \\
\hline & \multicolumn{5}{|c|}{ Conditioning banks: Spanish } \\
\hline Spain & $7 / 16 / 97(33.1)$ & $7 / 16 / 97(4.0)$ & & & \\
\hline Germany & $3 / 17 / 97(88.0)$ & $5 / 21 / 97(9.0)$ & & & \\
\hline Netherlands & $7 / 21 / 97(39.0)$ & $7 / 3 / 97(7.3)$ & & & \\
\hline France & $10 / 22 / 97(34.6)$ & $5 / 27 / 97(5.4)$ & & & \\
\hline Italy & $7 / 28 / 97(33.2)$ & $6 / 18 / 97(3.8)$ & & & \\
\hline Belgium & $7 / 17 / 97(47.7)$ & $2 / 25 / 97(12.4)$ & & & \\
\hline Ireland & $7 / 16 / 97(22.7)$ & - & & & \\
\hline Portugal & $6 / 16 / 97(42.7)$ & $3 / 31 / 97(12.8)$ & & & \\
\hline Finland & $10 / 24 / 97(21.3)$ & $7 / 23 / 97(3.9)$ & & & \\
\hline Greece & $6 / 2 / 97(37.9)$ & $3 / 27 / 97(12.4)$ & & & \\
\hline
\end{tabular}

Note: The table reports the results of tests examining the structural stability of the extreme spillover risks documented in table 3 . This is done by testing for the constancy of the $\eta$ tail dependence parameters (null hypothesis) that govern the spillover probabilities in table 3 . Applying the recursive test (4.1) through (4.4) by Quintos et al. (2001), each cell shows the endogenously found break date and the test value in parentheses. Dates are denoted XX/YY $/ Z Z$, where XX=month, YY=day and $\mathrm{ZZ}=$ year. The critical values of the test are 1.46, 1.78 and 2.54 for the $10 \%, 5 \%$ and $1 \%$ levels, respectively. A test value exceeding these numbers implies an increase in extreme dependence over time. The absence of a break over the sample period is marked with a dash. 
TABLE 10. Multivariate extreme spillover risk among euro area and US banks: Time variation

\begin{tabular}{|c|c|c|c|c|c|c|}
\hline \multirow{2}{*}{\multicolumn{2}{|c|}{ Country/Area }} & \multirow{2}{*}{$\begin{array}{c}\text { Full sample } \\
\text { break test }\end{array}$} & \multicolumn{2}{|c|}{ Sub-sample estimates } & \multicolumn{2}{|c|}{ Second sub-sample break tests } \\
\hline & & & $\widehat{\eta}_{1}$ & $\widehat{\eta}_{2}$ & Endogenous & Exogenous \\
\hline United St & $(N=25)$ & $11 / 22 / 95(18.5)$ & 0.20 & 0.41 & $3 / 11 / 97(2.2)$ & n.a. \\
\hline Euro area & $(N=25)$ & $12 / 5 / 96(4.9)$ & 0.13 & 0.20 & (B) $1 / 18 / 99(3.2)$ & $(1.4)$ \\
\hline Germany & $(N=6)$ & $\begin{array}{c}7 / 23 / 97(17.6) \\
\text { (B) } \quad 4 / 2 / 97(2.1)\end{array}$ & 0.24 & 0.52 & $\begin{array}{c}- \\
\text { (B) } 1 / 22 / 99(3.9)\end{array}$ & $(1.9)$ \\
\hline France & $(N=4)$ & $\begin{array}{r}6 / 17 / 94(21.9) \\
\text { (B) } 5 / 21 / 96(4.3)\end{array}$ & 0.19 & 0.52 & $\begin{array}{r}12 / 7 / 01(12.8) \\
\text { (B) } 2 / 24 / 97(3.0)\end{array}$ & $(-3.0)$ \\
\hline Italy & $(N=4)$ & $09 / 30 / 97(3.4)$ & 0.45 & 0.72 & (B) $4 / 11 / 03(2.2)$ & $(2.1)$ \\
\hline
\end{tabular}

Note: The table reports tests and estimations assessing time variation in the multivariate spillover probabilities of table 5 . The column on the left displays estimated break dates and values from the recursive Quintos et al. (2001) test (4.1) through (4.4) applied to the $\eta$ parameter governing the extreme tail dependence of the banks located in the countries/areas displayed on the extreme left. Dates are denoted $\mathrm{XX} / \mathrm{YY} / \mathrm{ZZ}$, where $\mathrm{XX}=$ month, $\mathrm{YY}=$ day and $\mathrm{ZZ}=$ year. The forward recursive version of the test is used, unless marked otherwise. (B) marks the backward recursive version of the test. The critical values of the test are 1.46, 1.78 and 2.54 for the $10 \%, 5 \%$ and $1 \%$ levels, respectively. The middle columns show pre- and post-break estimates for $\eta$. The columns on the right display two tests that assess the occurrence of further breaks in the second half of the sample. The first one is the same as the one on the left-hand side. The second one is a simple differencesin-means test based on (4.5). The exogenous break point is chosen to be $1 / 1 / 99$, the time of the introduction of the euro. Critical values for this test are 1.65, 1.96 and 2.58 for the $10 \%, 5 \%$ and $1 \%$ significance levels. Note that $\eta$ values for countries/areas with different numbers of banks may not be comparable. 
FiguRE 1. Evolution of multivariate extreme spillover risk among euro area and US banks
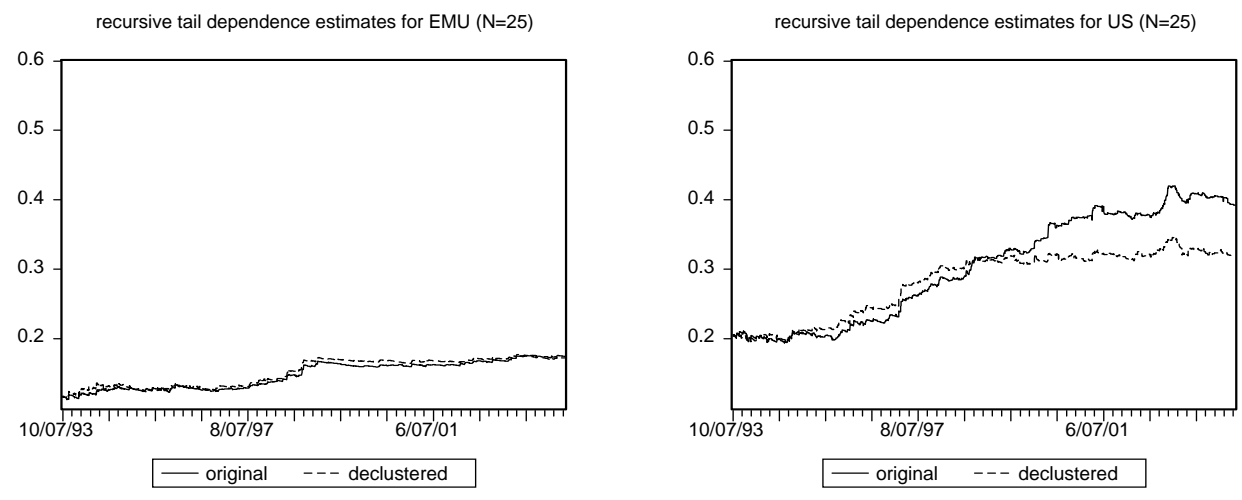

recursive tail dependence estimates for Germany $(\mathrm{N}=6)$

recursive tail dependence estimates for France $(\mathrm{N}=4)$
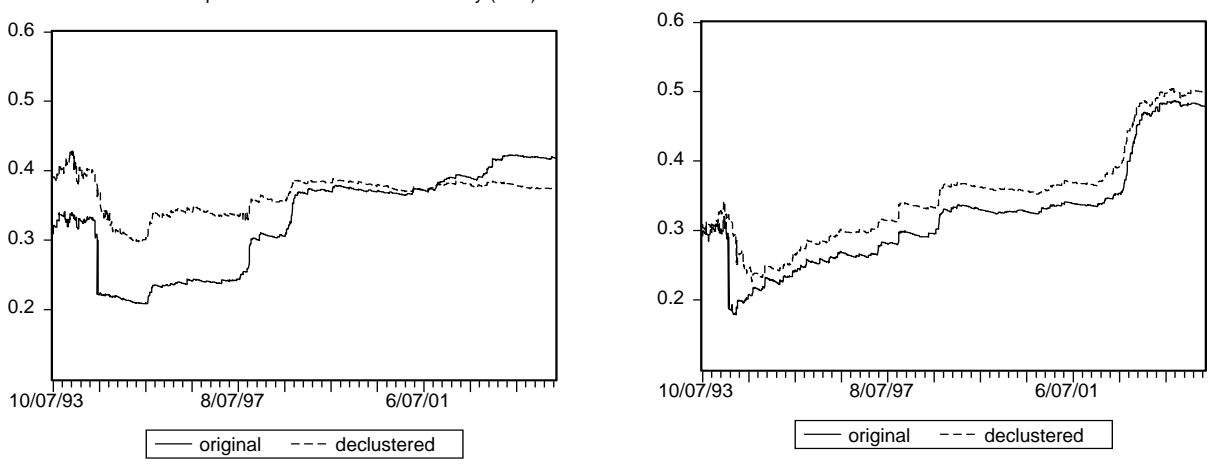

recursive tail dependence estimates for Italy $(\mathrm{N}=4)$

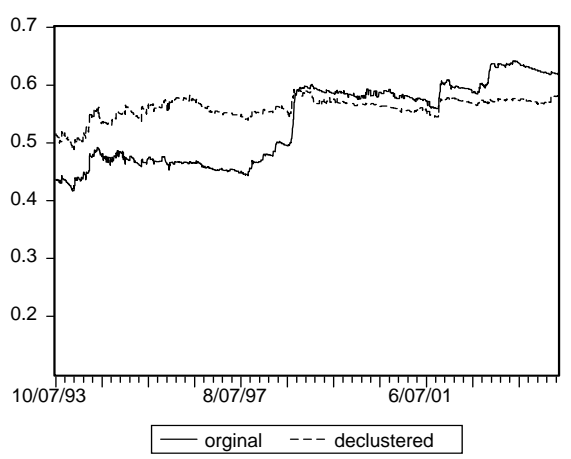


Figure 2. Comparisons of the evolution of extreme bank spillover risk across countries

US vs. EMU

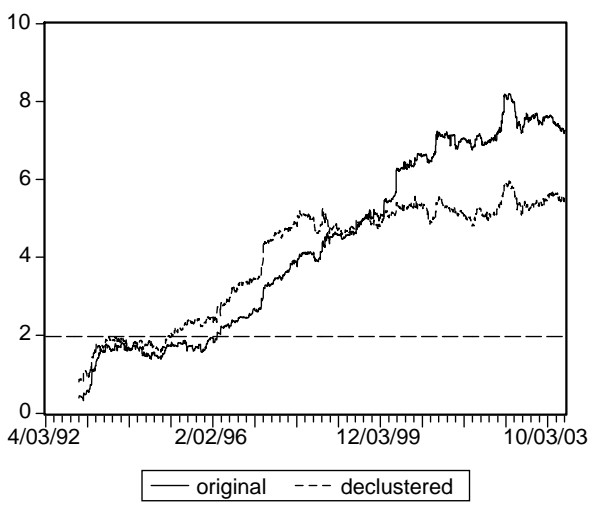

US vs. FR

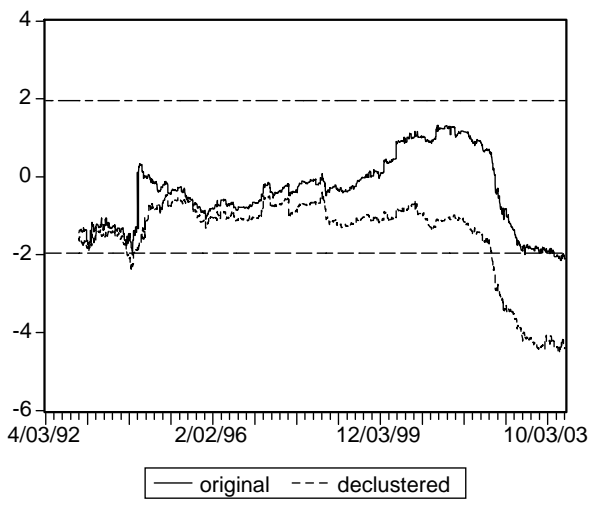

US vs. GE

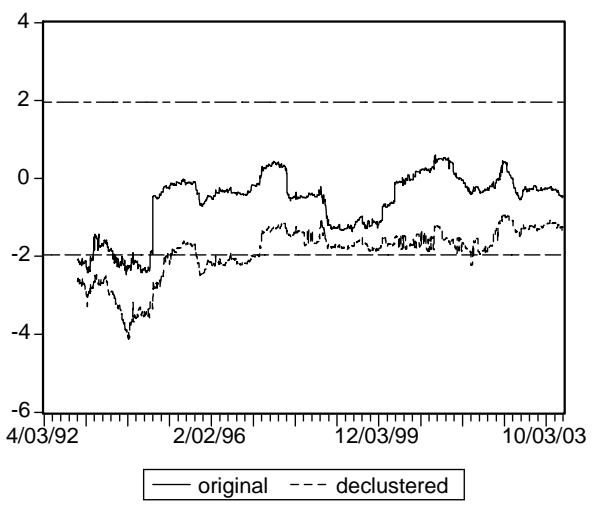

US vs. IT

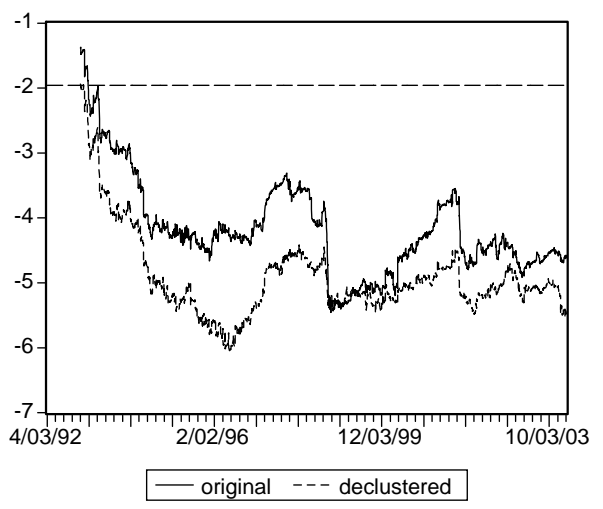


TABLE 11. Extreme systematic risk (tail- $\beta$ s) of euro area banks: Time variation

\begin{tabular}{|c|c|c|c|c|c|}
\hline \multirow[t]{2}{*}{$\overline{\text { Bank }}$} & \multicolumn{5}{|c|}{ Aggregate risk factor } \\
\hline & Bank index & Stock index & Global bank & Global stock & Yield spread \\
\hline DEUTSCHE & $3 / 12 / 97(45.3)$ & $3 / 12 / 97(57.7)$ & $8 / 15 / 97(53.3)$ & $12 / 5 / 96(86.1)$ & $9 / 14 / 00(153.4)$ \\
\hline HYPO & $7 / 21 / 97(40.1)$ & $10 / 22 / 97(60.0)$ & $9 / 9 / 97(62.8)$ & $10 / 22 / 97(60.5)$ & $10 / 4 / 00(124.1)$ \\
\hline DRESDNER & $8 / 1 / 97(69.1)$ & $12 / 5 / 96(53.1)$ & $12 / 5 / 96(48.5)$ & $12 / 5 / 96(59.5)$ & $8 / 22 / 00(44.1)$ \\
\hline $\mathrm{COMMl}$ & $7 / 21 / 97(22.8)$ & $3 / 19 / 97(34.8)$ & $8 / 1 / 97(30.4)$ & $8 / 21 / 97(70.4)$ & $10 / 3 / 00(142.7)$ \\
\hline BGBERLIN & $12 / 3 / 96(7.9)$ & $12 / 3 / 96(10.9)$ & $12 / 5 / 96(11.8)$ & $7 / 3 / 97(19.2)$ & $1 / 4 / 01(496.6)$ \\
\hline DEPFA & $7 / 5 / 96(33.7)$ & $7 / 15 / 96(37.6)$ & $8 / 21 / 97(19.4)$ & $8 / 12 / 97(33.6)$ & $9 / 13 / 00(97.5)$ \\
\hline BNPPAR & $8 / 15 / 97(34.7)$ & $7 / 17 / 97(41.1)$ & $10 / 22 / 97(27.5)$ & $8 / 27 / 97(34.0)$ & $9 / 15 / 00(77.3)$ \\
\hline $\mathrm{CA}$ & $10 / 5 / 00(50.4)$ & $9 / 19 / 00(52.7)$ & $10 / 9 / 00(26.6)$ & $9 / 19 / 00(31.7)$ & $7 / 21 / 00(127.3)$ \\
\hline SGENER & $10 / 22 / 97(40.9)$ & $10 / 22 / 97(35.4)$ & $10 / 22 / 97(37.4)$ & $10 / 22 / 97(42.6)$ & $9 / 21 / 00$ \\
\hline NA & $12 / 5 / 96(6.0)$ & $12 / 3 / 96(8.5)$ & $8 / 28 / 97(11.0)$ & $8 / 28 / 97(21.1)$ & $9 / 15 / 00(155.1)$ \\
\hline IN & $7 / 31 / 97(25.6)$ & $7 / 28 / 97(39.7)$ & $9 / 9 / 97(14.5)$ & $7 / 31 / 97(24.4)$ & $7 / 24 / 00(183.9)$ \\
\hline UNICRED & $10 / 8 / 97(23.8)$ & $9 / 25 / 97(14.2)$ & 10/8/97 (18.7) & $9 / 9 / 97(18.0)$ & $9 / 11 / 00(123.4)$ \\
\hline $\mathrm{LO}$ & $7 / 28 / 97(52.6)$ & $9 / 25 / 97(51.4)$ & $10 / 24 / 97(43.8)$ & $10 / 8 / 97(58.7)$ & $8 / 17 / 00(218.4)$ \\
\hline CAPITA & $8 / 12 / 97(17.0)$ & 9/10/97 (15.7) & $9 / 9 / 97(13.1)$ & $9 / 9 / 97(16.0)$ & $9 / 15 / 00(170.6)$ \\
\hline SANTAN & $7 / 23 / 97(60.3)$ & $5 / 27 / 97(64.0)$ & $8 / 21 / 97(28.3)$ & $10 / 8 / 97(51.5)$ & $9 / 15 / 00(207.3)$ \\
\hline BILBAO & $10 / 8 / 97(54.0)$ & $10 / 16 / 97(58.7)$ & $10 / 7 / 97(36.2)$ & $10 / 22 / 97(68.7)$ & $9 / 11 / 00(209.3)$ \\
\hline BANESP & $5 / 16 / 97(6.3)$ & $10 / 16 / 97(5.3)$ & $10 / 22 / 97(2.5)$ & $10 / 22 / 97(2.3)$ & $7 / 21 / 00(29.3)$ \\
\hline ING & $1 / 26 / 96(43.7)$ & $10 / 22 / 96(36.4)$ & $8 / 21 / 97(57.2)$ & $7 / 5 / 96(51.7)$ & $9 / 20 / 00(186.5)$ \\
\hline ABNAM & $11 / 26 / 96(48.1)$ & $12 / 5 / 96(56.3)$ & $7 / 4 / 96(73.9)$ & $7 / 4 / 96(61.6)$ & $9 / 15 / 00(132.5)$ \\
\hline FORTIS & $3 / 17 / 97(65.4)$ & $12 / 10 / 96(41.1)$ & $12 / 10 / 96(33.0)$ & $7 / 17 / 97(36.7)$ & $9 / 15 / 00(161.2)$ \\
\hline ALMANIJ & $3 / 14 / 97(59.4)$ & $1 / 23 / 97(56.7)$ & $1 / 23 / 97(54.5)$ & $8 / 7 / 97(77.1)$ & $9 / 14 / 00(238.2)$ \\
\hline ALPHA & $2 / 24 / 97(52.7)$ & $2 / 27 / 97(64.5)$ & 1/8/97 (36.6) & $2 / 6 / 97(66.1)$ & $9 / 29 / 00(80.7)$ \\
\hline $\mathrm{BCP}$ & $6 / 16 / 97(37.8)$ & $7 / 3 / 97(42.2)$ & $8 / 26 / 97(28.7)$ & $7 / 17 / 97(57.6)$ & $9 / 15 / 00(129.0)$ \\
\hline & $10 / 16 / 97(15.2)$ & $10 / 24 / 97(15.6)$ & $10 / 24 / 97(6.0)$ & $10 / 16 / 97(11.5)$ & $8 / 16 / 00(151.6)$ \\
\hline IRBAN & $8 / 12 / 97(22.4)$ & $3 / 12 / 97(25.2)$ & $8 / 21 / 97(16.5)$ & $8 / 20 / 97(25.3)$ & $9 / 29 / 00(164.7)$ \\
\hline
\end{tabular}

Note: The table reports the results of tests examining the structural stability of the extreme systematic risks of euro area banks documented in table 6 . This is done by testing for the constancy of the $\eta$ tail dependence parameters (null hypothesis) that govern the tail- $\beta$ s in table 6 . Applying the recursive test (4.1) through (4.4) by Quintos et al. (2001), each cell shows the endogenously found break date and the test value in parentheses. Dates are denoted XX/YY $/ \mathrm{ZZ}$, where XX=month, $\mathrm{YY}=$ day and $\mathrm{ZZ}=$ year. The critical values of the test are $1.46,1.78$ and 2.54 for the $10 \%, 5 \%$ and $1 \%$ levels, respectively. A test value exceeding these numbers implies an increase in extreme dependence over time. The absence of a break over the sample period is marked with a dash. 
FiguRE 3. Evolution of extreme systematic risk in the euro area and the US banking systems

tail dependence coefficient for US banks w.r.t. US global index

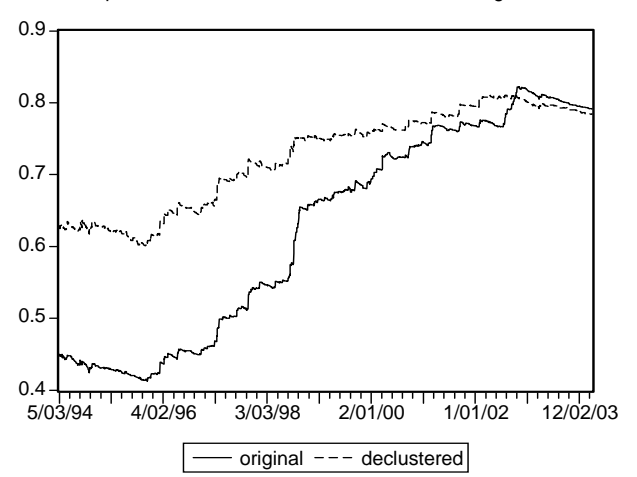

tail dependence coefficient for EMU banks w.r.t. EMU global index

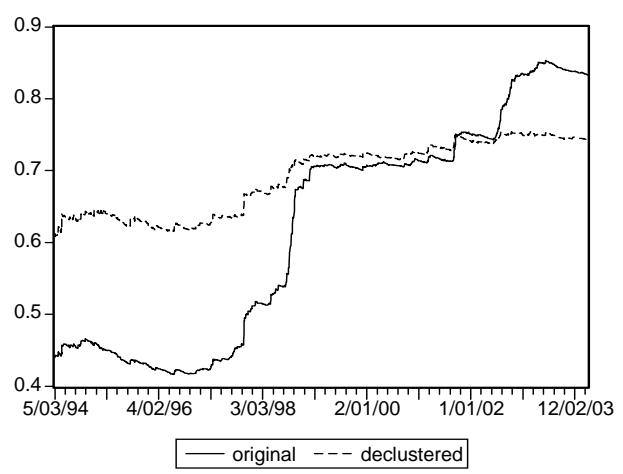


TABLE 12. Extreme systematic risk (tail- $\beta$ s) of US banks: Time variation

\begin{tabular}{|c|c|c|c|c|c|}
\hline \multirow[t]{2}{*}{$\overline{\text { Bank }}$} & \multicolumn{5}{|c|}{ Aggregate risk factor } \\
\hline & Bank index & Stock index & Global bank & Global stock & Yield spread \\
\hline CITIG & $12 / 20 / 96(28.0)$ & $12 / 15 / 95(17.8)$ & $10 / 22 / 97(34.0)$ & $10 / 23 / 97(30.8)$ & $10 / 20 / 00(93.5)$ \\
\hline JPMOR & $2 / 25 / 97(34.1)$ & $3 / 11 / 97(28.3)$ & $10 / 13 / 97(33.1)$ & $10 / 16 / 97(40.0)$ & $10 / 17 / 00(87.4)$ \\
\hline $\mathrm{BOA}$ & $12 / 2 / 96(27.4)$ & $12 / 10 / 96(27.9)$ & $11 / 29 / 96(33.1)$ & $12 / 2 / 96(38.6)$ & $9 / 25 / 00(64.7)$ \\
\hline WACHO & $3 / 10 / 97(14.9)$ & $12 / 10 / 96(22.0)$ & $2 / 26 / 97(66.4)$ & $2 / 26 / 97(41.3)$ & $10 / 10 / 00(64.5)$ \\
\hline FARGO & $1 / 3 / 96(14.4)$ & $12 / 15 / 95(14.7)$ & $2 / 27 / 97(23.4)$ & $2 / 26 / 97(15.6)$ & $10 / 5 / 00(35.4)$ \\
\hline $\mathrm{BO}$ & $12 / 6 / 95(23.7)$ & $12 / 13 / 95(32.3)$ & $11 / 29 / 96(47.6)$ & $2 / 19 / 96(40.3)$ & $10 / 5 / 00(98.8)$ \\
\hline WASHMU & $2 / 27 / 97(8.1)$ & $2 / 23 / 96(10.6)$ & $10 / 16 / 97(20.2)$ & $2 / 24 / 97(9.9)$ & $11 / 21 / 00(33.6)$ \\
\hline FLEET & $4 / 22 / 98(33.8)$ & $12 / 10 / 96(25.5)$ & $4 / 17 / 98(39.2)$ & $12 / 10 / 96(36.2)$ & $11 / 30 / 00(52.6)$ \\
\hline RK & $2 / 19 / 96(20.2)$ & $1 / 8 / 96(17.7)$ & $12 / 11 / 96(41.3)$ & $2 / 6 / 97(47.0)$ & $0(77.8)$ \\
\hline STA & $3 / 11 / 97(35.8)$ & $12 / 2 / 96(49.4)$ & $12 / 2 / 96(41.7)$ & $10 / 16 / 97(58.2)$ & $10 / 5 / 00(158.3)$ \\
\hline ST & $11 / 29 / 96(33.8)$ & $12 / 2 / 96(51.7)$ & $10 / 22 / 97(35.3)$ & $12 / 5 / 96(52.8)$ & $9 / 29 / 00$ \\
\hline MEL & $12 / 4 / 95(13.4)$ & $12 / 13 / 95(25.4)$ & $10 / 24 / 97(38.3)$ & $10 / 24 / 97(26.0)$ & $10 / 11 / 00(108.6)$ \\
\hline $\mathrm{NC}$ & $2 / 25 / 97(40.1)$ & $1 / 23 / 97(48.3)$ & $9 / 25 / 97(57.9)$ & $9 / 25 / 97(39.5)$ & $11 / 10 / 00(37.0)$ \\
\hline CITYCO & $1 / 29 / 96(26.7)$ & $12 / 2 / 96(28.8)$ & $11 / 29 / 96(45.9)$ & $12 / 2 / 96(44.7)$ & $10 / 10 / 0$ \\
\hline $\mathrm{PNC}$ & $12 / 10 / 96(24.3)$ & $12 / 13 / 95(26.3)$ & $12 / 10 / 96(34.6)$ & $3 / 7 / 96(34.5)$ & $11 / 30 / 00(51.6)$ \\
\hline KEYCO & $12 / 2 / 96(12.1)$ & $12 / 6 / 95(18.1)$ & $12 / 5 / 96(19.5)$ & $12 / 2 / 96(27.3)$ & $9 / 28 / 00(56.7)$ \\
\hline SUNTRL & $12 / 2 / 96(29.0)$ & $12 / 13 / 95(38.7)$ & $12 / 5 / 96(31.8)$ & $12 / 5 / 96(31.6)$ & $10 / 20 / 00(40.8)$ \\
\hline $\mathrm{COM}$ & $1 / 3 / 96(11.3)$ & $12 / 13 / 95(17.9)$ & $2 / 25 / 97(27.8)$ & $1 / 8 / 96(23.4)$ & $10 / 11 / 00(64.2)$ \\
\hline UNIONE & $7 / 21 / 97(29.6)$ & $10 / 24 / 97(44.6)$ & $6 / 26 / 97(6.4)$ & $10 / 23 / 97(17.2)$ & $9 / 26 / 00(19.6)$ \\
\hline AMSOUTH & $12 / 19 / 95(18.4)$ & $1 / 8 / 96(24.9)$ & $12 / 10 / 96(23.8)$ & $1 / 1 / 97(17.5)$ & $9 / 19 / 00(45.4)$ \\
\hline HUNTING & $2 / 6 / 97(34.2)$ & $1 / 22 / 97(67.3)$ & $10 / 13 / 97(29.9)$ & $10 / 16 / 97(40.9)$ & $10 / 5 / 00(30.3)$ \\
\hline $\mathrm{BBT}$ & $3 / 28 / 97(22.3)$ & $3 / 28 / 97(24.7)$ & $10 / 22 / 97(16.7)$ & $10 / 29 / 97(19.4)$ & $9 / 19 / 00(24.6)$ \\
\hline $53 \mathrm{BA}$ & $12 / 2 / 96(31.6)$ & $12 / 2 / 96(26.2)$ & $12 / 5 / 96(59.2)$ & $4 / 9 / 97(34.3)$ & $10 / 16 / 00(42.0)$ \\
\hline & $2 / 26 / 97(47.4)$ & $2 / 24 / 97(36.6)$ & $10 / 13 / 97(35.6)$ & $10 / 8 / 97(44.2)$ & $12 / 1 / 00(41.5)$ \\
\hline RFCORP & $3 / 7 / 96(36.4)$ & $2 / 23 / 96(40.7)$ & $12 / 10 / 96(23.3)$ & $12 / 10 / 96(33.9)$ & $10 / 10 / 00(24.0)$ \\
\hline
\end{tabular}

Note: The table reports the results of tests examining the structural stability of the extreme systematic risks of US banks documented in table 7. This is done by testing for the constancy of the $\eta$ tail dependence parameters (null hypothesis) that govern the tail- $\beta$ s in table 7 . Applying the recursive test (4.1) through (4.4) by Quintos et al. (2001), each cell shows the endogenously found break date and the test value in parentheses. Dates are denoted XX/YY $/ Z Z$, where XX=month, YY=day and $\mathrm{ZZ}=$ year. The critical values of the test are 1.46, 1.78 and 2.54 for the $10 \%, 5 \%$ and $1 \%$ levels, respectively. A test value exceeding these numbers implies an increase in extreme dependence over time. The absence of a break over the sample period is marked with a dash. 
A.1. Small sample properties of the bivariate estimator. In this section we investigate the small sample properties of our estimators. We limit our attention to the bivariate version, which could either be a spillover probability between two banks or a tail- $\beta$, and the respective dependence parameter. Without loss of generality, we will always refer to tail- $\beta$ below. Three different data generating processes are investigated: The bivariate Pareto distribution, the bivariate Morgenstern distribution (1956) with Pareto marginals and the bivariate standard normal distribution. The first two distributions both have Pareto marginals, but only the first distribution exhibits asymptotic dependence (in which case $\eta=1$ ). The bivariate normal is also asymptotically independent (as long as $|\rho| \neq 1$ ). The normal distribution has a dependence parameter $\eta$ that varies with the correlation coefficient, and we investigate different configurations. The precise specifications of the distributions are as follows:

1/ Bivariate Pareto

$$
\begin{aligned}
F(x, y) & =1-x^{-\alpha}-y^{-\alpha}+(x+y-1)^{-\alpha} \\
\rho & =1 / \alpha \text { for } \alpha>2 \\
\eta & =1 .
\end{aligned}
$$

2/ Bivariate Morgenstern distribution with Pareto marginals

$$
\begin{aligned}
F(x, y) & =\left(1-x^{-\alpha}\right)\left(1-y^{-\alpha}\right)\left(1+\delta x^{-\alpha} y^{-\alpha}\right), \quad-1 \leq \delta \leq 1 \\
\rho & =\delta \alpha(\alpha-2)(2 \alpha-1)^{-2} \text { for } \alpha>2, \\
\eta & =1 / 2 .
\end{aligned}
$$

3/ Bivariate normal with correlation coefficient $\rho$ and dependence parameter

$$
\eta=\frac{1+\rho}{2}
$$

The three specific distributions have the advantage that they allow us to calculate the true value of $\eta$ and the tail- $\beta\left(\tau_{\beta}\right)$. Thus, the estimation bias and asymptotic mean-squared error can be calculated 
explicitly. The true "benchmark" values of the tail- $\beta$ s are:

$$
\begin{aligned}
\tau_{\beta} & =\left(2-p^{1 / \alpha}\right)^{-\alpha} \quad \text { (bivariate Pareto) } \\
\tau_{\beta} & =(1+\delta) p-2 \delta p^{2}+\delta p^{3} \quad \text { (bivariate Morgenstern) } \\
\tau_{\beta} & =\frac{\Phi(-x,-x, \rho)}{p}, \quad \text { (bivariate standard normal) },
\end{aligned}
$$

where $p=P\{X>x\}$. In the tables below we evaluate the tail- $\beta$ s and dependence parameters at $p=0.05 \%$ which is one of the marginal significance levels we also use in the empirical applications. Two different sample sizes are considered, a truly small sample of 500 observations and a larger sample of 3,106, corresponding to the actual sample size in the empirical application to bank stocks.

The following three tables report true values of $\tau_{\beta}$ as well as estimates of the average, bias and standard deviation of $\eta$ and $\tau_{\beta}$ for 5,000 Monte Carlo replications. Notice that biases are reported in absolute and not in percentage terms. Back-of-the-envelope calculations of the relative (percentage) biases may nevertheless be handy for sake of comparing the bias across different parametrizations but were omitted for sake of space considerations. ${ }^{35}$ Averages, biases and standard deviations are multiplied with 100 for sake of convenience. The estimates are conditioned on cutoff points $m^{*}$ that minimize the Asymptotic Mean Squared error (AMSE). The AMSE is calculated for 5,000 Monte Carlo replications. ${ }^{36}$

We start with an evaluation for the Morgenstern distribution with Pareto marginals (see table A.1).

[Insert table A.1 about here]

Analytic tail- $\beta$ values are small which makes this model the least realistic as a benchmark for comparison with the tail- $\beta s$ we found in practice. We let both the tail index $\alpha$ and the parameter $\delta$ vary. The table shows that the Morgenstern bias in $\eta$ and $\tau_{\beta}$ does depend on $\delta$ but not on $\alpha$. This is not surprising given that $\alpha$ does not enter the analytic expression of the Morgenstern tail- $\beta$,i.e., the tail- $\beta$ is independent from

\footnotetext{
${ }^{35}$ Relative or percentage measures of the bias can be calculated as $100 \times(E(\widehat{\eta})-\eta) / \eta$ and $100 \times\left(E\left(\widehat{\tau}_{\beta}\right)-\tau_{\beta}\right) / \tau_{\beta}$ for the tail dependence parameter and the tail- $\beta$, respectively.

${ }^{36}$ If two (unit Pareto) random variables are independent, we previously noted that $P\{X>q, Y>q\}=p^{2}$ with $p=P\{X>q\}=P\{Y>q\}$. This exact Pareto tail allows the use of all extreme observations in estimation because of the unbiasedness of the Hill statistic under the Pareto law, i.e., $m^{*}=n-1$.
} 
marginal properties in this case. ${ }^{37}$ Biases are small for small $\delta$ but become substantial in both absolute and relative terms when $\delta$ is large. Also, the estimation accuracy - as reflected by the standard errors s.e. - is found to be higher for small values of $\delta$.

Next we turn to the results for the Pareto distribution. The results are in table A.2.

[Insert table A.2 about here]

In contrast to table A.1, there now appears a considerable downward bias in absolute terms for both $\eta$ and $\tau_{\beta}$. However, the relative (percentage) biases can be shown to be smaller than in the Morgenstern case. Recall that the true value of $\eta$ is equal to the boundary of 1 in this case, so that in any empirical exercise one expects at least some downward bias. Moreover, (absolute and relative) biases and standard errors decreases with a decrease in correlation (an increase in $\alpha$ ).

Lastly, we consider the small sample performance for the bivariate normal distribution (see table A.3).

[Insert table A.3 about here]

For the normal distribution the estimators appear to behave quite reasonably. Absolute and relative biases are found to be smaller than in the Pareto case. Moreover, it may be difficult to distinguish the normal distribution from the Pareto distribution just on the basis of, say, the dependence parameter estimate. To this end it would be helpful to investigate the tail properties of the marginals as well.

A.2. Small sample properties of the endogenous break test. In this part of the appendix we investigate the small sample properties of the recursive test for a single endogenous break in $\eta$. This is done through a simulation study in which we use the bivariate normal as the data-generating process (see table A.4).

[Insert table A.4 about here]

Recall that in this case $\eta=(1+\rho) / 2$. By changing the correlation coefficient, we can easily change the dependence parameter $\eta$.

The breaks are engineered at five different points in the sample (see $r$-columns in the table). Three different combinations of pre and postbreak $\eta \mathrm{s}$ are considered (see rows of the table). The sample size is 3,000 . The table shows that the test has more difficulty in accurately locating the break if it is close to the start or the end of the sample. The reason is that in these cases one has fewer observations available for one of the two sub-samples. When the change in the dependence

\footnotetext{
${ }^{37}$ It can be easily shown that the analytic expressions for Morgenstern bias and AMSE do not depend on the marginal distributional properties like scale and tail indices.
} 
parameter is small, then the standard errors tend to be more sizable. For example, the standard errors in the first and third scenario are about twice as large as in the second scenario. In sum, the cases in which we have to be more cautious in interpreting the test results are when the changes in $\eta$ are small and when they occur close to the boundaries of the sample.

TABle A.1. Small sample behavior of tail betas for bivariate Morgenstern distribution

\begin{tabular}{|c|c|c|c|c|c|c|c|c|}
\hline & \multicolumn{3}{|c|}{$\widehat{\widehat{\eta}}$} & \multicolumn{4}{|c|}{$\overline{\widehat{\tau}_{\beta}(\times 100)}$} & \multirow[t]{2}{*}{$\overline{\tau_{\beta}(\times 100)}$} \\
\hline & & & & & \multicolumn{3}{|c|}{$p=0.05 \%$} & \\
\hline$(\alpha ; \delta)$ & $m^{*}$ & aver. & bias & s.e. & aver. & bias & s.e. & \\
\hline & & \multicolumn{7}{|c|}{ panel A: $n=500$} \\
\hline$(2 ; 0)$ & 499 & 0.499 & -0.001 & 0.013 & 0.052 & 0.002 & 0.021 & 0.05 \\
\hline$(3 ; 0)$ & 499 & 0.499 & -0.001 & 0.013 & 0.052 & 0.002 & 0.021 & 0.05 \\
\hline$(4 ; 0)$ & 499 & 0.499 & -0.001 & 0.013 & 0.052 & 0.002 & 0.021 & 0.05 \\
\hline$(2 ; 0.5)$ & 150 & 0.546 & 0.046 & 0.034 & 0.231 & 0.156 & 0.190 & 0.075 \\
\hline$(3 ; 0.5)$ & 150 & 0.545 & 0.045 & 0.034 & 0.226 & 0.151 & 0.189 & 0.075 \\
\hline$(4 ; 0.5)$ & 150 & 0.546 & 0.046 & 0.034 & 0.232 & 0.157 & 0.198 & 0.075 \\
\hline$(2 ; 0.9)$ & 134 & 0.570 & 0.070 & 0.036 & 0.424 & 0.329 & 0.338 & 0.095 \\
\hline$(3 ; 0.9)$ & 134 & 0.570 & 0.070 & 0.037 & 0.427 & 0.332 & 0.349 & 0.095 \\
\hline \multirow[t]{2}{*}{$(4 ; 0.9)$} & 134 & 0.570 & 0.070 & 0.037 & 0.419 & 0.324 & 0.327 & 0.095 \\
\hline & & \multicolumn{7}{|c|}{ Panel B: $n=3,106$} \\
\hline$(2 ; 0)$ & 3,105 & 0.500 & 0 & 0.005 & 0.050 & 0 & 0.008 & 0.05 \\
\hline$(3 ; 0)$ & 3,105 & 0.500 & 0 & 0.005 & 0.050 & 0 & 0.008 & 0.05 \\
\hline$(4 ; 0)$ & 3,105 & 0.500 & 0 & 0.005 & 0.050 & 0 & 0.008 & 0.05 \\
\hline$(2 ; 0.5)$ & 376 & 0.532 & 0.032 & 0.023 & 0.152 & 0.077 & 0.083 & 0.075 \\
\hline$(3 ; 0.5)$ & 376 & 0.532 & 0.032 & 0.023 & 0.151 & 0.076 & 0.083 & 0.075 \\
\hline$(4 ; 0.5)$ & 376 & 0.532 & 0.032 & 0.023 & 0.148 & 0.073 & 0.080 & 0.075 \\
\hline$(2 ; 0.9)$ & 335 & 0.543 & 0.043 & 0.025 & 0.225 & 0.130 & 0.121 & 0.095 \\
\hline$(3 ; 0.9)$ & 335 & 0.543 & 0.043 & 0.025 & 0.224 & 0.129 & 0.120 & 0.095 \\
\hline$(4 ; 0.9)$ & 335 & 0.543 & 0.043 & 0.025 & 0.225 & 0.130 & 0.120 & 0.095 \\
\hline
\end{tabular}

Note: The table reports estimated values and true (analytic) values of the tail dependence parameter $\eta$ and the tail- $\beta\left(\tau_{\beta}\right)$ for different sample sizes and different parameter configurations $(\alpha, \delta)$. Tail- $\beta s$ and corresponding biases, accuracy are expressed in percentage terms (\%). Moreover, the linkage estimates are conditioned on the cutoff point $m^{*}$ that minimizes the Asymptotic Mean Squared Error of $\widehat{\eta}$. The conditioning quantiles for the tail- $\beta$ are chosen such that the corresponding marginal excess probabilities are equal to $0.05 \%$. 
TABlE A.2. Small sample behavior of tail betas for bivariate Pareto distribution

\begin{tabular}{|c|c|c|c|c|c|c|c|c|c|}
\hline$\alpha$ & $m^{*}$ & & $\widehat{\eta}$ & & $\widehat{\tau}_{\beta}(p$ & $(\times 1$ & $00)$ & $\tau_{\beta}(p)(\times 100)$ & $\eta$ \\
\hline & & & & & \multicolumn{5}{|c|}{$p=0.05 \%$} \\
\hline & & aver. & bias & s.e. & aver. & bias & s.e. & & \\
\hline & & \multicolumn{8}{|c|}{ Panel A: $n=500$} \\
\hline 2 & 31 & 0.831 & -0.169 & 0.113 & 15.44 & -10.12 & 13.15 & 25.57 & 1 \\
\hline 3 & 26 & 0.763 & -0.237 & 0.126 & 8.33 & -5.79 & 9.49 & 14.11 & 1 \\
\hline 4 & 22 & 0.719 & -0.280 & 0.134 & 5.49 & -3.04 & 7.40 & 8.53 & 1 \\
\hline indep. & 499 & 0.498 & 0 & 0.013 & 0.05 & 0 & 0.02 & 0.05 & $1 / 2$ \\
\hline \multicolumn{10}{|c|}{ Panel B: $n=3,106$} \\
\hline 2 & 89 & 0.889 & -0.111 & 0.073 & 19.19 & -6.38 & 8.73 & 25.57 & 1 \\
\hline 3 & 45 & 0.832 & -0.168 & 0.106 & 10.61 & -3.50 & 7.51 & 14.11 & 1 \\
\hline 4 & 42 & 0.777 & -0.222 & 0.110 & 6.28 & -2.25 & 5.37 & 8.53 & 1 \\
\hline indep. & 3,105 & 0.500 & 0 & 0.005 & 0.05 & 0 & 0 & 0.05 & $1 / 2$ \\
\hline
\end{tabular}

Note: The table reports estimated values and true (analytic) values of the tail dependence parameter $\eta$ and the tail- $\beta\left(\tau_{\beta}\right)$ for different sample sizes and different values of $\alpha$. Tail- $\beta s$ and corresponding biases, accuracy are expressed in percentage terms (\%). Moreover, the linkage estimates are conditioned on the cutoff point $m^{*}$ that minimizes the Asymptotic Mean Squared Error of $\hat{\eta}$. The conditioning quantiles for the tail- $\beta$ are chosen such that the corresponding marginal excess probabilities are equal to $0.05 \%$.

TABLE A.3. Small sample behavior of tail betas for bivariate normal distribution

\begin{tabular}{|c|c|c|c|c|c|c|c|c|c|}
\hline$\rho$ & $m^{*}$ & & $\widehat{\eta}$ & & & $(\times 100$ & & $\overline{\tau_{\beta}(\times 100)}$ & $\bar{\nu} \eta=\frac{1+\rho}{2}$ \\
\hline & & & & & \multicolumn{5}{|c|}{$p=0.05 \%$} \\
\hline & & aver. & bias & s.e. & aver. & bias & s.e. & & \\
\hline & & \multicolumn{8}{|c|}{ panel A: $n=500$} \\
\hline $3 / 4$ & 138 & 0.795 & -0.080 & 0.038 & 13.55 & -4.59 & 5.11 & 18.14 & 0.875 \\
\hline $1 / 2$ & 154 & 0.684 & -0.065 & 0.038 & 3.09 & -1.12 & 1.69 & 4.21 & 0.75 \\
\hline $1 / 4$ & 233 & 0.583 & -0.042 & 0.026 & 0.47 & -0.19 & 0.27 & 0.67 & 0.625 \\
\hline 0 & 499 & 0.499 & -0.001 & 0.013 & 0.05 & 0 & 0.02 & 0.05 & 0.5 \\
\hline & & \multicolumn{8}{|c|}{ Panel B: $n=3,106$} \\
\hline $3 / 4$ & 299 & 0.815 & -0.060 & 0.031 & 15.74 & -2.40 & 4.10 & 18.14 & 0.875 \\
\hline $1 / 2$ & 403 & 0.699 & -0.051 & 0.027 & 3.47 & -0.74 & 1.20 & 4.21 & 0.75 \\
\hline $1 / 4$ & 574 & 0.594 & -0.031 & 0.020 & 0.54 & -0.12 & 0.20 & 0.67 & 0.625 \\
\hline 0 & 3105 & 0.500 & 0 & 0.005 & 0.05 & 0 & 0 & 0.05 & 0.5 \\
\hline
\end{tabular}

Note: The table reports estimated values and true (analytic) values of the tail dependence parameter $\eta$ and the tail- $\beta\left(\tau_{\beta}\right)$ for different sample sizes and different correlations $\rho$. Tail- $\beta s$ and corresponding biases, accuracy are expressed in percentage terms (\%). Moreover, the linkage estimates are conditioned on the cutoff point $m^{*}$ that minimizes the Asymptotic Mean Squared Error of $\widehat{\eta}$. The conditioning quantiles for the tail- $\beta$ are chosen such that the corresponding marginal excess probabilities are equal to $0.05 \%$. 
TABLE A.4. Simulated breakpoints

\begin{tabular}{lccc}
\hline \hline & \multicolumn{3}{c}{ Estimated breakpoints } \\
\hline & \multicolumn{3}{c}{ (standard error) } \\
\hline$\left(\eta_{1} ; \eta_{2}\right)$ & $\mathrm{r}=1 / 3$ & $\mathrm{r}=1 / 2$ & $\mathrm{r}=2 / 3$ \\
\hline$(0.5 ; 0.7)$ & 0.364 & 0.514 & 0.617 \\
& $(0.190)$ & $(0.166)$ & $(0.117)$ \\
$(0.5 ; 0.9)$ & 0.264 & 0.485 & 0.636 \\
& $(0.095)$ & $(0.078)$ & $(0.092)$ \\
$(0.7 ; 0.9)$ & 0.394 & 0.508 & 0.587 \\
& $(0.209)$ & $(0.172)$ & $(0.194)$ \\
\hline \hline
\end{tabular}

Note: Estimated breakpoints are reported for the tail dependence parameter of the bivariate normal df. The break estimates are reported for varying locations of the true breakpoints $(\mathrm{r}=1 / 3,1 / 2,2 / 3)$. The number of Monte Carlo replications is set to 1,000 . The accompanying sampling errors are reported between brackets. Q-tests are calculated starting with a minimum sample size of 500. For sake of convenience, we set the number of upper order extremes used in estimating the tail index equal to $2 n^{2 / 3}$ 
Appendix B List of banks in the sample

Table B.1: List of banks in the sample

\begin{tabular}{|c|c|c|c|}
\hline \multicolumn{2}{|l|}{ Euro area } & \multicolumn{2}{|l|}{ United States } \\
\hline Bank name & Abbreviation & Bank name & Abbreviation \\
\hline Germany & & Citigroup & CITIG \\
\hline Deutsche Bank & DEUTSCHE & JP Morgan Chase & JP MORGAN \\
\hline Bayerische Hypo- und Vereinsbank & HYPO & Bank of America BOA & BAMERICA \\
\hline Dresdner Bank & DRESDNER & Wachovia Corporation & WACHOVIA \\
\hline Commerzbank & COMMERZ & Wells Fargo and Company & FARGO \\
\hline Bankgesellschaft Berlin & BGBERLIN & Bank One Corporation & BONE \\
\hline DePfa Group & DEPFA & Washington Mutual Inc & WASHING \\
\hline France & & Fleet Boston Financial Corporation & FLEET \\
\hline BNP Paribas & BNPPAR & Bank of New York & BNYORK \\
\hline Crédit Agricole & $\mathrm{CA}$ & State Street & SSTREET \\
\hline Societe Generale & SGENER & Northern Trust & NTRUST \\
\hline Natexis Banques Populaires & NATEXIS & Mellon & MELLON \\
\hline Italy & & US Bancorp & BCORP \\
\hline Banca Intesa & INTESA & National City Corporation & CITYCO \\
\hline UniCredito Italiano & UNICREDIT & PNC Financial Services Group & PNC \\
\hline Sanpaolo IMI & PAOLO & Keycorp & KEYCO \\
\hline Capitalia & CAPITA & Sun Trust & SUTRUST \\
\hline Spain & & Comerica Incorporated & COMERICA \\
\hline Banco Santander Central Hispano & SANTANDER & Unionbancal Corporation & UNIONBANK \\
\hline Banco Bilbao Vizcaya Argentaria & BILBAO & AmSouth Bancorp & AMSOUTH \\
\hline Banco Espagnol de Credito & BANESP & Huntington Bancshares Inc & HUNTING \\
\hline Netherlands & & BBT Corporation & BBT \\
\hline ABN AMRO & ABNAMRO & Fifth Third Bancorp & 53BANCO \\
\hline ING Bank & ING & Southtrust & SOTRUST \\
\hline Belgium & & Regions Financial Corporation & REGIONS \\
\hline Fortis & FORTIS & & \\
\hline Almanij & ALMANIJ & & \\
\hline \multicolumn{4}{|l|}{ Finland } \\
\hline Sampo Leonia & SAMPO & & \\
\hline \multicolumn{4}{|l|}{ Greece } \\
\hline Alpha Bank & ALPHA & & \\
\hline \multicolumn{4}{|l|}{ Ireland } \\
\hline Allied Irish Banks & IRBAN & & \\
\hline \multicolumn{4}{|l|}{ Portugal } \\
\hline Banco Commercial Portugues & $\mathrm{BCP}$ & & \\
\hline
\end{tabular}


Appendix C: Balance sheet data

Table C.1: Total assets of euro area banks (million US\$)

\begin{tabular}{|c|c|c|c|c|c|c|c|c|c|c|c|c|c|c|c|}
\hline Bank & 2003 & 2002 & 2001 & 2000 & 1999 & 1998 & 1997 & 1996 & 1995 & 1994 & 1993 & 1992 & Ave & $\begin{array}{c}\text { Average } \\
1998-2003 \\
\end{array}$ & $\begin{array}{c}\text { Average } \\
1992-1997 \\
\end{array}$ \\
\hline DEUTSCHE & 934,434 & 730,301 & 641,826 & 647,186 & 569,127 & 555,446 & 419,892 & 386,645 & 461,180 & 352,740 & 308,790 & 297,200 & 525,397 & 679,720 & 371,075 \\
\hline BNPPAR & 988,881 & 744,867 & 727,318 & 644,886 & 700,675 & 378,990 & 339,817 & 355,299 & 325,880 & 271,640 & 250,440 & 275,310 & 500,334 & 697,603 & 303,064 \\
\hline CA & $1,105,378$ & 609,055 & 496,421 & 498,433 & 441,524 & 455,781 & 419,971 & 477,591 & 387,130 & 328,130 & 282,870 & 292,090 & 482,864 & 601,099 & 364,630 \\
\hline ABNAMRO & 707,801 & 583,073 & 526,450 & 505,419 & 460,000 & 504,122 & 414,655 & 343,699 & 340,640 & 290,800 & 252,990 & 246,980 & 431,386 & 547,811 & 314,961 \\
\hline HYPO & 597,584 & 552,068 & 631,216 & 646,016 & 485,099 & 521,336 & 453,909 & n.a. & 203,960 & 173,600 & 151,150 & 134,300 & 413,658 & 572,220 & 223,384 \\
\hline SGENER & 681,216 & 525,789 & 451,660 & 424,198 & 437,558 & 447,486 & 410,655 & 339,586 & 326,670 & 277,550 & 259,790 & 251,320 & 402,790 & 494,651 & 310,929 \\
\hline DRESDNER & 602,461 & 433,489 & 446,238 & 449,036 & 397,944 & 424,620 & 372,779 & n.a. & 330,340 & 252,180 & 215,190 & 199,820 & 374,918 & 458,965 & 274,062 \\
\hline COMMERZ & 481,653 & 442,333 & 441,510 & 422,867 & 371,134 & 374,896 & 294,671 & n.a. & 275,700 & 217,640 & 162,120 & 142,130 & 329,696 & 422,399 & 218,452 \\
\hline ING & 684,004 & 500,326 & 390,725 & 378,149 & 351,234 & 326,813 & 190,269 & 179,933 & 154,050 & 125,330 & 105,880 & 109,540 & 291,354 & 438,542 & 144,167 \\
\hline INTESA & 327,353 & 290,917 & 275,967 & 308,334 & 309,719 & 330,138 & 158,597 & 163,712 & n.a. & n.a. & n.a. & n.a. & 270,592 & 307,071 & 161,154 \\
\hline FORTIS & 536,857 & 396,107 & 327,451 & 309,011 & 330,835 & 333,608 & n.a. & n.a. & 19,650 & 16,690 & 14,220 & 14,520 & 229,895 & 372,312 & 16,270 \\
\hline BILBAO & 356,921 & 288,311 & 269,208 & 272,225 & 236,802 & 235,799 & 214,978 & 213,680 & 115,820 & 98,820 & 81,420 & 87,640 & 205,969 & 276,544 & 135,393 \\
\hline UNICREDIT & 300,652 & 226,638 & 188,380 & 188,565 & 169,705 & 175,346 & 161,206 & n.a. & n.a. & n.a. & n.a. & n.a. & 201,499 & 208,214 & 161,206 \\
\hline BGBERLIN & 191,936 & 182,046 & 165,227 & 189,389 & 192,212 & 217,785 & 195,372 & 206,377 & 34,060 & 20,650 & n.a. & n.a. & 159,505 & 189,766 & 114,115 \\
\hline SANTANDER & 250,904 & 188,024 & 159,505 & 160,325 & n.a. & n.a. & n.a. & n.a. & 135,060 & 113,920 & 73,120 & 61,310 & 142,771 & 189,689 & 95,853 \\
\hline CAPITA & 159,915 & 146,148 & 115,815 & 123,504 & 134,397 & 142,745 & 114,969 & 140,831 & n.a. & n.a. & n.a. & n.a. & 134,790 & 137,087 & 127,900 \\
\hline ALMANIJ & 327,898 & 265,080 & 228,521 & 202,453 & 187,390 & 198,213 & 187,745 & 740 & 3,300 & 2,810 & 2,370 & 1,310 & 133,986 & 234,926 & 33,046 \\
\hline DEPFA & 219,708 & 152,944 & 159,425 & n.a. & n.a. & n.a. & n.a. & n.a. & 103,580 & 76,800 & 62,850 & 56,150 & 118,779 & 177,359 & 74,845 \\
\hline NATEXIS & 171,646 & 139,891 & 97,254 & 105,268 & 94,861 & 49,558 & 49,972 & 110,159 & n.a. & n.a. & n.a. & n.a. & 102,326 & 109,746 & 80,066 \\
\hline IRBAN & 98,699 & 87,717 & 76,551 & 72,516 & 65,548 & 61,439 & 52,815 & 43,105 & 37,810 & 32,200 & 29,430 & 29,940 & 57,314 & 77,078 & 37,550 \\
\hline BANESP & 72,923 & 51,919 & 39,384 & 41,296 & 39,958 & 42,800 & 36,606 & 42,715 & 41,760 & 43,120 & 53,210 & 61,750 & 47,287 & 48,047 & 46,527 \\
\hline $\mathrm{BCP}$ & 85,483 & 64,861 & 55,479 & 57,552 & 35,211 & 33,955 & 29,662 & n.a. & 36,170 & 13,960 & 10,900 & 10,370 & 39,418 & 55,423 & 20,212 \\
\hline SAMPO & 21,454 & 18,255 & 15,126 & n.a. & n.a. & n.a. & n.a. & n.a. & n.a. & n.a. & n.a. & n.a. & 18,278 & 18,278 & n.a. \\
\hline ALPHA & 38,902 & 30,123 & 26,052 & 28,420 & 25,445 & 16,372 & 12,409 & 11,680 & 9,250 & 7,130 & 5,610 & 5,020 & 18,034 & 27,552 & 8,517 \\
\hline PAOLO & 8,807 & 7,073 & 5,586 & 6,133 & 5,375 & 6,056 & 5,163 & 4,791 & 4,643 & 4,100 & 3,729 & 4,608 & 5,505 & 6,505 & 4,506 \\
\hline Sum & 953,470 & 657,353 & 958,293 & 681,182 & 041,753 & 333,304 & 36,112 & 20,543 & 346,653 & 719,810 & 26,079 & 281,308 & $5,638,347$ & $7,348,608$ & 341,882 \\
\hline
\end{tabular}

Notes: BNP PARIBAS until 1995 BNP. Banks are ordered in declining size of average assets over the sample period. n.a. means data not available.

Data source: Bankscope and own calculations. 
Appendix C: Balance sheet data

Table C.2: Total assets of US banks (million US\$)

\begin{tabular}{|c|c|c|c|c|c|c|c|c|c|c|c|c|c|c|c|}
\hline Bank Name & 2003 & 2002 & 2001 & 2000 & 1999 & 1998 & 1997 & 1996 & 1995 & 1994 & 1993 & 1992 & Average & $\begin{array}{c}\text { Average } \\
1998-2003\end{array}$ & $\begin{array}{c}\text { Average } \\
1992-1997\end{array}$ \\
\hline CITIG & $1,264,032$ & $1,097,190$ & $1,051,450$ & 902,210 & 716,937 & 668,641 & n.a. & n.a. & 220,110 & 210,487 & 175,712 & 163,846 & 647,062 & 950,077 & 192,539 \\
\hline JP MORGAN & 770,912 & 758,800 & 693,575 & 715,348 & 406,105 & 365,875 & 365,521 & 336,099 & 184,879 & 154,917 & 133,888 & 102,941 & 415,738 & 618,436 & 213,041 \\
\hline BAMERICA & 736,445 & 660,458 & 621,764 & 642,191 & 632,574 & 617,679 & 264,562 & 185,794 & 163,398 & 147,670 & 136,693 & 133,449 & 411,890 & 651,852 & 171,928 \\
\hline BONE & 326,563 & 277,383 & 268,954 & 269,300 & 269,425 & 261,496 & 115,901 & 101,848 & n.a. & n.a. & n.a. & n.a. & 236,359 & 278,854 & 108,875 \\
\hline FARGO & 387,798 & 349,259 & 307,569 & 272,426 & 218,102 & 202,475 & 88,540 & 80,175 & 50,316 & 53,374 & 52,513 & 52,537 & 176,257 & 289,605 & 62,909 \\
\hline WACHOVIA & 401,032 & 341,839 & 330,452 & 74,032 & 67,353 & 64,123 & 65,397 & 46,886 & 44,964 & 39,171 & 36,514 & 33,356 & 128,760 & 213,138 & 44,382 \\
\hline FLEET & 200,356 & 190,589 & 203,638 & 179,519 & 190,692 & 104,554 & 85,690 & 85,555 & 11,037 & 9,757 & 8,246 & 8,288 & 106,493 & 178,225 & 34,762 \\
\hline BCORP & 189,286 & 180,027 & 171,390 & 87,336 & 81,530 & 76,438 & 71,295 & 36,489 & 31,865 & 21,784 & 21,458 & 20,773 & 82,473 & 131,001 & 33,944 \\
\hline CITYCO & 113,934 & 118,258 & 105,817 & 88,535 & 87,122 & 88,246 & 54,684 & 50,856 & 36,199 & 32,114 & 31,068 & 28,964 & 69,649 & 100,318 & 38,981 \\
\hline KEYCO & 84,147 & 84,710 & 80,400 & 87,165 & 83,344 & 79,966 & 73,625 & 67,688 & 66,339 & 66,798 & 32,648 & 25,457 & 69,357 & 83,289 & 55,426 \\
\hline PNC & 68,193 & 66,410 & 69,570 & 69,916 & 75,428 & 77,232 & 75,101 & 73,174 & 73,507 & 64,221 & 61,945 & 51,523 & 68,852 & 71,125 & 66,578 \\
\hline BNYORK & 89,258 & 74,948 & 78,019 & 74,266 & 71,795 & 60,078 & 56,154 & 52,121 & 42,712 & 39,287 & 36,088 & 36,644 & 59,281 & 74,727 & 43,834 \\
\hline SSTREET & 80,435 & 79,621 & 65,410 & 64,644 & 56,226 & 43,185 & 37,450 & 31,390 & 25,785 & 21,744 & 18,720 & 16,490 & 45,092 & 64,920 & 25,263 \\
\hline SOTRUST & 51,885 & 50,570 & 48,850 & 45,170 & 43,203 & 38,054 & 30,715 & 13,339 & n.a. & n.a. & n.a. & n.a. & 40,223 & 46,288 & 22,027 \\
\hline BBT & 90,467 & 80,217 & 70,870 & 59,340 & 43,481 & 34,427 & 29,178 & 21,247 & 15,992 & 9,179 & 7,794 & 6,256 & 39,037 & 63,134 & 14,941 \\
\hline 53BANCO & 91,143 & 80,899 & 71,026 & 45,857 & 41,590 & 28,922 & 21,375 & 20,549 & 17,057 & 14,973 & 11,981 & 10,232 & 37,967 & 59,906 & 16,028 \\
\hline MELLON & 20,839 & 26,841 & 27,813 & 41,974 & 39,619 & 42,235 & 38,802 & 37,339 & 40,734 & 38,716 & 36,050 & 31,541 & 35,209 & 33,220 & 37,197 \\
\hline COMERICA & 52,684 & 39,643 & 37,256 & 33,697 & 31,243 & 29,375 & 28,936 & 27,052 & 28,394 & 27,044 & 24,935 & 22,364 & 31,885 & 37,317 & 26,454 \\
\hline REGIONS & 48,881 & 47,939 & 45,383 & 43,688 & 42,714 & 36,832 & 23,034 & 18,930 & 13,709 & 12,839 & 10,476 & 7,881 & 29,359 & 44,240 & 14,478 \\
\hline UNIONBANK & 42,488 & 40,193 & 36,078 & 35,170 & 33,685 & 32,301 & 30,612 & 29,304 & 19,518 & 16,761 & 16,391 & 16,844 & 29,112 & 36,652 & 21,572 \\
\hline AMSOUTH & 45,670 & 40,598 & 38,622 & 38,968 & 43,427 & 19,919 & 18,657 & 18,440 & 17,740 & 16,845 & 12,584 & 9,790 & 26,772 & 37,867 & 15,676 \\
\hline WASHING & 29,327 & 26,723 & 31,639 & 34,715 & 35,036 & 32,466 & 26,070 & 21,241 & 21,633 & 18,458 & 15,827 & n.a. & 26,649 & 31,651 & 20,646 \\
\hline HUNTING & 30,566 & 27,702 & 28,497 & 28,599 & 37 & 28,296 & 31 & 20,852 & 20,255 & 17,771 & 17 & 16,247 & 24,347 & 28,783 & 9,912 \\
\hline NTRUST & 33,403 & 31,974 & 32,758 & 29,709 & 23,500 & 23,304 & 21,185 & 18,127 & 15,231 & 14,736 & 13,538 & 11,907 & 22,448 & 29,108 & 15,787 \\
\hline SUTRUST & n.a. & 4,638 & 3,991 & 3,459 & 3,504 & 3,478 & 2,292 & n.a. & 46,472 & 42,534 & 40,728 & 36,647 & 18,774 & 3,814 & 33,735 \\
\hline Sum & $5,249,743$ & $4,777,430$ & $4,520,789$ & $, 967,235$ & 366,670 & $, 059,596$ & 651,505 & 394,493 & ,207,844 & ,091,179 & 953,416 & 843,975 & $2,879,044$ & $4,157,546$ & $1,350,913$ \\
\hline
\end{tabular}

Notes: Comerica until 1995 Comerica Detroit. Banks are ordered in declining size of average assets over the sample period. n.a. means data not available.

Data source: Bankscope and own calculations. 
Appendix C: Balance sheet data

Table C.3: Due from banks for euro area banks (million US\$)

\begin{tabular}{|c|c|c|c|c|c|c|c|c|c|c|c|c|c|c|c|}
\hline Bank Name & 2003 & 2002 & 2001 & 2000 & 1999 & 1998 & 1997 & 1996 & 1995 & 1994 & 1993 & 1992 & Average & $\begin{array}{c}\text { Average } \\
1998-2003\end{array}$ & $\begin{array}{c}\text { Average } \\
1992-1997\end{array}$ \\
\hline BNPPAR & 205,797 & 153,641 & 164,469 & 121,536 & 160,510 & 83,169 & 82,147 & 103,735 & 96,870 & 77,920 & 72,780 & 87,370 & 117,495 & 148,187 & 86,804 \\
\hline DEUTSCHE & 180,570 & 147,226 & 136,059 & 135,624 & 134,235 & 124,204 & 100,119 & 99,183 & 77,060 & 63,300 & 54,860 & 56,490 & 109,078 & 142,986 & 75,169 \\
\hline CA & 119,534 & 70,083 & 56,052 & 61,259 & 62,275 & 79,898 & 78,699 & 112,656 & 98,490 & 78,040 & 68,290 & 63,250 & 79,044 & 74,850 & 83,237 \\
\hline DRESDNER & 154,862 & 92,666 & 68,276 & 83,419 & 56,934 & 77,022 & 68,836 & n.a. & 55,910 & 40,830 & 29,470 & 32,300 & 69,139 & 88,863 & 45,469 \\
\hline SGENER & 76,133 & 56,999 & 56,004 & 50,409 & 55,263 & 77,499 & 89,485 & 66,669 & 72,850 & 66,720 & 61,240 & 62,910 & 66,015 & 62,051 & 69,979 \\
\hline ABNAMRO & 74,261 & 43,964 & 43,729 & 45,205 & 47,419 & 71,047 & 69,495 & 68,983 & 81,860 & 73,220 & 65,820 & 65,080 & 62,507 & 54,271 & 70,743 \\
\hline COMMERZ & 65,191 & 56,900 & 55,770 & 69,266 & 50,026 & 67,994 & 49,210 & n.a. & 59,180 & 44,880 & 32,660 & 23,250 & 52,212 & 60,858 & 41,836 \\
\hline HYPO & 66,489 & 60,068 & 78,634 & 84,804 & 56,089 & 67,207 & 68,637 & 0 & 25,000 & 17,000 & 18,050 & 12,910 & 50,444 & 68,882 & 28,319 \\
\hline FORTIS & 105,699 & 87,860 & 57,640 & 60,307 & 82,766 & 68,522 & n.a. & n.a. & 2,150 & 2,620 & 2,530 & 2,570 & 47,266 & 77,132 & 2,468 \\
\hline INTESA & 36,657 & 31,916 & 35,400 & 44,249 & 44,398 & 64,423 & 33,975 & 34,586 & n.a. & n.a. & n.a. & n.a. & 40,701 & 42,841 & 34,281 \\
\hline ALMANIJ & 47,735 & 39,979 & 34,662 & 28,575 & 27,128 & 43,366 & 53,842 & n.a. & n.a. & n.a. & n.a. & n.a. & 39,327 & 36,907 & 53,842 \\
\hline ING & 77,115 & 47,905 & 47,662 & 41,087 & 42,126 & 59,516 & 26,071 & 21,783 & 22,000 & 16,850 & 13,840 & 16,320 & 36,023 & 52,568 & 19,477 \\
\hline BGBERLIN & 35,502 & 32,286 & 29,606 & 35,579 & 36,738 & 45,972 & 43,037 & 43,984 & 14,340 & 6,710 & n.a. & n.a. & 32,375 & 35,947 & 27,018 \\
\hline UNICREDIT & 41,404 & 30,915 & 23,319 & 23,173 & 20,100 & 27,181 & 35,089 & n.a. & n.a. & n.a. & n.a. & n.a. & 28,740 & 27,682 & 35,089 \\
\hline BILBAO & 12,129 & 12,371 & 8,691 & 19,582 & 22,621 & 31,674 & 41,493 & 43,787 & 35,430 & 31,930 & 27,030 & 24,580 & 25,943 & 17,845 & 34,042 \\
\hline SANTANDER & 35,994 & 35,630 & 29,007 & 25,513 & n.a. & n.a. & n.a. & n.a. & 28,570 & 20,990 & 17,390 & 12,470 & 25,695 & 31,536 & 19,855 \\
\hline NATEXIS & 54,015 & 38,767 & 14,694 & 14,853 & 23,422 & 7,821 & 8,874 & 20,808 & n.a. & n.a. & n.a. & n.a. & 22,907 & 25,595 & 14,841 \\
\hline CAPITA & 21,622 & 21,410 & 17,360 & 15,500 & 18,592 & 23,072 & 23,793 & 26,081 & n.a. & n.a. & n.a. & n.a. & 20,929 & 19,593 & 24,937 \\
\hline DEPFA & 23,323 & 14,117 & 12,373 & n.a. & n.a. & n.a. & n.a. & n.a. & 4,170 & 4,320 & 3,540 & 4,620 & 9,495 & 16,604 & 4,163 \\
\hline BANESP & 5,461 & 2,521 & 1,804 & 4,663 & 4,965 & 7,802 & 6,486 & 8,069 & 10,470 & 8,410 & 7,920 & 6,940 & 6,293 & 4,536 & 8,049 \\
\hline IRBAN & 4,069 & 5,198 & 5,828 & 4,312 & 4,122 & 6,186 & 6,270 & 4,645 & 3,950 & 4,070 & 3,740 & 2,980 & 4,614 & 4,953 & 4,276 \\
\hline $\mathrm{BCP}$ & 4,724 & 3,515 & 4,104 & 5,531 & 2,376 & 3,568 & 5,951 & n.a. & 7,720 & 4,140 & 2,690 & 1,500 & 4,165 & 3,970 & 4,400 \\
\hline ALPHA & 2,130 & 1,728 & 2,563 & 5,399 & 4,239 & 3,338 & 1,592 & 2,449 & 1,540 & 1,340 & 290 & 390 & 2,250 & 3,233 & 1,267 \\
\hline SAMPO & 1,284 & 2,707 & 1,790 & n.a. & n.a. & n.a. & n.a. & n.a. & n.a. & n.a. & n.a. & n.a. & 1,927 & 1,927 & n.a. \\
\hline PAOLO & 2,323 & 1,681 & 1,262 & 1,528 & 863 & 1,690 & 1,391 & 1,233 & 1,356 & 1,226 & 1,298 & 1,577 & 1,453 & 1,558 & 1,347 \\
\hline Sum & $1,454,021$ & $1,092,053$ & 986,757 & 981,372 & 957,208 & $1,042,172$ & 894,490 & 658,649 & 698,916 & 564,516 & 483,438 & 477,507 & 956,035 & $1,105,375$ & 790,906 \\
\hline
\end{tabular}

Notes: BNP PARIBAS until 1995 BNP. Banks are ordered in declining size of average amounts due from banks over the sample period. n.a. means data not available.

Data source: Bankscope and own calculations. 
Appendix C: Balance sheet data

Table C.4: Due from banks for US banks (million US\$)

\begin{tabular}{|c|c|c|c|c|c|c|c|c|c|c|c|c|c|c|c|}
\hline Bank Name & 2003 & 2002 & 2001 & 2000 & 1999 & 1998 & 1997 & 1996 & 1995 & 1994 & 1993 & 1992 & Average & $\begin{array}{c}\text { Average } \\
1998-2003\end{array}$ & $\begin{array}{c}\text { Average } \\
1992-1997\end{array}$ \\
\hline SSTREET & 21,628 & 28,133 & 20,306 & 21,289 & 16,902 & 12,008 & 10,076 & 7,562 & 5,975 & 4,847 & 5,148 & 4,803 & 13,223 & 20,044 & 6,402 \\
\hline CITIG & 19,777 & 16,382 & 19,216 & 17,274 & 13,429 & 13,425 & n.a. & n.a. & 9,256 & 7,201 & 7,137 & 6,249 & 12,935 & 16,584 & 7,461 \\
\hline JP MORGAN & 10,175 & 8,942 & 12,743 & 8,333 & 28,076 & 7,212 & 2,886 & 8,344 & 1,986 & 1,362 & 1,221 & 1,516 & 7,733 & 12,580 & 2,886 \\
\hline BAMERICA & 8,051 & 6,813 & 5,932 & 5,448 & 4,838 & 6,750 & 2,395 & 1,843 & 5,899 & 6,771 & 2,956 & 2,779 & 5,040 & 6,305 & 3,774 \\
\hline NTRUST & 8,766 & 8,267 & 6,954 & 5,191 & 2,291 & 3,264 & 2,282 & 2,060 & 1,567 & 1,865 & 2,090 & 1,860 & 3,871 & 5,789 & 1,954 \\
\hline BONE & 3,093 & 1,503 & 1,030 & 5,210 & 6,645 & 4,642 & n.a. & n.a. & n.a. & n.a. & n.a. & n.a. & 3,687 & 3,687 & n.a. \\
\hline BNYORK & 7,154 & 4,418 & 5,924 & 4,949 & 6,208 & 4,134 & 1,343 & 809 & 644 & 854 & 652 & 672 & 3,147 & 5,464 & 829 \\
\hline WACHOVIA & 2,308 & 3,512 & 6,875 & 3,239 & 1,073 & 2,916 & 710 & 316 & 451 & 7 & 13 & 190 & 1,801 & 3,321 & 281 \\
\hline MELLON & 2,770 & 1,768 & 4,089 & 2,349 & 657 & 991 & 925 & 790 & 553 & 433 & 889 & 992 & 1,434 & 2,104 & 764 \\
\hline FLEET & 2,695 & 3,679 & 3,744 & 2,826 & 1,772 & 444 & 76 & 858 & 0 & 1,000 & 0 & 0 & 1,425 & 2,527 & 322 \\
\hline UNIONBANK & 235 & 279 & 64 & 74 & 183 & 210 & 629 & 1,131 & 505 & 1,030 & 1,200 & 1,201 & 562 & 174 & 949 \\
\hline PNC & 493 & 518 & 413 & 380 & 207 & 174 & 570 & 145 & 139 & 149 & 233 & 695 & 343 & 364 & 322 \\
\hline CITYCO & 592 & 615 & 120 & 49 & 129 & 141 & 49 & 282 & 51 & 97 & 543 & 1,234 & 325 & 274 & 376 \\
\hline SUTRUST & n.a. & n.a. & n.a. & n.a. & n.a. & n.a. & n.a. & n.a. & 29 & 56 & 476 & 695 & 314 & n.a. & 314 \\
\hline FARGO & 988 & 352 & 206 & 95 & 421 & 113 & 47 & 1,238 & 10 & 7 & 0 & 0 & 290 & 363 & 217 \\
\hline BCORP & n.a. & 434 & 625 & 200 & 897 & 76 & 238 & 50 & 11 & 7 & 33 & 46 & 238 & 446 & 64 \\
\hline COMERICA & 23 & 14 & 43 & 24 & 13 & 8 & 1 & 26 & 1 & 377 & 897 & 1,231 & 221 & 21 & 422 \\
\hline KEYCO & 186 & 112 & 83 & 34 & 35 & 20 & 531 & 217 & 45 & 381 & 14 & 141 & 150 & 78 & 221 \\
\hline REGIONS & n.a. & 304 & 667 & 3 & 10 & 144 & 30 & 33 & 47 & 0 & 11 & 0 & 114 & 226 & 20 \\
\hline BBT & 271 & 148 & 115 & 39 & 71 & 5 & 27 & 1 & 1 & 4 & 7 & n.a. & 63 & 108 & 8 \\
\hline 53BANCO & 58 & 198 & 152 & 109 & 82 & 51 & 27 & 31 & 1 & 11 & 1 & 1 & 60 & 108 & 12 \\
\hline HUNTING & 34 & 37 & 21 & 5 & 7 & 103 & 40 & 2 & 284 & 3 & 13 & 134 & 57 & 34 & 79 \\
\hline WASHING & 17 & 16 & 28 & 18 & 15 & 15 & n.a. & n.a. & n.a. & n.a. & n.a. & n.a. & 18 & 18 & n.a. \\
\hline AMSOUTH & 7 & 28 & 12 & 61 & 24 & 29 & 0 & 0 & 1 & 1 & 1 & 0 & 14 & 27 & 0 \\
\hline SOTRUST & 5 & 4 & 6 & 1 & 0 & 1 & 0 & 0 & n.a. & n.a. & n.a. & n.a. & 2 & 3 & 0 \\
\hline Sum & 89,325 & 86,476 & 89,369 & 77,200 & 83,984 & 56,875 & 22,881 & 25,736 & 27,458 & 26,460 & 23,534 & 24,437 & 57,064 & 80,650 & 27,677 \\
\hline
\end{tabular}

Notes: Comerica until 1995 Comerica Detroit. Banks are ordered in declining size of average amounts due from banks over the sample period. n.a. means data not available.

Data source: Bankscope and own calculations. 
Appendix D: Return and spread data

Table D.1: Moments of euro area returns and correlations with aggregate risk factors

\begin{tabular}{|c|c|c|c|c|c|c|c|c|}
\hline Bank & Mean & $\begin{array}{l}\text { Standard } \\
\text { Deviation }\end{array}$ & Skewness & Kurtosis & $\begin{array}{l}\text { Correlation, } \\
\text { Bank index }\end{array}$ & $\begin{array}{l}\text { Correlation, } \\
\text { Stock index }\end{array}$ & $\begin{array}{l}\text { Correlation, Yield } \\
\text { spread, 1998-2004 }\end{array}$ & $\begin{array}{l}\text { Correlation, } \\
\text { Yield spread }\end{array}$ \\
\hline DEUTSCHE & 0.01 & 2.0 & -0.1 & 4.0 & 76.8 & 69.2 & -2.8 & n.a. \\
\hline HYPO & -0.01 & 2.4 & 0.1 & 6.1 & 65.7 & 57.1 & -5.3 & n.a. \\
\hline DRESDNER & 0.01 & 2.1 & 0.2 & 5.9 & 67.2 & 59.3 & -2.8 & n.a. \\
\hline COMMERZ & 0.00 & 2.0 & 0.2 & 6.9 & 68.2 & 62.3 & -5.3 & n.a. \\
\hline BGBERLIN & -0.06 & 2.4 & -1.4 & 32.8 & 20.4 & 17.6 & -5.1 & n.a. \\
\hline DEPFA & 0.05 & 1.9 & 0.2 & 6.2 & 31.2 & 30.3 & -5.5 & n.a. \\
\hline BNPPAR & 0.03 & 2.2 & 0.1 & 3.7 & 69.8 & 64.1 & -1.3 & n.a. \\
\hline $\mathrm{CA}$ & 0.02 & 1.4 & -0.8 & 21.3 & 29.6 & 25.7 & -2.6 & n.a. \\
\hline SGENER & 0.04 & 2.2 & 0.1 & 3.9 & 72.7 & 66.1 & -1.7 & n.a. \\
\hline NATEXIS & 0.01 & 1.7 & 0.3 & 6.3 & 34.8 & 34.4 & -2.7 & n.a. \\
\hline INTESA & 0.02 & 2.5 & 0.3 & 2.9 & 55.5 & 48.8 & -2.9 & n.a. \\
\hline UNICREDIT & 0.04 & 2.3 & 0.9 & 8.5 & 57.5 & 52.2 & -1.0 & n.a. \\
\hline PAOLO & 0.00 & 2.3 & 0.2 & 2.1 & 65.5 & 59.5 & -4.0 & n.a. \\
\hline CAPITA & -0.04 & 2.6 & 0.3 & 5.2 & 51.4 & 46.5 & -5.0 & n.a. \\
\hline SANTANDER & 0.04 & 2.1 & -0.1 & 5.1 & 74.4 & 69.0 & -1.8 & n.a. \\
\hline BILBAO & 0.04 & 2.0 & 0.0 & 5.5 & 76.6 & 71.4 & -1.3 & n.a. \\
\hline BANESP & -0.02 & 2.4 & -14.5 & 543.2 & 23.3 & 19.9 & -6.4 & n.a. \\
\hline ABNAMRO & 0.04 & 2.0 & -0.1 & 5.3 & 77.7 & 72.5 & -1.3 & n.a. \\
\hline ING & 0.04 & 2.2 & -0.1 & 7.5 & 76.8 & 73.7 & -3.1 & n.a. \\
\hline FORTIS & 0.03 & 2.0 & 0.2 & 8.4 & 68.3 & 63.0 & -1.3 & n.a. \\
\hline ALMANIJ & 0.03 & 1.6 & 0.4 & 5.1 & 48.3 & 44.9 & -1.9 & n.a. \\
\hline ALPHA & 0.03 & 2.1 & 0.4 & 3.7 & 23.4 & 24.3 & -6.1 & n.a. \\
\hline $\mathrm{BCP}$ & 0.00 & 1.5 & -0.2 & 12.2 & 39.4 & 37.6 & -5.3 & n.a. \\
\hline SAMPO & 0.07 & 2.8 & 0.3 & 7.7 & 26.5 & 27.6 & -2.5 & n.a. \\
\hline IRBAN & 0.05 & 1.7 & -0.4 & 7.4 & 44.5 & 43.2 & 1.5 & n.a. \\
\hline POOLED Euro area & 0.02 & 2.1 & -0.7 & 41.2 & & & & \\
\hline Bank index & 0.02 & 0.5 & -0.2 & 5.6 & & & & \\
\hline Stock index & 0.02 & 0.5 & -0.3 & 3.5 & & & & \\
\hline Yield spread, 1998-2004 & 8.05 & 3.2 & 0.6 & -0.7 & & & & \\
\hline
\end{tabular}

Notes: Returns for individual bank stocks are daily excess returns, calculated as total return indices minus 1-month LIBORs. Returns for indices are calculated without substracting LIBOR. Means, standard deviations and correlation coefficients are in \%. Return data series run from 2 April 1992 to 27 February 2004 . n.a. means not Data source: Datastream and own calculations. 
Appendix D: Return and spread data

Table D.2: Moments of US returns and correlations with aggregate risk factors

\begin{tabular}{|c|c|c|c|c|c|c|c|c|}
\hline Bank & Mean & $\begin{array}{l}\text { Standard } \\
\text { Deviation }\end{array}$ & Skewness & Kurtosis & $\begin{array}{l}\text { Correlation, } \\
\text { Bank index }\end{array}$ & $\begin{array}{l}\text { Correlation, } \\
\text { Stock index }\end{array}$ & $\begin{array}{l}\text { Correlation, Yield } \\
\text { spread, 1998-2004 }\end{array}$ & $\begin{array}{l}\text { Correlation, } \\
\text { Yield spread }\end{array}$ \\
\hline CITIG & 0.08 & 2.2 & 0.1 & 4.3 & 80.0 & 68.8 & -0.5 & 0.0 \\
\hline JP MORGAN & 0.04 & 2.3 & 0.1 & 5.0 & 81.2 & 67.1 & -1.5 & -1.3 \\
\hline WACHOVIA & 0.03 & 1.8 & 0.0 & 2.9 & 77.8 & 58.0 & 0.5 & 2.1 \\
\hline FARGO & 0.05 & 1.7 & 0.1 & 2.2 & 74.1 & 54.3 & 0.0 & 1.5 \\
\hline BONE & 0.02 & 1.9 & -0.6 & 13.0 & 74.8 & 56.5 & 0.7 & 1.6 \\
\hline WASHING & 0.06 & 2.1 & 0.3 & 3.8 & 53.0 & 40.3 & 0.8 & 1.6 \\
\hline FLEET & 0.04 & 2.0 & 0.5 & 6.5 & 76.2 & 59.6 & -0.7 & -0.1 \\
\hline BNYORK & 0.05 & 2.1 & 0.0 & 4.7 & 76.8 & 60.4 & -2.6 & -2.1 \\
\hline SSTREET & 0.05 & 2.1 & -0.2 & 6.7 & 67.8 & 57.5 & -1.4 & -1.3 \\
\hline NTRUST & 0.05 & 2.0 & 0.6 & 6.5 & 68.5 & 58.4 & -2.8 & -2.7 \\
\hline MELLON & 0.05 & 2.0 & 0.1 & 3.7 & 76.2 & 60.1 & -1.6 & -0.8 \\
\hline BCORP & 0.07 & 1.9 & 0.5 & 16.4 & 61.8 & 45.7 & -1.0 & 0.6 \\
\hline CITYCO & 0.04 & 1.6 & 0.0 & 3.0 & 75.7 & 56.5 & 0.6 & 2.6 \\
\hline PNC & 0.03 & 1.8 & -0.2 & 5.0 & 77.3 & 59.3 & -0.5 & 0.1 \\
\hline KEYCO & 0.03 & 1.7 & 0.1 & 3.5 & 75.9 & 57.5 & 0.4 & 1.9 \\
\hline SUTRUST & 0.04 & 1.6 & 0.0 & 3.5 & 79.6 & 61.4 & -0.1 & 1.9 \\
\hline COMERICA & 0.03 & 1.7 & -0.7 & 12.0 & 74.0 & 57.3 & -1.8 & -0.5 \\
\hline UNIONBANK & 0.06 & 2.1 & -1.7 & 33.3 & 47.9 & 35.8 & 0.4 & 2.5 \\
\hline AMSOUTH & 0.04 & 1.6 & -0.6 & 14.5 & 65.0 & 48.1 & 1.0 & 3.4 \\
\hline HUNTING & 0.03 & 1.9 & 0.1 & 9.6 & 60.4 & 47.3 & 0.9 & 3.0 \\
\hline BBT & 0.05 & 1.6 & 0.5 & 5.9 & 68.4 & 53.0 & 0.0 & 1.9 \\
\hline 53BANCO & 0.05 & 1.7 & 0.3 & 2.6 & 66.5 & 53.3 & -0.6 & 0.8 \\
\hline SOTRUST & 0.05 & 1.7 & 0.0 & 4.0 & 64.2 & 48.6 & 1.2 & 3.8 \\
\hline REGIONS & 0.03 & 1.7 & 0.0 & 3.2 & 66.2 & 51.1 & 1.2 & 4.3 \\
\hline BAMERICA & 0.04 & 1.9 & -0.2 & 2.8 & 82.8 & 59.1 & 0.7 & 2.0 \\
\hline POOLED US & 0.04 & 1.9 & -0.1 & 8.1 & & & & \\
\hline Bank index & 0.03 & 0.6 & 0.1 & 3.4 & & & & \\
\hline Stock index & 0.02 & 0.5 & -0.1 & 4.1 & & & & \\
\hline Yield spread, 1998-2004 & 6.18 & 1.9 & 0.4 & -0.8 & & & & \\
\hline Yield spread & 5.41 & 1.7 & 1.0 & 0.1 & & & & \\
\hline
\end{tabular}

Notes: Returns for individual bank stocks are daily excess returns, calculated as total return indices minus 1-month LIBORs. Returns for indices are calculated without

substracting LIBOR. Means, standard deviations and correlation coefficients are in \%. Return data series run from 2 April 1992 to 27 February 2004. n.a. means not available. Data source: Datastream and own calculations. 
Appendix D: Return and spread data

Table D.3: Correlations of euro area bank returns

DEUTSCHE HYPO DRESDNER COMMERZ BGBERLIN DEPFA BNPPAR CA SGENER NATEXIS INTESA UNICREDIT PAOLO CAPITA SANTANDER BILBAO BANESP ING ABNAMRO FORTIS ALMANIJ ALPHA BCP SAMPO IRBAN

\begin{tabular}{|c|c|c|c|c|c|c|c|c|c|c|c|c|c|c|c|c|c|c|c|c|c|c|c|c|c|}
\hline DEUTSCHE & 100.0 & 60.8 & 67.6 & 64.8 & 16.8 & 24.7 & 48.6 & 19.5 & 52.6 & 24.2 & 33.6 & 35.9 & 43.1 & 31.9 & 48.0 & 49.1 & 12.6 & 55.9 & 56.2 & 47.7 & 33.8 & 17.1 & 27.9 & 17.4 & 27.1 \\
\hline HYPO & 60.8 & 100.0 & 56.4 & 62.0 & 14.7 & 21.0 & 40.8 & 21.8 & 43.1 & 19.9 & 33.1 & 29.9 & 40.0 & 28.8 & 39.8 & 42.3 & 10.2 & 48.5 & 47.1 & 42.0 & 28.4 & 15.1 & 25.5 & 13.9 & 23.6 \\
\hline DRESDNER & 67.6 & 56.4 & 100.0 & 61.3 & 13.6 & 21.5 & 42.9 & 19.1 & 43.6 & 22.0 & 31.9 & 28.1 & 37.3 & 25.2 & 42.4 & 43.8 & 13.6 & 50.0 & 49.6 & 43.9 & 31.0 & 15.0 & 25.7 & 17.3 & 23.5 \\
\hline COMMERZ & 64.8 & 62.0 & 61.3 & 100.0 & 16.3 & 24.2 & 42.4 & 21.7 & 43.7 & 21.2 & 32.7 & 32.0 & 39.8 & 30.9 & 43.5 & 45.9 & 11.9 & 51.7 & 49.6 & 45.4 & 28.5 & 14.8 & 25.8 & 15.5 & 24.5 \\
\hline BGBERLIN & 16.8 & 14.7 & 13.6 & 16.3 & 100.0 & 11.6 & 11.9 & 2.7 & 12.5 & 7.1 & 9.3 & 8.9 & 8.6 & 7.8 & 13.8 & 12.1 & 3.0 & 12.0 & 10.0 & 9.4 & 7.6 & 7.4 & 9.6 & 9.3 & 13.3 \\
\hline DEPFA & 24.7 & 21.0 & 21.5 & 24.2 & 11.6 & 100.0 & 19.1 & 11.4 & 21.8 & 14.3 & 13.6 & 15.8 & 16.4 & 11.0 & 19.3 & 20.7 & 5.8 & 24.3 & 22.9 & 21.8 & 17.7 & 9.1 & 14.1 & 13.2 & 19.1 \\
\hline BNPPAR & 48.6 & 40.8 & 42.9 & 42.4 & 11.9 & 19.1 & 100.0 & 25.0 & 66.1 & 31.1 & 34.8 & 37.4 & 42.8 & 33.9 & 49.8 & 51.0 & 16.7 & 54.2 & 52.8 & 46.3 & 29.9 & 14.2 & 25.4 & 19.0 & 30.3 \\
\hline CA & 19.5 & 21.8 & 19.1 & 21.7 & 2.7 & 11.4 & 25.0 & 100.0 & 25.0 & 12.3 & 15.4 & 10.4 & 19.3 & 11.3 & 20.2 & 22.2 & 5.3 & 28.2 & 24.7 & 26.0 & 15.9 & 4.8 & 10.3 & 6.0 & 11.8 \\
\hline SGENER & 52.6 & 43.1 & 43.6 & 43.7 & 12.5 & 21.8 & 66.1 & 25.0 & 100.0 & 29.9 & 34.1 & 38.9 & 44.1 & 32.9 & 51.3 & 52.5 & 15.4 & 57.2 & 55.3 & 48.8 & 32.7 & 17.3 & 24.9 & 19.6 & 33.8 \\
\hline NATEXIS & 24.2 & 19.9 & 22.0 & 21.2 & 7.1 & 14.3 & 31.1 & 12.3 & 29.9 & 100.0 & 16.5 & 18.5 & 21.1 & 13.4 & 24.2 & 26.4 & 9.8 & 27.1 & 27.7 & 21.7 & 15.5 & 10.7 & 16.1 & 13.4 & 18.7 \\
\hline INTESA & 33.6 & 33.1 & 31.9 & 32.7 & 9.3 & 13.6 & 34.8 & 15.4 & 34.1 & 16.5 & 100.0 & 46.5 & 49.3 & 48.1 & 36.3 & 38.1 & 11.1 & 39.6 & 37.9 & 36.8 & 23.7 & 11.9 & 20.5 & 15.3 & 22.1 \\
\hline UNICREDIT & 35.9 & 29.9 & 28.1 & 32.0 & 8.9 & 15.8 & 37.4 & 10.4 & 38.9 & 18.5 & 46.5 & 100.0 & 50.5 & 48.3 & 35.7 & 39.5 & 12.3 & 40.1 & 40.6 & 34.6 & 23.6 & 9.0 & 18.4 & 13.6 & 21.9 \\
\hline PAOLO & 43.1 & 40.0 & 37.3 & 39.8 & 8.6 & 16.4 & 42.8 & 19.3 & 44.1 & 21.1 & 49.3 & 50.5 & 100.0 & 47.6 & 46.1 & 47.9 & 12.2 & 48.6 & 48.5 & 41.3 & 27.4 & 12.3 & 24.4 & 17.3 & 26.0 \\
\hline CAPITA & 31.9 & 28.8 & 25.2 & 30.9 & 7.8 & 11.0 & 33.9 & 11.3 & 32.9 & 13.4 & 48.1 & 48.3 & 47.6 & 100.0 & 34.3 & 36.6 & 9.5 & 34.6 & 33.3 & 30.7 & 19.6 & 5.6 & 16.2 & 13.9 & 20.8 \\
\hline SANTANDER & 48.0 & 39.8 & 42.4 & 43.5 & 13.8 & 19.3 & 49.8 & 20.2 & 51.3 & 24.2 & 36.3 & 35.7 & 46.1 & 34.3 & 100.0 & 76.8 & 22.3 & 55.1 & 55.7 & 46.6 & 30.3 & 17.0 & 29.7 & 18.9 & 30.8 \\
\hline BILBAO & 49.1 & 42.3 & 43.8 & 45.9 & 12.1 & 20.7 & 51.0 & 22.2 & 52.5 & 26.4 & 38.1 & 39.5 & 47.9 & 36.6 & 76.8 & 100.0 & 21.1 & 56.0 & 56.4 & 48.9 & 32.9 & 18.0 & 31.0 & 18.5 & 30.6 \\
\hline BANESP & 12.6 & 10.2 & 13.6 & 11.9 & 3.0 & 5.8 & 16.7 & 5.3 & 15.4 & 9.8 & 11.1 & 12.3 & 12.2 & 9.5 & 22.3 & 21.1 & 100.0 & 12.5 & 13.0 & 11.0 & 6.4 & 5.1 & 10.8 & 5.8 & 9.0 \\
\hline ABNAMRO & 56.2 & 47.1 & 49.6 & 49.6 & 10.0 & 22.9 & 52.8 & 24.7 & 55.3 & 27.7 & 37.9 & 40.6 & 48.5 & 33.3 & 55.7 & 56.4 & 13.0 & 73.7 & 100.0 & 59.1 & 40.0 & 18.1 & 28.5 & 19.1 & 33.6 \\
\hline ING & 55.9 & 48.5 & 50.0 & 51.7 & 12.0 & 24.3 & 54.2 & 28.2 & 57.2 & 27.1 & 39.6 & 40.1 & 48.6 & 34.6 & 55.1 & 56.0 & 12.5 & 100.0 & 73.7 & 65.1 & 42.3 & 18.7 & 29.9 & 21.7 & 35.7 \\
\hline FORTIS & 47.7 & 42.0 & 43.9 & 45.4 & 9.4 & 21.8 & 46.3 & 26.0 & 48.8 & 21.7 & 36.8 & 34.6 & 41.3 & 30.7 & 46.6 & 48.9 & 11.0 & 65.1 & 59.1 & 100.0 & 45.0 & 17.3 & 24.3 & 19.1 & 30.0 \\
\hline ALMANIJ & 33.8 & 28.4 & 31.0 & 28.5 & 7.6 & 17.7 & 29.9 & 15.9 & 32.7 & 15.5 & 23.7 & 23.6 & 27.4 & 19.6 & 30.3 & 32.9 & 6.4 & 42.3 & 40.0 & 45.0 & 100.0 & 12.5 & 20.4 & 15.9 & 23.7 \\
\hline ALPHA & 17.1 & 15.1 & 15.0 & 14.8 & 7.4 & 9.1 & 14.2 & 4.8 & 17.3 & 10.7 & 11.9 & 9.0 & 12.3 & 5.6 & 17.0 & 18.0 & 5.1 & 18.7 & 18.1 & 17.3 & 12.5 & 100.0 & 14.4 & 13.1 & 13.9 \\
\hline $\mathrm{BCP}$ & 27.9 & 25.5 & 25.7 & 25.8 & 9.6 & 14.1 & 25.4 & 10.3 & 24.9 & 16.1 & 20.5 & 18.4 & 24.4 & 16.2 & 29.7 & 31.0 & 10.8 & 29.9 & 28.5 & 24.3 & 20.4 & 14.4 & 100.0 & 13.1 & 19.2 \\
\hline SAMPO & 17.4 & 13.9 & 17.3 & 15.5 & 9.3 & 13.2 & 19.0 & 6.0 & 19.6 & 13.4 & 15.3 & 13.6 & 17.3 & 13.9 & 18.9 & 18.5 & 5.8 & 21.7 & 19.1 & 19.1 & 15.9 & 13.1 & 13.1 & 100.0 & 20.4 \\
\hline IRBAN & 27.1 & 23.6 & 23.5 & 24.5 & 13.3 & 19.1 & 30.3 & 11.8 & 33.8 & 18.7 & 22.1 & 21.9 & 26.0 & 20.8 & 30.8 & 30.6 & 9.0 & 35.7 & 33.6 & 30.0 & 23.7 & 13.9 & 19.2 & 20.4 & 100.0 \\
\hline
\end{tabular}

Notes: Correlation coefficients between individual banks are in \%. Return data series run from 2 April 1992 to 27 February 2004. n.a. means not available.

Data source: Datastream and own calculations. 
Appendix D: Return and spread data

Table D.4: Correlations of US bank returns

\begin{tabular}{|c|c|c|c|c|c|c|c|c|c|c|c|c|c|c|c|c|c|c|c|c|c|c|c|c|c|}
\hline CITIG & 100.0 & 64.8 & 55.9 & 51.7 & 52.6 & 38.1 & 55.7 & 55.8 & 51.6 & 50.6 & 55.0 & 41.2 & 53.0 & 54.4 & 53.2 & 56.5 & 51.7 & 33.5 & 46.1 & 41.1 & 50.0 & 47.0 & 45.0 & 44.3 & 61.0 \\
\hline JP MORGAN & 64.8 & 100.0 & 59.2 & 54.6 & 56.7 & 39.3 & 60.9 & 61.2 & 52.7 & 52.1 & 60.7 & 43.4 & 56.4 & 58.1 & 56.8 & 58.2 & 55.6 & 33.7 & 47.9 & 44.4 & 50.3 & 47.5 & 46.1 & 48.6 & 64.7 \\
\hline WACHOVIA & 55.9 & 59.2 & 100.0 & 56.6 & 60.2 & 40.5 & 60.0 & 56.9 & 50.0 & 51.8 & 58.6 & 48.6 & 61.2 & 61.6 & 61.9 & 64.5 & 59.2 & 38.4 & 51.3 & 48.5 & 55.0 & 51.7 & 48.8 & 51.5 & 65.9 \\
\hline FARGO & 51.7 & 54.6 & 56.6 & 100.0 & 53.0 & 41.5 & 55.2 & 57.4 & 50.7 & 48.8 & 56.7 & 46.2 & 58.4 & 59.6 & 58.3 & 63.0 & 55.7 & 33.6 & 48.7 & 42.9 & 52.5 & 51.1 & 49.0 & 49.6 & 60.4 \\
\hline BONE & 52.6 & 56.7 & 60.2 & 53.0 & 100.0 & 40.7 & 55.2 & 55.5 & 50.2 & 49.1 & 55.6 & 45.0 & 58.2 & 59.4 & 57.5 & 61.4 & 54.8 & 35.2 & 47.4 & 44.5 & 50.0 & 48.5 & 45.8 & 49.2 & 59.7 \\
\hline WASHING & 38.1 & 39.3 & 40.5 & 41.5 & 40.7 & 100.0 & 39.3 & 40.7 & 39.1 & 40.6 & 41.6 & 35.1 & 43.9 & 44.2 & 45.1 & 43.9 & 42.4 & 27.4 & 37.5 & 34.1 & 41.9 & 41.7 & 41.5 & 40.3 & 41.2 \\
\hline FLEET & 55.7 & 60.9 & 60.0 & 55.2 & 55.2 & 39.3 & 100.0 & 59.6 & 51.4 & 52.8 & 60.5 & 48.9 & 60.6 & 60.4 & 59.0 & 62.6 & 59.6 & 36.8 & 52.2 & 46.7 & 53.8 & 51.0 & 49.0 & 52.3 & 59.3 \\
\hline BNYORK & 55.8 & 61.2 & 56.9 & 57.4 & 55.5 & 40.7 & 59.6 & 100.0 & 58.0 & 59.1 & 63.4 & 49.2 & 58.4 & 61.6 & 59.5 & 63.7 & 59.7 & 35.7 & 50.6 & 46.9 & 54.5 & 52.2 & 47.9 & 51.8 & 60.1 \\
\hline SSTREET & 51.6 & 52.7 & 50.0 & 50.7 & 50.2 & 39.1 & 51.4 & 58.0 & 100.0 & 59.8 & 58.1 & 45.3 & 51.4 & 53.5 & 50.6 & 56.2 & 51.8 & 33.9 & 46.6 & 43.8 & 46.3 & 49.5 & 44.4 & 47.2 & 52.4 \\
\hline NTRUST & 50.6 & 52.1 & 51.8 & 48.8 & 49.1 & 40.6 & 52.8 & 59.1 & 59.8 & 100.0 & 55.3 & 48.4 & 51.7 & 54.9 & 52.7 & 54.4 & 53.1 & 37.2 & 48.2 & 46.6 & 50.0 & 51.9 & 46.9 & 49.8 & 49.9 \\
\hline MELLON & 55.0 & 60.7 & 58.6 & 56.7 & 55.6 & 41.6 & 60.5 & 63.4 & 58.1 & 55.3 & 100.0 & 48.6 & 59.1 & 62.9 & 60.5 & 63.5 & 57.7 & 37.0 & 51.5 & 45.1 & 53.8 & 50.1 & 50.7 & 52.9 & 60.5 \\
\hline BCORP & 41.2 & 43.4 & 48.6 & 46.2 & 45.0 & 35.1 & 48.9 & 49.2 & 45.3 & 48.4 & 48.6 & 100.0 & 49.9 & 51.0 & 49.5 & 50.3 & 48.8 & 33.4 & 45.6 & 44.0 & 48.7 & 43.1 & 45.3 & 46.5 & 46.2 \\
\hline CITYCO & 53.0 & 56.4 & 61.2 & 58.4 & 58.2 & 43.9 & 60.6 & 58.4 & 51.4 & 51.7 & 59.1 & 49.9 & 100.0 & 62.3 & 63.0 & 65.9 & 60.6 & 36.9 & 54.6 & 49.0 & 54.1 & 53.1 & 52.7 & 54.4 & 61.3 \\
\hline PNC & 54.4 & 58.1 & 61.6 & 59.6 & 59.4 & 44.2 & 60.4 & 61.6 & 53.5 & 54.9 & 62.9 & 51.0 & 62.3 & 100.0 & 64.0 & 66.2 & 62.2 & 36.7 & 52.7 & 47.8 & 55.7 & 53.2 & 52.3 & 53.8 & 62.0 \\
\hline KEYCO & 53.2 & 56.8 & 61.9 & 58.3 & 57.5 & 45.1 & 59.0 & 59.5 & 50.6 & 52.7 & 60.5 & 49.5 & 63.0 & 64.0 & 100.0 & 66.2 & 63.1 & 37.4 & 52.7 & 51.1 & 57.1 & 53.9 & 53.4 & 55.9 & 59.3 \\
\hline SUTRUST & 56.5 & 58.2 & 64.5 & 63.0 & 61.4 & 43.9 & 62.6 & 63.7 & 56.2 & 54.4 & 63.5 & 50.3 & 65.9 & 66.2 & 66.2 & 100.0 & 64.1 & 40.0 & 55.6 & 48.9 & 56.9 & 55.5 & 53.7 & 57.2 & 64.7 \\
\hline COMERICA & 51.7 & 55.6 & 59.2 & 55.7 & 54.8 & 42.4 & 59.6 & 59.7 & 51.8 & 53.1 & 57.7 & 48.8 & 60.6 & 62.2 & 63.1 & 64.1 & 100.0 & 37.7 & 53.7 & 50.0 & 55.9 & 54.1 & 51.4 & 55.6 & 58.6 \\
\hline UNIONBANK & 33.5 & 33.7 & 38.4 & 33.6 & 35.2 & 27.4 & 36.8 & 35.7 & 33.9 & 37.2 & 37.0 & 33.4 & 36.9 & 36.7 & 37.4 & 40.0 & 37.7 & 100.0 & 37.2 & 31.8 & 35.6 & 31.7 & 36.6 & 35.2 & 38.4 \\
\hline AMSOUTH & 46.1 & 47.9 & 51.3 & 48.7 & 47.4 & 37.5 & 52.2 & 50.6 & 46.6 & 48.2 & 51.5 & 45.6 & 54.6 & 52.7 & 52.7 & 55.6 & 53.7 & 37.2 & 100.0 & 46.1 & 51.1 & 45.5 & 48.9 & 52.0 & 50.3 \\
\hline HUNTING & 41.1 & 44.4 & 48.5 & 42.9 & 44.5 & 34.1 & 46.7 & 46.9 & 43.8 & 46.6 & 45.1 & 44.0 & 49.0 & 47.8 & 51.1 & 48.9 & 50.0 & 31.8 & 46.1 & 100.0 & 49.2 & 46.7 & 48.0 & 47.8 & 46.2 \\
\hline BBT & 50.0 & 50.3 & 55.0 & 52.5 & 50.0 & 41.9 & 53.8 & 54.5 & 46.3 & 50.0 & 53.8 & 48.7 & 54.1 & 55.7 & 57.1 & 56.9 & 55.9 & 35.6 & 51.1 & 49.2 & 100.0 & 52.5 & 51.7 & 52.0 & 52.5 \\
\hline 53BANCO & 47.0 & 47.5 & 51.7 & 51.1 & 48.5 & 41.7 & 51.0 & 52.2 & 49.5 & 51.9 & 50.1 & 43.1 & 53.1 & 53.2 & 53.9 & 55.5 & 54.1 & 31.7 & 45.5 & 46.7 & 52.5 & 100.0 & 49.4 & 49.5 & 48.8 \\
\hline SOTRUST & 45.0 & 46.1 & 48.8 & 49.0 & 45.8 & 41.5 & 49.0 & 47.9 & 44.4 & 46.9 & 50.7 & 45.3 & 52.7 & 52.3 & 53.4 & 53.7 & 51.4 & 36.6 & 48.9 & 48.0 & 51.7 & 49.4 & 100.0 & 52.0 & 49.4 \\
\hline REGIONS & 44.3 & 48.6 & 51.5 & 49.6 & 49.2 & 40.3 & 52.3 & 51.8 & 47.2 & 49.8 & 52.9 & 46.5 & 54.4 & 53.8 & 55.9 & 57.2 & 55.6 & 35.2 & 52.0 & 47.8 & 52.0 & 49.5 & 52.0 & 100.0 & 51.2 \\
\hline BAMERICA & 61.0 & 64.7 & 65.9 & 60.4 & 59.7 & 41.2 & 59.3 & 60.1 & 52.4 & 49.9 & 60.5 & 46.2 & 61.3 & 62.0 & 59.3 & 64.7 & 58.6 & 38.4 & 50.3 & 46.2 & 52.5 & 48.8 & 49.4 & 51.2 & 100.0 \\
\hline
\end{tabular}

Notes: Correlation coefficients between individual banks are in \%. Return data series run from 2 April 1992 to 27 February 2004. n.a. means not available.

Data source: Datastream and own calculations. 


\section{Appendix E. Results For GARCH-Filtered DATA}

A widely recognized feature of financial market returns is volatility clustering (see, e.g., Bollerslev, Chou and Kroner, 1992). So, a question that comes to mind is to which extent the extreme dependence between bank stock returns and its changes we discover in this paper is associated with changes in volatility. In this appendix we therefore reproduce the results of the paper for return data that are filtered of conditional heteroskedasticity.

Before providing some answers to this question, we need to first establish the relationship between the filtered data and the objectives of our paper. The main objective of our work is to measure systemic risk in banking on the basis of market data. The amount of systemic risk in banking is instrumental for the assessment of financial stability and for the design of policies to preserve the stability of financial systems, such as banking regulation and crisis management.

The indicators of banking system stability we are using are designed to satisfy the demand by policy makers who need to have a view about the likelihood of crises and who need to devise the best financial regulations to preserve financial stability. To assess system stability banking supervisors need to know how likely it is that one or several banks break down given that other banks break down or how likely it is that one or several banks break down given that there is an adverse macroeconomic shock. They are not interested in two-sided volatility of bank stock returns per se or in its persistence. In addition, banking regulations are determined in advance for longer periods of time. They cannot be changed within a few days. So, they need to be based on long-term structural risk assessments and not on the likelihood of volatility tomorrow given today's volatility. This is why for the questions we are interested in straight returns are preferable to volatility of returns and unconditional modelling is preferable to conditional models. In contrast, conditional models will be preferable for short-term volatility forecasting, as today's volatility is informative for tomorrow's volatility. This type of analysis maybe more important for short-term pricing of financial instruments.

Although the indicators (2.1) and (2.2) are the right ones for answering the questions of interest in this paper, we may learn from unclustered return data more about the statistical components of spillover and extreme systematic risk in banking. For example, Poon et al. (2004) argue that conditional heteroskedasticity is an important source of extreme dependence in stock markets in general, but not the only one. 
So, in this appendix we ask to which extent the extreme dependence of bank stock returns uncovered above results from univariate volatility clustering or multivariate dependence in volatilities. The next subsection reports the multivariate spillover probabilities (2.1) for unclustered return data and the subsequent one the tail- $\beta$ estimations (2.2). The filter used in both cases is a standard $\operatorname{GARCH}(1,1)$ process.

E.1. Bank contagion risk. Tables E.1 through E.5 reproduce tables $3,4,5,9$ and 10 in the main text for GARCH-filtered returns. While extreme dependence generally tends to decrease, the qualitative results are quite similar to the ones for plain bank returns. Only very few of the spillover risk changes in Europe (table 9) seem to be entirely related to volatility clustering. But clustering plays more of a role in the differences between domestic and cross-border spillovers (table 4). Multivariate spillover risk in the US and Europe, as well as its changes over time seem little related to volatility clustering (tables 5 and 10). This is also confirmed by the dotted lines in figures 1 and 2, which describe the same stastics as the solid lines for GARCH-filtered returns.

[Insert tables E.1, E.2, E.3, E.4 and E.5 about here]

E.2. Aggregate banking system risk. Tables E.6 through E.10 reproduce tables $6,7,8,11$ and 12 in the main text for unclustered returns. As for the spillover risk above, dependencies generally decrease, but none of the qualitative results is fundamentally changed. Again this is also confirmed by the dotted lines in figure 3, which illustrate the more muted changes in GARCH-filtered tail- $\beta$ s and the same direction of their movements.

Overall, we can conclude that in line with the results of Poon et al. (2004) for stock markets in general, part of the extreme dependencies in bank stock returns we find in this paper are related to time-varying volatility and volatility clustering. From the little exercise in this appendix we can not ascertain whether this phenomenon is related to the marginal distributions or to multivariate dependence of volatilities. Nevertheless, the primary results that supervisors should pay attention to in order to assess general banking system stability and decide upon regulatory policies are the unadjusted spillover and systematic risk probabilities.

[Insert tables E.6, E.7, E.8, E.9 and E.10 about here] 
TABLE E.1. Domestic versus cross-border extreme spillover risk among euro area banks for GARCH-filtered data: Estimations

\begin{tabular}{|c|c|c|c|c|c|}
\hline \multirow[t]{2}{*}{ Largest bank } & $\widehat{P}_{1}$ & $\widehat{P}_{2}$ & $\widehat{P}_{3}$ & $\widehat{P}_{4}$ & $\widehat{P}_{5}$ \\
\hline & \multicolumn{5}{|c|}{ Conditioning banks: German } \\
\hline Germany & 12.3 & 63.7 & 70.7 & 57.0 & 35.0 \\
\hline Netherlands & 5.1 & 23.3 & 35.9 & 6.3 & 19.4 \\
\hline France & 1.6 & 20.7 & 32.1 & 9.4 & 10.3 \\
\hline Spain & 1.8 & 12.1 & 14.4 & 8.9 & 31.0 \\
\hline Italy & 1.5 & 3.7 & 6.6 & 1.2 & 5.5 \\
\hline Belgium & 3.1 & 18.0 & 18.7 & 6.5 & 4.2 \\
\hline Ireland & 1.9 & 4.2 & 7.4 & 7.4 & 19.8 \\
\hline Portugal & 1.4 & 6.7 & 11.2 & 5.6 & 8.3 \\
\hline Finland & 0.6 & 2.5 & 5.4 & 1.0 & 3.3 \\
\hline \multirow[t]{2}{*}{ Greece } & 0.7 & 0.9 & 2.5 & 0.2 & 0.8 \\
\hline & \multicolumn{5}{|c|}{ Conditioning banks: French } \\
\hline France & 1.4 & 30.2 & 6.6 & & \\
\hline Germany & 0.4 & 15.0 & 3.0 & & \\
\hline Netherlands & 1.6 & 14.8 & 7.7 & & \\
\hline Italy & 0.7 & 5.3 & 1.7 & & \\
\hline Spain & 1.3 & 23.4 & 5.2 & & \\
\hline Belgium & 0.9 & 12.0 & 4.3 & & \\
\hline Ireland & 0.8 & 3.2 & 3.0 & & \\
\hline Portugal & 1.0 & 4.9 & 10.1 & & \\
\hline Finland & 0.1 & 0.6 & 1.5 & & \\
\hline \multirow[t]{2}{*}{ Greece } & 0.2 & 0.7 & 0.3 & & \\
\hline & \multicolumn{5}{|c|}{ Conditioning banks: Italian } \\
\hline Italy & 3.2 & 13.4 & 18.9 & & \\
\hline Germany & 2.4 & 8.8 & 7.6 & & \\
\hline Netherlands & 1.5 & 10.2 & 8.2 & & \\
\hline Spain & 1.1 & 9.1 & 3.7 & & \\
\hline France & 1.2 & 6.6 & 2.4 & & \\
\hline Belgium & 1.1 & 5.5 & 2.5 & & \\
\hline Ireland & 1.1 & 2.3 & 3.6 & & \\
\hline Portugal & 0.5 & 1.1 & 1.9 & & \\
\hline Finland & 0.4 & 1.4 & 1.5 & & \\
\hline \multirow[t]{2}{*}{ Greece } & $1.6 \mathrm{E}-0.2$ & 0.3 & 0.6 & & \\
\hline & \multicolumn{5}{|c|}{ Conditioning banks: Spanish } \\
\hline Spain & 21.6 & 13.5 & & & \\
\hline Germany & 3.8 & 3.0 & & & \\
\hline Netherlands & 6.4 & 6.8 & & & \\
\hline France & 7.0 & 7.8 & & & \\
\hline Italy & 0.8 & 1.9 & & & \\
\hline Belgium & 3.6 & 1.5 & & & \\
\hline Ireland & 2.7 & 1.9 & & & \\
\hline Portugal & 1.4 & 0.6 & & & \\
\hline Finland & 0.3 & 0.5 & & & \\
\hline Greece & 0.5 & 0.4 & & & \\
\hline
\end{tabular}

Note: The table shows the same results as table 3 in the main text for data that have been filtered for volatility clustering. The returns used here are the residuals of a $\operatorname{GARCH}(1,1)$ process fitted on the original excess returns. The table reports estimated extreme spillover probabilities between banks, as defined in (2.1). Each column $\widehat{P}_{j}$ shows the spillover probabilities for the largest bank of the country mentioned on the left-hand side conditional on a set of banks $j$ from either the same country or other countries. The number of conditioning banks varies from 1 to 5 for Germany (top panel), 1 to 3 for France (upper middle panel), 1 to 3 for Italy (lower middle panel) and 1 to 2 for Spain (bottom panel). For example, the $\widehat{P}_{2}$ column contains probabilities for a stock market crash of the largest bank in each country, conditional on crashes of the 2nd and 3rd largest bank in Germany, France, Italy or Spain. All probabilities are estimated with the extension of the approach by Ledford and Tawn (1996) described in section 3 and reported in \%. Univariate crash probabilities (crisis levels) are set to $p=0.05 \%$. 
TABLE E.2. Domestic versus cross-border extreme spillover risk among euro area banks for GARCH-filtered data: Tests

\begin{tabular}{|c|c|c|c|c|c|}
\hline \multirow[t]{2}{*}{ Largest bank } & $T_{1}$ & $T_{2}$ & $T_{3}$ & $T_{4}$ & $T_{5}$ \\
\hline & \multicolumn{5}{|c|}{ Conditioning banks: German } \\
\hline Netherlands & 1.49 & 1.56 & 0.84 & 0.81 & 0.11 \\
\hline France & $* * * 3.30$ & 1.23 & 0.30 & 0.51 & 1.06 \\
\hline Spain & $* * * 2.93$ & $* * 2.11$ & -0.18 & -0.28 & 0.29 \\
\hline Italy & $* * * 2.82$ & $* * * 3.75$ & -0.35 & -0.13 & -0.50 \\
\hline Belgium & $* * 2.07$ & 1.55 & 0.46 & -0.26 & -0.76 \\
\hline Ireland & $* * 2.47$ & $* * * 3.34$ & -1.54 & 1.20 & 0.91 \\
\hline Portugal & $* * * 3.06$ & $* * * 3.71$ & 0.46 & 1.31 & 0.29 \\
\hline Finland & $* * * 4.21$ & $* * * 2.67$ & -1.55 & -0.10 & -0.83 \\
\hline \multirow[t]{2}{*}{ Greece } & $* * * 3.59$ & $* * * 4.12$ & $* * *_{-} 3.15$ & -1.31 & -0.61 \\
\hline & \multicolumn{5}{|c|}{ Conditioning banks: French } \\
\hline Germany & $* * 2.02$ & -0.49 & 0.85 & & \\
\hline Netherlands & -0.25 & 1.25 & 1.37 & & \\
\hline Spain & 0.07 & -0.84 & 0.22 & & \\
\hline Italy & 0.84 & -1.53 & -0.03 & & \\
\hline Belgium & 0.63 & 0.84 & 1.28 & & \\
\hline Ireland & 0.58 & $* * *-3.34$ & -1.39 & & \\
\hline Portugal & 0.36 & -1.50 & 1.13 & & \\
\hline Finland & $* * * 2.91$ & $* * *-4.22$ & $* *_{-}-2.21$ & & \\
\hline \multirow[t]{2}{*}{ Greece } & $* * 2.29$ & $* * *-3.76$ & $* * * \_2.77$ & & \\
\hline & \multicolumn{3}{|c|}{ Conditioning banks: Italian } & & \\
\hline Germany & 0.26 & 0.28 & -0.09 & & \\
\hline Netherlands & 1.18 & 1.06 & 0.21 & & \\
\hline Spain & 1.51 & -0.59 & -0.27 & & \\
\hline France & 1.32 & 0.28 & -0.09 & & \\
\hline Belgium & 1.25 & -0.52 & -0.72 & & \\
\hline Ireland & 1.07 & -0.75 & -1.00 & & \\
\hline Portugal & $* * 2.01$ & -0.65 & -1.42 & & \\
\hline Finland & $* * 2.54$ & -0.90 & -1.47 & & \\
\hline \multirow[t]{2}{*}{ Greece } & $* * * 3.36$ & -1.86 & $* *_{-} 2.20$ & & \\
\hline & \multirow{2}{*}{\multicolumn{3}{|c|}{$\begin{array}{l}\text { Conditioning banks: Spanish } \\
* * * 288\end{array}$}} & & \\
\hline Germany & & & & & \\
\hline Netherlands & $* * 2.17$ & -0.30 & & & \\
\hline France & $* 1.82$ & -0.05 & & & \\
\hline Italy & $* * * 4.35$ & -0.57 & & & \\
\hline Belgium & $* * * 2.84$ & -0.62 & & & \\
\hline Ireland & $* * * 2.82$ & -0.91 & & & \\
\hline Portugal & $* * * 4.03$ & -0.77 & & & \\
\hline Finland & $* * * 5.55$ & -1.05 & & & \\
\hline Greece & $* * * 4.47$ & -1.29 & & & \\
\hline
\end{tabular}

Note: The table shows the same results as table 4 in the main text for data that have been filtered for volatility clustering. The returns used here are the residuals of a $\operatorname{GARCH}(1,1)$ process fitted on the original excess returns. The table reports the statistics for the cross sectional test (4.5). Within each panel the degree of extreme domestic spillover risk is compared with the degree of extreme cross-border spillover risk for a given fixed number of conditioning banks. So, each T-statistic describes whether the differences between domestic and cross-border values of $\eta$ that entered the estimations in table 3 are statistically significant. For example, in the top panel the test statistic in the row "Netherlands" and the column $T_{1}$ indicates whether the difference between the $\eta$ for the spillover probability between ABN AMRO and HypoVereinsbank and the $\eta$ between Deutsche Bank and HypoVereinsbank is statistically signifcant. The null hypothesis is that the respective two $\eta \mathrm{s}$ are equal. Insignificant T-statistics imply that the domestic and cross-border spillover risks are indistinguishable. A significant rejection with positive sign implies that cross-border spillover risk is statistically smaller than its domestic counterpart; and a rejection with negative sign implies that cross-border risk is larger than domestic risk. The critical values of the test are 1.65, 1.96 and 2.58 for the $10 \%, 5 \%$ and $1 \%$ levels, respectively. Asterisks $*,{ }^{* *}$ and ${ }^{* * *}$ indicate rejections of the null hypothesis at $10 \%, 5 \%$ and $1 \%$ significance. 
TABLE E.3. Domestic and cross-border extreme spillover risk among euro area banks for GARCH-filtered data: Time variation

\begin{tabular}{|c|c|c|c|c|c|}
\hline \multirow[t]{2}{*}{ Largest bank } & $\widehat{\eta}_{1}$ & $\widehat{\eta}_{2}$ & $\widehat{\eta}_{3}$ & $\widehat{\eta}_{4}$ & $\widehat{\eta}_{5}$ \\
\hline & \multicolumn{5}{|c|}{ Conditioning banks: German } \\
\hline Germany & - & - & - & $9 / 30 / 98(2.8)$ & - \\
\hline Netherlands & $4 / 14 / 00(6.1)$ & $9 / 9 / 97(3.8)$ & $8 / 27 / 01(5.6)$ & - & $10 / 27 / 97(2.6)$ \\
\hline France & - & $9 / 11 / 97(8.9)$ & $9 / 9 / 97(7.8)$ & $8 / 15 / 97(6.0)$ & $8 / 15 / 97(3.9)$ \\
\hline Spain & $3 / 31 / 97(2.8)$ & $10 / 22 / 97(6.8)$ & $10 / 16 / 97(6.2)$ & $8 / 27 / 97(2.4)$ & $1 / 22 / 99(6.5)$ \\
\hline Italy & $10 / 24 / 97(16.9)$ & $9 / 9 / 97(8.6)$ & $1 / 20 / 94(8.6)$ & $8 / 21 / 97(6.6)$ & $10 / 24 / 97(5.6)$ \\
\hline Belgium & $8 / 4 / 98(8.7)$ & $2 / 28 / 01(6.2)$ & $1 / 19 / 94(3.5)$ & - & $10 / 22 / 97(3.0)$ \\
\hline Ireland & $10 / 22 / 97(5.0)$ & $10 / 22 / 97(2.2)$ & - & - & $10 / 24 / 97(2.2)$ \\
\hline Portugal & $2 / 4 / 94(5.3)$ & $2 / 4 / 94(10.9)$ & $1 / 25 / 94(21.7)$ & $8 / 28 / 97(5.2)$ & $10 / 22 / 97(2.1)$ \\
\hline Finland & $10 / 22 / 97(5.4)$ & $6 / 6 / 94(15.0)$ & $6 / 6 / 94(31.9)$ & $10 / 16 / 97(12.1)$ & $7 / 23 / 97(6.7)$ \\
\hline \multirow[t]{2}{*}{ Greece } & $5 / 29 / 97(14.1)$ & $5 / 29 / 97(8.7)$ & $5 / 29 / 97(10.3)$ & $8 / 15 / 97(8.3)$ & - \\
\hline & \multicolumn{5}{|c|}{ Conditioning banks: French } \\
\hline France & $10 / 10 / 00(26.5)$ & $1 / 25 / 02(32.6)$ & $6 / 7 / 95(34.0)$ & & \\
\hline Germany & $10 / 9 / 00(22.4)$ & $11 / 21 / 00(29.3)$ & $12 / 11 / 01(33.8)$ & & \\
\hline Netherlands & $10 / 9 / 00(17.8)$ & $9 / 20 / 00(39.5)$ & $10 / 22 / 97(44.0)$ & & \\
\hline Italy & $2 / 19 / 01(10.2)$ & $10 / 24 / 97(44.3)$ & $8 / 22 / 97(50.8)$ & & \\
\hline Spain & $10 / 10 / 00(11.4)$ & $9 / 19 / 00(27.3)$ & $10 / 22 / 97(37.9)$ & & \\
\hline Belgium & $2 / 21 / 01(15.1)$ & $2 / 3 / 94(68.2)$ & $8 / 4 / 98(67.2)$ & & \\
\hline Ireland & $9 / 20 / 00(3.1)$ & $2 / 1 / 94(19.2)$ & $12 / 7 / 01(13.4)$ & & \\
\hline Portugal & $10 / 12 / 00(5.5)$ & $10 / 10 / 00(27.6)$ & $6 / 19 / 97(34.3)$ & & \\
\hline Finland & $4 / 14 / 00(3.9)$ & $5 / 31 / 94(49.2)$ & $3 / 1 / 96(43.2)$ & & \\
\hline \multirow[t]{2}{*}{ Greece } & $8 / 4 / 98(10.2)$ & $7 / 23 / 98(27.3)$ & $12 / 7 / 01(34.2)$ & & \\
\hline & \multicolumn{3}{|c|}{ Conditioning banks: Italian } & & \\
\hline Italy & - & - & - & & \\
\hline Germany & $7 / 31 / 97(4.6)$ & 10/8/97 (10.1) & $9 / 9 / 97(5.5)$ & & \\
\hline Netherlands & $8 / 4 / 98(3.4)$ & $8 / 7 / 97(17.7)$ & $8 / 6 / 97(11.8)$ & & \\
\hline Spain & $8 / 5 / 98(2.9)$ & $4 / 22 / 98(16.2)$ & $10 / 8 / 97(8.8)$ & & \\
\hline France & $8 / 7 / 98(3.5)$ & $4 / 15 / 94(4.6)$ & $4 / 21 / 94(9.1)$ & & \\
\hline Belgium & $6 / 18 / 97(17.4)$ & $10 / 8 / 97(25.2)$ & $10 / 8 / 97(15.1)$ & & \\
\hline Ireland & - & $2 / 21 / 94(6.1)$ & $2 / 21 / 94(7.6)$ & & \\
\hline Portugal & $2 / 21 / 94(7.4)$ & $8 / 1 / 97(11.9)$ & $2 / 21 / 94(12.4)$ & & \\
\hline Finland & - & $6 / 13 / 94(9.0)$ & $6 / 17 / 94(7.4)$ & & \\
\hline \multirow[t]{2}{*}{ Greece } & $2 / 12 / 97(10.3)$ & $9 / 9 / 97(16.9)$ & $9 / 9 / 97(22.7)$ & & \\
\hline & \multicolumn{3}{|c|}{ Conditioning banks: Spanish } & & \\
\hline Spain & $10 / 1 / 97(7.2)$ & $1 / 14 / 99(3.4)$ & & & \\
\hline Germany & $2 / 24 / 97(10.0)$ & $3 / 31 / 99(4.4)$ & & & \\
\hline Netherlands & $10 / 8 / 97(4.9)$ & $3 / 9 / 99(6.5)$ & & & \\
\hline France & $10 / 22 / 97(9.2)$ & $1 / 14 / 99(5.9)$ & & & \\
\hline Italy & $9 / 10 / 97(3.4)$ & $1 / 25 / 99(6.3)$ & & & \\
\hline Belgium & $11 / 26 / 96(10.5)$ & $2 / 4 / 94(3.0)$ & & & \\
\hline Ireland & $12 / 10 / 96(6.3)$ & $3 / 8 / 99(5.1)$ & & & \\
\hline Portugal & $9 / 10 / 97(15.5)$ & $6 / 27 / 97(6.0)$ & & & \\
\hline Finland & $10 / 16 / 97(3.6)$ & $3 / 3 / 99(4.0)$ & & & \\
\hline Greece & $5 / 15 / 97(16.7)$ & $2 / 27 / 97(9.5)$ & & & \\
\hline
\end{tabular}

Note: The table shows the same results as table 9 in the main text for data that have been filtered for volatility clustering. The returns used here are the residuals of a $\operatorname{GARCH}(1,1)$ process fitted on the original excess returns. The table reports the results of tests examining the structural stability of the extreme spillover risks documented in table E.1. This is done by testing for the constancy of the $\eta$ tail dependence parameters (null hypothesis) that govern the spillover probabilities in table E.1. Applying the recursive test (4.1) through (4.4) by Quintos et al. (2001), each cell shows the endogenously found break date and the test value in parentheses. Dates are denoted $\mathrm{XX} / \mathrm{YY} / \mathrm{ZZ}$, where $\mathrm{XX}=$ month, $\mathrm{YY}=$ day and $\mathrm{ZZ}=$ year. The critical values of the test are $1.46,1.78$ and 2.54 for the $10 \%, 5 \%$ and $1 \%$ levels, respectively. A test value exceeding these numbers implies an increase in extreme dependence over time. The absence of a break over the sample period is marked with a dash. 
TABLE E.4. Multivariate extreme spillover risk among euro area and US banks for GARCH-filtered data

\begin{tabular}{|c|c|c|c|c|}
\hline \multicolumn{2}{|c|}{ Country/Area } & \multicolumn{2}{|c|}{ Estimations } & \multirow{2}{*}{$\begin{array}{c}\text { Cross-sectional } \\
\text { test } T\end{array}$} \\
\hline & & $\widehat{\eta}$ & $P$ & \\
\hline United States & $(N=25)$ & 0.32 & $4.7 \mathrm{E}-6$ & $\overline{H_{0}: \eta_{U S}}$ \\
\hline Euro area & $(N=25)$ & 0.17 & $3.9 \mathrm{E}-15$ & $T=$ \\
\hline Germany & $(N=6)$ & 0.38 & $2.3 \mathrm{E}-4$ & \\
\hline France & $(N=4)$ & 0.50 & $2.6 \mathrm{E}-2$ & \\
\hline Italy & $(N=4)$ & 0.58 & $2.7 \mathrm{E}-0.3$ & \\
\hline
\end{tabular}

Note: The table shows the same results as table 5 in the main text for data that have been filtered for volatility clustering. The returns used here are the residuals of a $\mathrm{GARCH}(1,1)$ process fitted on the original excess returns. The table reports in the column $\widehat{\eta}$ the coefficient that governs the multivariate extreme tail dependence for all the banks of the countries/areas detailed on the left-hand side. In the column $\widehat{P}$ it shows the probabililty that all banks of a specific country/area crash given that one of them crashes. Both statistics are estimates of system-wide extreme spillover risks. Univariate crash probabilities (crisis levels) are set to $p=0.05 \%$. The right-hand column describes the cross-sectional test (4.5) for the whole US and euro area banking systems. A positive (negative) test statistic indicates that the US (euro area) $\eta$ is larger than the euro area (US) $\eta$. The critical values of the test are 1.65, 1.96 and 2.58 for the $10 \%, 5 \%$ and $1 \%$ levels, respectively. Note that $\eta$ values for countries/areas with different numbers of banks may not be comparable. 
TABLE E.5. Multivariate extreme spillover risk among euro area and US banks for GARCH-filtered data: Time variation

\begin{tabular}{lcccc}
\hline \hline \multicolumn{2}{c}{ Country/Area } & Full sample & \multicolumn{2}{c}{ Second sub-sample break tests } \\
\cline { 3 - 5 } & break test & Endogenous & Exogenous \\
\hline \multicolumn{2}{l}{ United States $(N=25)$} & $11 / 13 / 95(4.8)$ & - & n.a. \\
Euro area & $(N=25)$ & $12 / 5 / 96(4.9)$ & $(\mathrm{B}) 1 / 18 / 99(5.3)$ & $(1.5)$ \\
\hline Germany & $(N=6)$ & - & - & $(1.6)$ \\
\multirow{2}{*}{ France } & $(N=4)$ & $6 / 7 / 95(19.1)$ & $11 / 27 / 01(23.7)$ & $(-2.8)$ \\
Italy & $(N=4)$ & $(\mathrm{B}) 3 / 4 / 97(4.6)$ & $(\mathrm{B}) 8 / 25 / 00(3.8)$ & \\
\hline \hline
\end{tabular}

Note: The table shows the same results as table 10 in the main text for data that have been filtered for volatility clustering. The returns used here are the residuals of a $\operatorname{GARCH}(1,1)$ process fitted on the original excess returns. The table reports tests and estimations assessing time variation in the multivariate spillover probabilities of table E.4. The column on the left displays estimated break dates and values from the recursive Quintos et al. (2001) test (4.1) through (4.4) applied to the $\eta$ parameter governing the extreme tail dependence of the banks located in the countries/areas displayed on the extreme left. Dates are denoted $\mathrm{XX} / \mathrm{YY} / \mathrm{ZZ}$, where $\mathrm{XX}=$ month, $\mathrm{YY}=$ day and $\mathrm{ZZ}=$ year. The forward recursive version of the test is used, unless marked otherwise. (B) marks the backward recursive version of the test. The critical values of the test are 1.46, 1.78 and 2.54 for the $10 \%, 5 \%$ and $1 \%$ levels, respectively. The middle columns show pre- and post-break estimates for $\eta$. The columns on the right display two tests that assess the occurrence of further breaks in the second half of the sample. The first one is the same as the one on the left-hand side. The second one is a simple differences-in-means test based on (4.5). The exogenous break point is chosen to be $1 / 1 / 99$, the time of the introduction of the euro. Critical values for this test are 1.65, 1.96 and 2.58 for the $10 \%, 5 \%$ and $1 \%$ significance levels. Note that $\eta$ values for countries/areas with different numbers of banks may not be comparable. 
TABle E.6. Extreme systematic risk (tail- $\beta \mathrm{s}$ ) of euro area banks for GARCH-filtered data

\begin{tabular}{lrrrrr}
\hline \hline \multirow{2}{*}{ Bank } & \multicolumn{5}{c}{ Aggregate risk factor } \\
\cline { 2 - 5 } & Bank index & Stock index & Global bank & Global stock & Yield spread \\
\hline DEUTSCHE & 34.3 & 19.1 & 8.1 & 4.2 & $9.0 \mathrm{E}-6$ \\
HYPO & 12.7 & 6.9 & 1.7 & 1.2 & $3.0 \mathrm{E}-2$ \\
DRESDNER & 20.1 & 17.3 & 7.1 & 3.7 & $7.7 \mathrm{E}-3$ \\
COMMERZ & 14.8 & 11.0 & 3.0 & 1.9 & $6.9 \mathrm{E}-2$ \\
BGBERLIN & 2.0 & 1.4 & 0.6 & 0.4 & $7.3 \mathrm{E}-2$ \\
DEPFA & 2.1 & 2.1 & 0.7 & 0.9 & $6.2 \mathrm{E}-2$ \\
BNPPAR & 12.7 & 8.5 & 5.3 & 3.6 & $3.9 \mathrm{E}-2$ \\
CA & 2.2 & 1.4 & 0.4 & 0.6 & 0.2 \\
SGENERAL & 19.3 & 11.8 & 5.8 & 4.2 & $4.8 \mathrm{E}-2$ \\
NATEXIS & 0.8 & 1.0 & 1.5 & 0.7 & $3.5 \mathrm{E}-2$ \\
INTESA & 4.6 & 3.5 & 1.7 & 1.9 & $1.7 \mathrm{E}-0.2$ \\
UNICREDIT & 4.3 & 3.7 & 3.6 & 2.2 & $6.8 \mathrm{E}-2$ \\
PAOLO & 10.7 & 10.8 & 4.3 & 2.9 & $6.0 \mathrm{E}-2$ \\
CAPITA & 6.1 & 5.5 & 2.3 & 2.6 & 0.1 \\
SANTANDER & 9.8 & 10.9 & 4.5 & 3.4 & $7.0 \mathrm{E}-2$ \\
BILBAO & 16.0 & 11.6 & 6.0 & 5.3 & $7.0 \mathrm{E}-2$ \\
BANESP & 1.5 & 0.9 & 0.6 & 0.3 & $2.0 \mathrm{E}-3$ \\
ING & 22.7 & 23.4 & 8.5 & 4.2 & $8.5 \mathrm{E}-2$ \\
ABNAMRO & 14.3 & 12.3 & 6.7 & 3.6 & $4.5 \mathrm{E}-2$ \\
FORTIS & 17.2 & 10.1 & 4.9 & 2.7 & $2.2 \mathrm{E}-2$ \\
ALMANIJ & 2.7 & 3.1 & 1.8 & 1.0 & $8.5 \mathrm{E}-2$ \\
ALPHA & 1.9 & 2.5 & 0.9 & 0.6 & $2.2 \mathrm{E}-2$ \\
BCP & 4.0 & 3.2 & 2.3 & 1.3 & 0.1 \\
SAMPO & 1.6 & 1.9 & 0.6 & 0.5 & $3.8 \mathrm{E}-2$ \\
IRBAN & 6.3 & 6.5 & 2.0 & 1.7 & $1.8 \mathrm{E}-2$ \\
\hline \multicolumn{1}{c}{ average } & 9.8 & 7.6 & 3.4 & 2.2 & $6.5 \mathrm{E}-2$ \\
\multicolumn{1}{c}{ st. dev. } & 8.5 & 6.1 & 2.5 & 1.5 & $4.4 \mathrm{E}-2$ \\
\hline \hline
\end{tabular}

Note: The table shows the same results as table 6 in the main text for data that have been filtered for volatility clustering. The returns used here are the residuals of a $\operatorname{GARCH}(1,1)$ process fitted on the original excess returns. The table exhibits the estimates of extreme systematic risk (2.2) (tail- $\beta$ s) for individual euro area banks and for the euro area banking system as a whole. The entries show the probability that a given bank crashes given that a market indicator of aggregate risk crashes (or in the case of the yield spread booms). Results are reported for five different aggregate risk factors: The euro area banking sector sub-index, the euro area stock index, the world banking sector sub-index, the world stock index and the euro area high-yield bond spread. Data for the euro area yield spread are only available from 1998 to 2004. All probabilities are estimated with the extension of the approach by Ledford and Tawn (1996) described in section 3 and reported in \%. Univariate crash probabilities (crisis levels) are set to $p=0.05 \%$. The average and the standard deviation at the bottom of the table are calculated over the 25 individual tail- $\beta \mathrm{s}$ in the upper rows, respectively. 
TABlE E.7. Extreme systematic risk (tail- $\beta \mathrm{s}$ ) of US banks for GARCH-filtered data

\begin{tabular}{|c|c|c|c|c|c|}
\hline \multirow[t]{2}{*}{ Bank } & \multicolumn{5}{|c|}{ Aggregate risk factor } \\
\hline & Bank index & Stock index & Global bank & Global stock & Yield spread \\
\hline CITIG & 32.6 & 24.8 & 6.3 & 11.7 & $6.9 \mathrm{E}-2$ \\
\hline JPMORGAN & 24.9 & 9.0 & 3.3 & 4.9 & 0.1 \\
\hline $\mathrm{BOA}$ & 28.2 & 12.4 & 5.9 & 7.2 & 0.2 \\
\hline WACHO & 25.2 & 10.5 & 4.1 & 5.2 & 0.2 \\
\hline FARGO & 14.6 & 7.5 & 4.5 & 6.5 & $4.1 \mathrm{E}-2$ \\
\hline BONEC & 27.1 & 12.6 & 3.6 & 6.0 & 0.1 \\
\hline WASHMU & 9.8 & 4.5 & 2.3 & 2.4 & 0.1 \\
\hline FLEET & 15.2 & 13.9 & 5.4 & 6.4 & 0.2 \\
\hline BNYORK & 17.5 & 9.5 & 4.9 & 7.1 & 0.1 \\
\hline STATEST & 16.0 & 14.3 & 7.2 & 10.3 & 0.4 \\
\hline NOTRUST & 14.6 & 9.9 & 4.2 & 5.6 & 0.2 \\
\hline MELLON & 25.0 & 19.6 & 5.7 & 10.2 & 0.3 \\
\hline USBANC & 10.9 & 3.8 & 3.5 & 2.4 & $6.4 \mathrm{E}-2$ \\
\hline CITYCO & 24.9 & 11.8 & 4.7 & 7.0 & $9.9 \mathrm{E}-2$ \\
\hline $\mathrm{PNC}$ & 14.6 & 10.4 & 5.3 & 6.9 & 0.1 \\
\hline KEYCO & 23.6 & 11.0 & 2.3 & 4.9 & $8.8 \mathrm{E}-2$ \\
\hline SUNTRUST & 19.7 & 15.4 & 5.7 & 8.9 & 0.2 \\
\hline COMERICA & 24.3 & 14.0 & 4.7 & 7.3 & 0.2 \\
\hline UNIONBAN & 5.9 & 2.7 & 2.3 & 2.8 & 0.1 \\
\hline AMSOUTH & 10.5 & 6.5 & 6.6 & 4.5 & 0.2 \\
\hline HUNTING & 10.4 & 5.5 & 4.3 & 3.3 & 0.1 \\
\hline BBT & 9.8 & 5.0 & 4.1 & 4.2 & 0.1 \\
\hline $53 \mathrm{BANCO}$ & 11.2 & 5.9 & 2.0 & 2.5 & $9.7 \mathrm{E}-2$ \\
\hline SOTRUST & 12.6 & 4.3 & 3.0 & 2.6 & 0.1 \\
\hline RFCORP & 11.4 & 9.5 & 3.8 & 4.5 & 0.2 \\
\hline average & 17.6 & 78.4 & 4.4 & 5.8 & 0.1 \\
\hline st. dev. & 7.3 & 4.7 & 1.4 & 2.6 & $7.1 \mathrm{E}-2$ \\
\hline
\end{tabular}

Note: The table shows the same results as table 7 in the main text for data that have been filtered for volatility clustering. The returns used here are the residuals of a GARCH $(1,1)$ process fitted on the original excess returns. The table exhibits the estimates of extreme systematic risk (2.2) (tail- $\beta \mathrm{s}$ ) for individual US banks and for the US banking system as a whole. The entries show the probability that a given bank crashes given that a market indicator of aggregate risk crashes (or in the case of the yield spread booms). Results are reported for five different aggregate risk factors: The US banking sector sub-index, the US stock index, the world banking sector sub-index, the world stock index and the US high-yield bond spread. All probabilities are estimated with the extension of the approach by Ledford and Tawn (1996) described in section 3 and reported in \%. Univariate crash probabilities (crisis levels) are set to $p=0.05 \%$. The average and the standard deviation at the bottom of the table are calculated over the 25 individual tail- $\beta \mathrm{s}$ in the upper rows, respectively. 
TABle E.8. Comparisons of extreme systematic risk across different banking systems for GARCH-filtered data

\begin{tabular}{cccccc}
\hline \hline & \multicolumn{5}{c}{ Aggregate risk factor } \\
\cline { 2 - 6 } Banking system & Bank index & Stock index & Global bank & Global stock & Yield spread \\
\hline $\bar{\eta}_{U S}$ & 0.83 & 0.78 & 0.72 & 0.74 & 0.53 \\
$\bar{\eta}_{E A}$ & 0.76 & 0.74 & 0.69 & 0.67 & 0.50 \\
\hline $\bar{\eta}_{F R}$ & 0.74 & 0.71 & 0.69 & 0.67 & 0.50 \\
$\bar{\eta}_{G E}$ & 0.79 & 0.76 & 0.69 & 0.66 & 0.50 \\
$\bar{\eta}_{I T}$ & 0.74 & 0.74 & 0.70 & 0.69 & 0.53 \\
\hline Null hypothesis & & & & & 0.71 \\
\hline $\bar{\eta}_{U S}=\bar{\eta}_{E A}$ & $* * 2.09$ & 1.25 & 0.85 & $* * 2.28$ & 0.72 \\
$\bar{\eta}_{U S}=\bar{\eta}_{F R}$ & $* * 2.25$ & $* * 1.99$ & 1.12 & $* * 2.35$ & 0.87 \\
$\bar{\eta}_{U S}=\bar{\eta}_{G E}$ & 0.91 & 0.56 & 1.16 & $* * 2.72$ & 0.19 \\
$\bar{\eta}_{U S}=\bar{\eta}_{I T}$ & $* 1.92$ & 1.14 & 0.54 & 1.60 & \\
\hline \hline
\end{tabular}

Note: The table shows the same results as table 9 in the main text for data that have been filtered for volatility clustering. The returns used here are the residuals of a $\operatorname{GARCH}(1,1)$ process fitted on the original excess returns. The table exhibits the average tail dependence parameters $\eta$ that govern the tail- $\beta$ estimates reported in tables E. 6 and E. 7 for the US, euro area, French, German and Italian banking system (upper panel) and the statistics of tests examining differences in extreme systematic risk between the US and euro area banking systems (lower panel). Each $\bar{\eta}$ is calculated as the mean of tail- $\beta$ dependence parameters across all the banks in our sample for the respective country/area. The tests are applications of the cross-sectional test (4.5). The null hypothesis is that extreme systematic risk in the US banking system is the same as in the other banking systems. A positive (negative) test statistic indicates that extreme systematic risk in the US banking system (in the respective euro area banking system) is larger than in the respective euro area (US) banking system. The critical values of the test are 1.65, 1.96 and 2.58 for the $10 \%, 5 \%$ and $1 \%$ levels, respectively. All results are reported for the five different aggregate risk factors: The euro area/US banking sector sub-index, the euro area/US stock index, the world banking sector sub-index, the world stock index and the euro area/US high-yield bond spread. Univariate crash probabilities (crisis levels) are set to $p=0.05 \%$. 
TABle E.9. Extreme systematic risk (tail- $\beta$ s) of euro area banks for GARCH-filtered data: Time variation

\begin{tabular}{|c|c|c|c|c|c|}
\hline \multirow[t]{2}{*}{ Bank } & \multicolumn{5}{|c|}{ Aggregate risk factor } \\
\hline & EMU banks & EMU stocks & World Banks & World Stocks & Yield spread \\
\hline$\overline{\text { DEUTSCHE }}$ & $10 / 8 / 97(2.9)$ & - & $12 / 3 / 96(7.0)$ & $12 / 3 / 96(4.3)$ & $9 / 14 / 00(139.5)$ \\
\hline HYPO & - & - & $3 / 13 / 98(3.3)$ & $10 / 22 / 97(7.1)$ & $10 / 4 / 00(135.7)$ \\
\hline DRESDNER & - & $12 / 5 / 96(1.9)$ & $12 / 3 / 96(9.6)$ & $12 / 5 / 96(8.5)$ & $9 / 13 / 00(123.3)$ \\
\hline COMMERZ & - & - & - & $10 / 22 / 97(4.5)$ & $8 / 22 / 00(158.6)$ \\
\hline BGBERLIN & - & $2 / 27 / 97(1.9)$ & 2/6/97 (2.8) & $2 / 24 / 97(3.3)$ & $9 / 27 / 00(188.4)$ \\
\hline DEPFA & $7 / 4 / 96(5.1)$ & $9 / 21 / 95(4.4)$ & - & $9 / 21 / 95(4.8)$ & $9 / 13 / 00(118.2)$ \\
\hline BNPPAR & $10 / 8 / 97(3.8)$ & $10 / 8 / 97(5.2)$ & $8 / 28 / 97(6.8)$ & $8 / 26 / 97(5.2)$ & $9 / 15 / 00(128.5)$ \\
\hline $\mathrm{CA}$ & $10 / 10 / 00(17.4)$ & $10 / 5 / 00(13.3)$ & 2/19/01 (12.4) & $9 / 19 / 00(11.9)$ & $7 / 21 / 00(133.2)$ \\
\hline SGENERAL & $10 / 22 / 97(3.3)$ & - & $12 / 5 / 96(8.0)$ & $12 / 5 / 96(6.6)$ & $9 / 21 / 00(152.9)$ \\
\hline NATEXIS & - & - & $10 / 27 / 97(3.9)$ & $8 / 28 / 97(5.8)$ & $7 / 21 / 00(172.7)$ \\
\hline INTESA & - & $7 / 4 / 96(3.2)$ & - & $9 / 10 / 97(2.8)$ & $7 / 24 / 00(142.9)$ \\
\hline UNICREDIT & $8 / 1 / 97(1.8)$ & - & $9 / 9 / 97(5.6)$ & $10 / 22 / 97(4.9)$ & $8 / 15 / 00(168.0)$ \\
\hline PAOLO & $9 / 9 / 97(2.6)$ & $2 / 4 / 94(4.5)$ & $9 / 25 / 97(7.1)$ & $9 / 9 / 97(6.9)$ & $8 / 17 / 00(186.1)$ \\
\hline CAPITA & - & - & $9 / 9 / 97(3.9)$ & $9 / 10 / 97(3.3)$ & $9 / 15 / 00(141.8)$ \\
\hline SANTANDER & $10 / 8 / 97(4.3)$ & $12 / 5 / 96(9.1)$ & $12 / 10 / 96(9.1)$ & $12 / 10 / 96(7.3)$ & $9 / 12 / 00(162.0)$ \\
\hline BILBAO & $10 / 22 / 97(6.7)$ & $11 / 26 / 96(9.3)$ & $12 / 10 / 96(13.1)$ & $10 / 8 / 97(24.7)$ & $10 / 3 / 00(172.9)$ \\
\hline BANESP & - & - & - & - & $7 / 6 / 00(33.1)$ \\
\hline ING & - & - & 8/21/97 (13.3) & $7 / 5 / 96(8.4)$ & $9 / 11 / 00(144.6)$ \\
\hline ABNAMRO & $8 / 4 / 98(3.3)$ & $7 / 12 / 96(4.0)$ & $7 / 4 / 96(8.1)$ & $7 / 4 / 96(4.5)$ & $9 / 15 / 00(136.5)$ \\
\hline FORTIS & $2 / 16 / 96(5.6)$ & - & $7 / 17 / 97(14.8)$ & $7 / 3 / 97(6.7)$ & $9 / 14 / 00(127.0)$ \\
\hline ALMANIJ & $8 / 8 / 97(5.2)$ & $3 / 8 / 96(4.8)$ & $6 / 1 / 94(8.5)$ & $9 / 21 / 94(13.3)$ & $9 / 21 / 00(234.4)$ \\
\hline ALPHA & $2 / 27 / 97(19.3)$ & $5 / 29 / 97(18.0)$ & $2 / 26 / 97(12.0)$ & $7 / 3 / 97(19.1)$ & $7 / 26 / 00(92.5)$ \\
\hline $\mathrm{BCP}$ & $1 / 31 / 94(5.4)$ & $2 / 4 / 94(8.6)$ & $2 / 4 / 94(10.7)$ & $2 / 4 / 94(16.5)$ & $8 / 31 / 00(106.7)$ \\
\hline SAMPO & $5 / 20 / 94(3.6)$ & $5 / 20 / 94(3.2)$ & $12 / 18 / 97(4.6)$ & $12 / 17 / 97(2.5)$ & $8 / 1 / 00(209.2)$ \\
\hline IRBAN & $6 / 6 / 96(2.4)$ & - & - & - & $9 / 29 / 00(106.3)$ \\
\hline
\end{tabular}

Note: The table shows the same results as table 11 in the main text for data that have been filtered for volatility clustering. The returns used here are the residuals of a $\operatorname{GARCH}(1,1)$ process fitted on the original excess returns. The table reports the results of tests examining the structural stability of the extreme systematic risks of euro area banks documented in table E.6. This is done by testing for the constancy of the $\eta$ tail dependence parameters (null hypothesis) that govern the tail- $\beta \mathrm{s}$ in table E.6. Applying the recursive test (4.1) through (4.4) by Quintos et al. (2001), each cell shows the endogenously found break date and the test value in parentheses. Dates are denoted XX/YY/ZZ, where $\mathrm{XX}=$ month, $\mathrm{YY}=$ day and $\mathrm{ZZ}=$ year. The critical values of the test are 1.46, 1.78 and 2.54 for the $10 \%, 5 \%$ and $1 \%$ levels, respectively. A test value exceeding these numbers implies an increase in extreme dependence over time. The absence of a break over the sample period is marked with a dash. 
TABLE E.10. Extreme systematic risk (tail- $\beta \mathrm{s}$ ) of US banks for GARCH-filtered data: Time variation

\begin{tabular}{lcrrrr}
\hline \hline \multirow{2}{*}{ Bank } & \multicolumn{5}{c}{ Aggregate risk factor } \\
\cline { 2 - 6 } & Bank index & \multicolumn{1}{c}{ Stock index } & Global bank & \multicolumn{1}{c}{ Global stock } & \multicolumn{1}{c}{ Yield spread } \\
\hline CITIG & - & - & $7 / 4 / 96(7.7)$ & $11 / 18 / 94(8.4)$ & $10 / 24 / 00(97.9)$ \\
JPMORGAN & - & - & $2 / 19 / 96(3.6)$ & $1 / 8 / 96(3.3)$ & $10 / 16 / 00(74.8)$ \\
BOA & - & $4 / 1 / 96(5.4)$ & $12 / 5 / 96(13.6)$ & $2 / 15 / 96(11.8)$ & $9 / 26 / 00(65.7)$ \\
WACHO & - & - & $9 / 16 / 94(8.7)$ & $12 / 4 / 95(5.2)$ & $10 / 16 / 00(66.4)$ \\
FARGO & $3 / 7 / 96(2.9)$ & - & $9 / 21 / 95(7.2)$ & $1 / 8 / 96(5.6)$ & $9 / 28 / 00(35.3)$ \\
BONEC & $9 / 15 / 95(2.2)$ & $10 / 19 / 95(3.8)$ & $10 / 23 / 95(7.1)$ & $6 / 5 / 95(9.0)$ & $10 / 20 / 00(78.8)$ \\
WASHMU & $3 / 1 / 96(1.8)$ & $2 / 26 / 96(2.2)$ & $2 / 27 / 97(10.8)$ & $2 / 23 / 96(7.2)$ & $12 / 13 / 00(57.6)$ \\
FLEET & $12 / 6 / 95(2.1)$ & $3 / 12 / 97(7.7)$ & $10 / 7 / 97(13.7)$ & $1 / 9 / 96(12.2)$ & $10 / 5 / 00(52.3)$ \\
BNYORK & - & $1 / 8 / 96(1.9)$ & $7 / 4 / 96(10.6)$ & $1 / 8 / 96(13.9)$ & $9 / 22 / 00(49.5)$ \\
STATEST & $12 / 15 / 95(12.9)$ & $12 / 15 / 95(11.9)$ & $9 / 29 / 95(12.1)$ & $9 / 15 / 95(7.5)$ & $10 / 11 / 00(139.1)$ \\
NOTRUST & $12 / 3 / 96(6.1)$ & $12 / 15 / 95(4.2)$ & $10 / 7 / 97(3.3)$ & $12 / 5 / 96(5.7)$ & $9 / 29 / 00(60.3)$ \\
MELLON & $9 / 15 / 95(2.8)$ & $10 / 19 / 95(4.2)$ & $9 / 9 / 97(7.7)$ & $11 / 18 / 94(10.2)$ & $10 / 16 / 00(90.3)$ \\
USBANC & $12 / 15 / 95(5.4)$ & $12 / 11 / 95(2.1)$ & $10 / 13 / 97(9.2)$ & $9 / 15 / 95(8.0)$ & $2 / 19 / 01(58.3)$ \\
CITYCO & $12 / 10 / 96(2.4)$ & $12 / 2 / 96(4.7)$ & $1 / 8 / 96(9.6)$ & $12 / 15 / 95(11.4)$ & $10 / 5 / 00(37.7)$ \\
PNC & $3 / 7 / 96(2.2)$ & $10 / 19 / 95(5.5)$ & $7 / 4 / 96(18.8)$ & $10 / 20 / 95(14.5)$ & $11 / 9 / 00(39.4)$ \\
KEYCO & - & $10 / 24 / 95(3.1)$ & $6 / 19 / 96(2.4)$ & $10 / 24 / 95(7.1)$ & $1 / 1 / 01(44.7)$ \\
SUNTRUST & $10 / 6 / 95(5.3)$ & $12 / 4 / 95(5.1)$ & $10 / 24 / 95(8.7)$ & $10 / 24 / 95(16.9)$ & $12 / 5 / 00(42.4)$ \\
COMERICA & - & $1 / 8 / 96(2.3)$ & $7 / 4 / 96(7.0)$ & $9 / 15 / 95(10.2)$ & $10 / 4 / 00(61.1)$ \\
UNIONBAN & $6 / 27 / 97(6.3)$ & $3 / 4 / 98(5.4)$ & $1 / 5 / 98(2.9)$ & $1 / 5 / 98(6.5)$ & $10 / 25 / 00(32.3)$ \\
AMSOUTH & $11 / 13 / 95(3.4)$ & $12 / 4 / 95(4.3)$ & $12 / 10 / 96(7.7)$ & $1 / 5 / 96(4.4)$ & $10 / 17 / 00(54.5)$ \\
HUNTING & $2 / 4 / 97(5.9)$ & $1 / 22 / 97(8.2)$ & $2 / 27 / 97(9.1)$ & $1 / 22 / 97(9.3)$ & $10 / 5 / 00(50.5)$ \\
BBT & $3 / 6 / 96(4.7)$ & $7 / 20 / 98(7.2)$ & $5 / 22 / 98(14.0)$ & $3 / 7 / 96(8.1)$ & $10 / 5 / 00(35.5)$ \\
$53 B A N C O$ & $1 / 2 / 96(2.3)$ & $12 / 13 / 95(1.3)$ & $1 / 8 / 96(9.1)$ & $12 / 7 / 95(3.9)$ & $10 / 17 / 00(44.5)$ \\
SOTRUST & $2 / 26 / 97(10.6)$ & $6 / 17 / 96(9.2)$ & $7 / 4 / 96(9.0)$ & $3 / 7 / 96(7.0)$ & $11 / 21 / 00(41.1)$ \\
RFCORP & $3 / 7 / 96(4.1)$ & $2 / 23 / 96(12.3)$ & $12 / 5 / 96(9.2)$ & $2 / 23 / 96(12.7)$ & $9 / 20 / 00(46.4)$ \\
\hline \hline
\end{tabular}

Note: The table shows the same results as table 12 in the main text for data that have been filtered for volatility clustering. The returns used here are the residuals of a $\operatorname{GARCH}(1,1)$ process fitted on the original excess returns. The table reports the results of tests examining the structural stability of the extreme systematic risks of US banks documented in table E.7. This is done by testing for the constancy of the $\eta$ tail dependence parameters (null hypothesis) that govern the tail- $\beta$ s in table E.7. Applying the recursive test (4.1) through (4.4) by Quintos et al. (2001), each cell shows the endogenously found break date and the test value in parentheses. Dates are denoted XX/YY/ZZ, where $\mathrm{XX}=$ month, $\mathrm{YY}=$ day and $\mathrm{ZZ}=$ year. The critical values of the test are $1.46,1.78$ and 2.54 for the $10 \%, 5 \%$ and $1 \%$ levels, respectively. A test value exceeding these numbers implies an increase in extreme dependence over time. The absence of a break over the sample period is marked with a dash. 
Current address: Philipp Hartmann, European Central Bank and CEPR, DG Research, Kaiserstraße 29, 60311 Frankfurt, Germany

E-mail address: philipp.hartmann@ecb.int

$U R L:$ http://papers.ssrn.com/sol3/cf_dev/AbsByAuth.cfm?per_id=229414

Current address: Stefan Straetmans, Limburg Institute of Financial Economics (LIFE), Economics Faculty, Maastricht University, P.O.Box 616, 6200 MD Maastricht, The Netherlands

E-mail address: s.straetmans@berfin.unimaas.nl

$U R L:$ http://www.fdewb.unimaas.nl/finance/faculty/straetmans/

Current address: Casper G. de Vries, Erasmus Universiteit Rotterdam, Economics, P. O. Box 1738, 3000 DR Rotterdam, The Netherlands

E-mail address: cdevries@few.eur.nl

$U R L:$ http://www.few.eur.nl/people/cdevries/ 